Check for updates

Cite this: Mater. Adv., 2022, 3, 859

Received 12th September 2021 Accepted 30th November 2021

DOI: 10.1039/d1ma00840d

rsc.li/materials-advances

\section{Supported nanocatalysts: recent developments in microwave synthesis for application in heterogeneous catalysis $\dagger$}

\begin{abstract}
Hasan Ahmad (D) *a and Mohammad Kawsar Hossain ${ }^{\text {ab }}$
The synthesis of nanocatalysts on high surface area solid supports is gaining attention from synthetic chemists for application in heterogeneous catalysis due to their high catalytic performance and easy recoverability. However, the synthesis of nanocatalysts on solid supports mostly composed of metals/ metal oxides/hybrids is challenging for researchers considering their durability and discrete nanodispersibility. Microwave (MW)-assisted synthetic methods, attractive as fast and green approaches, are being widely studied for the synthesis of solid-supported nanocatalysts. This review article describes recent advances devoted towards $\mathrm{MW}$-assisted synthetic strategies for creating nanostructured catalysts on solid supports, as well as their characterization and applications in catalyzing various organic transformations, including electrocatalysis. The sustainable use of solid-supported nanocatalysts is then discussed in comparison with similar supported nanocatalysts prepared by conventional methods. The pros and cons of MW-assisted strategies for the synthesis of solid-supported nanocatalysts are then summarized, and their limitations as well as future directions for further investigation are emphasized.
\end{abstract}

${ }^{a}$ Research Laboratory of Polymer Colloids and Nanomaterials,

Department of Chemistry, Rajshahi University, Rajshahi 6205, Bangladesh. E-mail: samarhass@yahoo.com, hahmad@ru.ac.bd

${ }^{b}$ Biomedical and Toxicological Research Institute, Bangladesh Council for Science and Industrial Research, Kudrat-E-Khoda Road, Dhanmondi, Dhaka 1205,

Bangladesh

$\dagger$ Electronic supplementary information (ESI) available. See DOI: 10.1039/ d1ma00840d

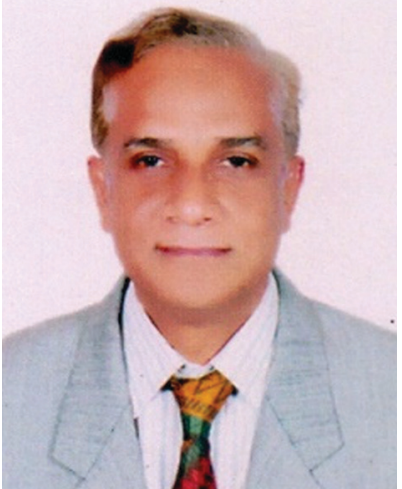

Hasan Ahmad
Hasan Ahmad graduated from the Department of Applied Chemistry, Rajshahi University, Bangladesh. He obtained his Doctor of Engineering degree in 1997 from Kobe University, Japan with a specialization in Material Sciences. He did his postdoctoral research at different institutes including the Max Planck Institute of Colloid and Interfaces, Germany; Sheffield University, UK; and GIST, South Korea. Dr Hasan has published more than 100 research articles in journals from publishers such as Elsevier, Springer, the American Chemical Society, The Royal Society of Chemistry and Wiley InterScience. He is presently serving as a Professor and Chairman at the Department of Chemistry at Rajshahi University, Bangladesh.

\section{Introduction}

To meet the rising demand of fine chemicals and to reduce the dependency on the use of expensive and non-recyclable homogeneous catalysts, synthetic chemists are searching for more durable nanostructured heterogeneous catalysts. Compared to bulk materials, nanostructured materials have

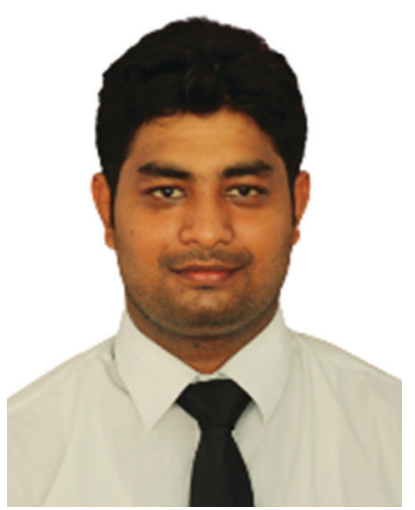

Mohammad Kawsar Hossain
Md. Kawsar Hossain has completed BSc and MSc (Organic) degrees and achieved the 1st Merit Position from the Department of Chemistry, Rajshahi University, Bangladesh. $\mathrm{He}$ did his research for his MSc degree under the supervision of Professor Hasan Ahmad. His research is focused mainly on polymer colloid chemistry, nanochemistry and hybrid materials. He has published 6 articles in international journals and is presently working as a Scientific Officer in the Biomedical and Toxicological Research Institute, Bangladesh Council for Science and Industrial Research, Dhaka. 
proved beneficial in catalysis because they offer improved physicochemical properties such as high surface-to-volume ratio, surface energy, active sites and better compositionbased selectivity towards particular reaction pathways. ${ }^{1,2}$ Additionally, the vast improvement in characterization tools has also enabled researchers to follow catalytic reactions from nanoparticles (NPs) down to even single atoms. ${ }^{3}$

Transition metals (Ti, Cr, Mn, Fe, Ni, Cu, Ru, Pd, Pt, $\mathrm{Au}$ and $\mathrm{Ag}$ ), which can easily donate and accept electrons from molecules, have been considered ideal for heterogeneous catalysis in many organic and bioorthogonal syntheses. ${ }^{4,5}$ However, nanocatalysts derived from transition metals/metal oxides/blends are prone to aggregation due to stronger inter-particle dipolar forces compared to their bulk counterparts, thereby reducing their potential for long-time application and preservation. Some transition metals $(\mathrm{Cu}, \mathrm{Ni})$ are also unstable and readily oxidized in air, preventing their sustainable use. $^{6}$ The modification of transition metal nanocatalysts with functionalizing agents such as surfactants ${ }^{7,8}$ or polymers ${ }^{9}$ has helped to improve their stability against aggregation, but such modification often deteriorates their catalytic properties via changes in the electronic structure of the metal nanocatalysts. ${ }^{10}$ An alternative way proposed to overcome aggregation and the deterioration of catalytic properties is the implanting or anchoring of nanocatalysts on inert low-density solid supports. Solid supports help to maintain the size, shape, and morphology of the nanocatalysts and also limit the leaching of metal ions, which is favorable for achieving durable and enhanced catalytic performance. The solid supports used prominently include graphene, ${ }^{11,12}$ zeolites, ${ }^{13}$ cellulose ${ }^{14-16}$ activated coke/carbon, ${ }^{17,18}$ sepiolite, ${ }^{19}$ bentonite, ${ }^{20} \mathrm{SiO}_{2},{ }^{21,22}$ and $\mathrm{Al}_{2} \mathrm{O}_{3} \cdot{ }^{23,24}$ In general, the preparation of supported nanocatalysts is usually conducted in two steps. In the first step, the deposition or impregnation of the metal precursor on a solid support is achieved via impregnation/precipitation/coprecipitation/electrostatic/co-ordination, depending on the support functional groups. ${ }^{25,26}$ The second step involves calcination/reduction/both by different techniques such as chemical reduction, ${ }^{24,27}$ sonochemical reduction, ${ }^{28,29}$ laser ablation, ${ }^{30,31}$ and thermal decomposition. ${ }^{32}$ These methods generally require high temperatures, long reaction times and inert atmosphere. All these factors adversely affect the large-scale synthesis of supported nanocatalysts, and therefore the search for simple and scalable synthetic methods has become imperative. Recently, microwave (MW) irradiation/heating has gained popularity for the synthesis of metal/metal oxide nanocatalysts due to the fast and uniform heating of the reaction medium, which results in fast reaction kinetics, ${ }^{33,34}$ uniform growth of the NPs, ${ }^{35-37}$ easy operation and green synthesis. ${ }^{38}$

In this review, we discuss the recent articles on supported nanocatalysts prepared using MW strategies. The nanocatalysts discussed herein include metals, metal oxides, multi-metals, mixed metal-metal oxides and metal carbides. However, the few studies available on metal sulfides, nitrides and phosphides are not included. Some review articles on the optimization of catalytic performance by controlling the size, shape and morphology of different metal nanocomposites, both supported and non-supported, are available. ${ }^{39-43}$ However, these reviews hardly considered all types of metals and metal oxides, rather focusing on a group of metals or metal oxides. Jamkhande et al. reviewed the different methods used for the preparation of metal NPs and focused on their advantages, disadvantages and applications. ${ }^{44}$ In a recent review, MW chemistry was discussed briefly to understand the formation mechanism and growth of particles, focusing on improving the performance of MW methods for future research. ${ }^{45}$ In this review, we discuss the latest articles on the MW-assisted synthesis of transition metals, metal oxides, hybrids and perovskite-type nanocatalysts supported on solid supports. Initially, the chemistry of MW synthesis is shortly outlined, and then the preparation of various types of nanocatalysts is discussed. Subsequently, an explicit review is presented on the applications of supported nanocatalysts in various organic transformations. Particular emphasis is given to the recyclability/durability of supported nanocatalysts and the comparison of their performance with that of similar nanocatalysts prepared via other methods. Finally, the future challenges and ways of further improving the catalytic performance of nanocatalysts prepared via the MW method are described in the Scope and outlook section.

\section{MW chemistry and its applications}

Since the 1950s, MW energy was found to be useful for heating foodstuffs, food processing, chemical drying, etc. Upon irradiation with MW, the dielectric heating creates a heating effect on matter and the heating efficiency depends on the ability of the substance to interact with MW radiation. ${ }^{46}$ In 1986 , two research groups first reported the utilization of MW warming to speed up organic chemical changes. ${ }^{47,48}$ In the early days, a household oven was used to perform experiments in sealed Teflon or glass vessels with no mechanism for controlling the temperature or pressure. This fast and uncontrolled heating of organic solvents later encouraged researchers to use solvent-free MW chemistry. ${ }^{49}$ The solvent free methodology is based on the pre-adsorption of reagents and catalysts on MW transparent inorganic supports, enabling controlled reactions in MW-assisted organic synthesis. With continuous improvement in MW technology and the availability of online temperature and pressure control, in the mid-90s Strauss developed a method of organic synthesis in a sealed vessel using a conventional solvent. ${ }^{50}$ Consequently, MW heating/irradiation has now become a recognized tool in all areas of organic synthesis including both solvent-free and water-mediated reactions. ${ }^{51-54}$ Additionally, the further development of MW reactor technology now facilitates the synthesis of nanomaterials. ${ }^{55-58}$ Recently, the continuous flow microfluidic approach has been attempted in MW-assisted synthesis to improve the control of the temperature gradient, rate of heating and mixing, and also to enable fast quenching to stop prolonged nucleation events. ${ }^{59}$

The frequency and wavelength of $\mathrm{MW}$ radiation (i.e., electromagnetic radiation) are in the range of $0.3-300 \mathrm{GHz}$ and $1 \mathrm{~mm}-1 \mathrm{~m}$, which are between the infrared and radio region in the electromagnetic range. Commercial and domestic 
MW ovens operate at a frequency of up to $2.45 \mathrm{GHz}$ to eliminate interference from the communication frequency bands of cellular phones. MW radiation travels with the speed of light and provides energy that is insufficient to break a chemical bond, which in most cases does not affect the framework of chemical molecules. ${ }^{60}$ MW heating depends on the capacity of materials to absorb and transform MW radiation into heat. Three categories of materials including MW reflectors, MW transmitters and MW absorbers describe the interaction with MW. Metals classified as MW reflectors are not effectively heated by MW. Materials that are transparent to MW (e.g., Teflon and polystyrene) are classified as MW transmitters and ideal for use as MW reactor and vessel materials. Materials known as MW absorbers can absorb energy from the MW field (e.g., solvents/reactants) and are heated very quickly in the process. ${ }^{61}$ The addition of a small amount of ionic liquid, a strong MW absorbing agent, to a non-polar solvent generally enhances the heating rate, and hence increases the reaction rate and product yield. ${ }^{62}$

MW-assisted reactions proceed at lightning speed, reducing the reaction time from several hours to minutes due to the reduction in the activation energy barrier. ${ }^{63}$ For example, the MW-irradiated green synthesis of $\mathrm{Ag}$ nanoclusters $(2 \mathrm{~nm})$ was possible within just $70 \mathrm{~s},{ }^{63}$ whereas the sonochemical method required $1 \mathrm{~h}$ to produce AgNPs, ${ }^{28}$ and chemical reduction of the precursor $\mathrm{AgNO}_{3}$ required an even longer reaction time $(6 \mathrm{~h}) .{ }^{64}$ The conventional heating process using hot plates or mantles is slow and inefficient for transferring energy to the reactants, given that it depends on convective currents and the conductive nature of various compounds and the materials to be penetrated. This often produces a temperature gradient between the reaction medium and vessel, which is responsible for non-uniform growth, hindering scaled-up production. In contrast, MW irradiation causes volumetric heating, i.e., uniform temperature rise throughout the liquid volume via direct coupling of MW energy to the molecules present in the reaction vessel. ${ }^{65-67}$ This volumetric heating in the synthesis of nanomaterials causes rapid and homogeneous heating, which reduces the temperature gradient and provides instantaneous nucleation, controlled and uniform growth with good reproducibility in terms of size, shape and morphology. ${ }^{45}$ The shorter reaction time reduces the probability of the formation of byproducts through side reactions and increases the product yield, homogeneity and crystallinity. ${ }^{38}$

Thus far, MW-assisted irradiation/heating has been attempted for the synthesis of a large variety of unsupported mono- and bi-metallic NPs as well as different types of simple to quaternary metal oxdes. ${ }^{68-76}$ The morphology and average size can be controlled by the precursor type, concentration, solvent type, $\mathrm{pH}$ and MW heating conditions such as power, pressure, temperature and time.

\section{Synthesis and characterization}

\subsection{Simple metal catalysts}

3.1.1. Carbon supported. Carbon materials are considered attractive for applications in the fields of adsorption, separation, sensors, energy storage, hydrogen storage, catalysts and catalyst supports given that they exhibit some interesting properties such as large specific surface area, large pore volume, tunable mesoporous structure, high electron conductivity and high thermal and chemical durability. ${ }^{77-80}$ Different types of carbon materials such as graphite (Grp), carbon black, activated carbon (AC), nanotubes, and graphene (G) have been used as support materials for catalysts in $\mathrm{MW}$-assisted synthesis.

Chuang et al. observed changes in the morphology of a $\mathrm{Cu} /$ AC catalyst due to a variation in MW irradiation power $(400,700$ and 900), irradiation time (45, 60 or $110 \mathrm{~s})$, and $\mathrm{pH}(4,7,10$ and 12) of the polyol precursor during its preparation from a homogeneous solution of $\mathrm{Cu}$ precursor salt in ethylene glycol (EG). ${ }^{81}$ The obtained solids from the MW reactor were washed and dried, and then calcined under an $\mathrm{H}_{2} / \mathrm{He}$ atmosphere at $475{ }^{\circ} \mathrm{C}$ for $4 \mathrm{~h}$ before characterization. The maximum surface area and pore size were observed when the MW power was set at $700 \mathrm{~W}$ for $60 \mathrm{~s}$ and the $\mathrm{pH}$ of the polyol precursor was $7(\mathrm{Cu} / \mathrm{AC}-700 \mathrm{~W}-60$ sec-7). Under these conditions, $\mathrm{Cu}^{0}$ was the dominant phase. In contrast, the minimum $16 \mathrm{~nm}$-sized $\mathrm{Cu}$ cubes (some aggregated) were formed when the $\mathrm{pH}$ of the polyol precursor was 12. Ren et al. employed pre-impregnation of AC with an aqueous $\mathrm{Cu}\left(\mathrm{NO}_{3}\right)_{2} \cdot 3 \mathrm{H}_{2} \mathrm{O}$ solution and carbothermic $\mathrm{MW}$ irradiation at three different temperatures of $150{ }^{\circ} \mathrm{C}, 410{ }^{\circ} \mathrm{C}$ and $540{ }^{\circ} \mathrm{C} .{ }^{82}$ The characteristic diffraction signal due to $\mathrm{Cu}^{0}$ was the strongest in Cat-48-540 among the catalysts, and optimistically a decrease in the average size of the cubic $\mathrm{Cu}_{2} \mathrm{O}$ and $\mathrm{Cu}^{0}$ particles from $43 \pm 12$ to $37 \pm 12 \mathrm{~nm}$ was observed with an increase in irradiation temperature from $410{ }^{\circ} \mathrm{C}$ to $540{ }^{\circ} \mathrm{C}$. The higher irradiation temperature was favorable to produce a higher $\mathrm{Cu}^{0}$ content. The same group also prepared hollow $\mathrm{Cu} / \mathrm{AC}$ via template-free carbothermic $\mathrm{MW}$ reduction using a homogeneous solution of $\mathrm{Cu}\left(\mathrm{NO}_{3}\right)_{2} \cdot 3 \mathrm{H}_{2} \mathrm{O} .{ }^{83}$ The formation mechanism of hollow CuNPs was explained based on the Ostwald ripening effect and self-assembly under MW-induced reduction (Fig. 1). Under the optimum conditions, hollow CuNPs with large cavities of $\sim 35 \mathrm{~nm}$ diameter and $50 \mathrm{~nm}$ outer diameter were obtained within $8 \mathrm{~min}$ when the precursor was heated from room temperature to $360{ }^{\circ} \mathrm{C}$.

An Fe/AC catalyst was prepared via the impregnation of $\mathrm{Fe}(\mathrm{NO})_{3} \cdot 9 \mathrm{H}_{2} \mathrm{O}$ in $\mathrm{AC}$, drying and $\mathrm{MW}$ treatment for $2 \mathrm{~h}$ at $400{ }^{\circ} \mathrm{C}$ under an He flow. ${ }^{84}$ The theoretical ratio of $\mathrm{Fe}$ to AC was $10 \mathrm{wt} \%$. The Brunauer-Emmett-Teller (BET) surface area of the catalyst obviously decreased in the Fe loading process; however, microscopic evidence was not provided.

Veerakumar et al. generated 3D ordered mesoporous carbon materials (CPMs) for supporting RuNPs by subjecting a cured mixture of polymer and $\mathrm{Ru}(\mathrm{acac})_{3}$ to $\mathrm{MW}$ thermal reduction and carbonization. ${ }^{85}$ The catalysts were labeled as Ru/CPM-1 and Ru/CPM-2 based on 0.5 and 1.0 wt\% Ru loading, respectively. Hexagonal close-packed (hcp) $\mathrm{Ru}^{0} \mathrm{NPs}$ on a 3D CPM matrix with a crystallite size of 3-5 $\mathrm{nm}$ were detected and the average size of the RuNPs from transmission electron microscopy (TEM) was $2.6 \pm 0.5 \mathrm{~nm}$. The same group employed porous plastic-derived carbon (PDC) to prepare a PDC@RuNP catalyst by applying MW irradiation to a mixture of $\mathrm{Ru}(\mathrm{acac})_{3}$ and $\mathrm{PDC}$ in tetrahydrofuran 


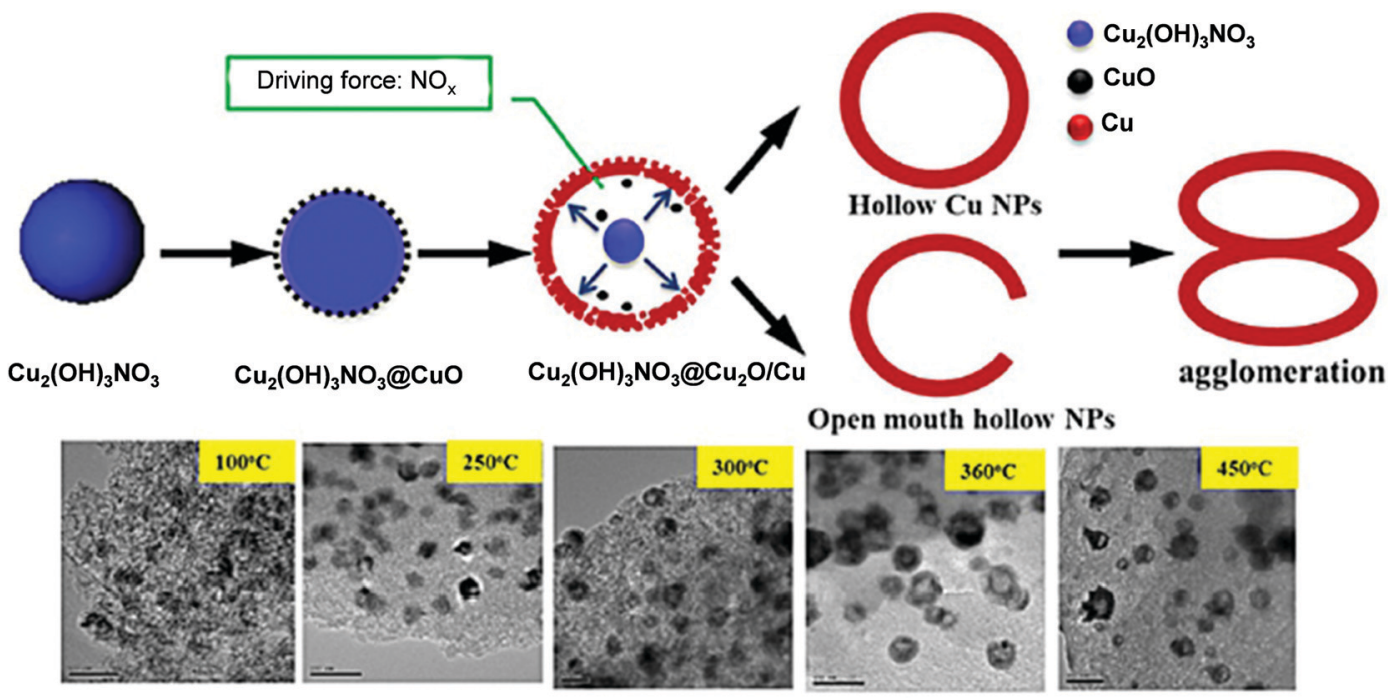

Fig. 1 Schematic representation of the Ostwald ripening-coupled self-assembly process of the hollow Cu structures. ${ }^{83}$ (Copyright 2016, Wiley-VCH.)

at $300 \mathrm{~W}$ for $1 \mathrm{~h}^{86}$ Very fine $\mathrm{Ru}^{0}$ crystallites with an average size of 5-6 nm were formed under these conditions.

The chemistry of supported Pt catalysts on carbon-based materials via MW synthesis started at the beginning of the 21st century. ${ }^{87,88}$ Here, they discussed the preparation of homogeneously distributed $<4 \mathrm{~nm}$ sized PtNPs on either carbon or carbon nanotubes (CNT). In most cases Pt had a face centered cubic structure (fcc) and contained $\mathrm{Pt}^{0}$ as the major component. Later, Bo et al. used coal-derived granular $\mathrm{AC}$ (GAC) for the preparation of a Pt/GAC catalyst via $\mathrm{MW}$ irradiation. ${ }^{89}$ GAC was impregnated with an $\mathrm{H}_{2} \mathrm{PtCL}_{6} \cdot 6 \mathrm{H}_{2} \mathrm{O}$ aqueous solution, evaporated to near-dryness in an MW oven at $500 \mathrm{~W}$, and then calcined by $\mathrm{MW}$ at $500 \mathrm{~W}$ for $5 \mathrm{~min}$. The Pt particles on the porous GAC support had an asymmetric dispersion and irregular shape with a size of 100-800 nm. Comparatively, Gan et al. obtained homogeneously distributed PtNPs (3-5 nm) on CNT via a one-pot MW polyol method using a mixture of $\mathrm{H}_{2} \mathrm{PtCl}_{6}, \mathrm{EG}$ and sodium dodecyl sulfate (SDS). ${ }^{90}$ The anchored Pt had an fcc crystalline structure and average crystallite size of $4.6 \mathrm{~nm}$. A similar polyol method also produced well-dispersed spherical $2.7 \mathrm{~nm}$-sized PtNPs in a Pt/carbon aerogel (CA) catalyst. ${ }^{91} \mathrm{Pt}$ had an identical fcc structure and the average crystallite size $(2.88 \mathrm{~nm})$ matched the microscopic image diameter. Sharma et al. observed an improvement in the Pt loading up to $23.7 \mathrm{wt} \%$ in $\mathrm{Pt} / \mathrm{C}$ electrocatalysts when the $\left(\mathrm{NH}_{4}\right)_{2} \mathrm{PtCl}_{6}$ precursor was used in the $\mathrm{MW}$-assisted polyol method. ${ }^{92}$ In contrast, the $\mathrm{H}_{2} \mathrm{PtCl}_{6}$-sourced and commercial $20 \% \mathrm{Pt} / \mathrm{C}$ catalysts contained 19.5 and $18.8 \mathrm{wt} \% \mathrm{Pt}$, respectively. Independent of the nature of the precursor, the average size of the PtNPs was around $2 \mathrm{~nm}$. Thus, the precursor type is important during the MW synthesis of supported catalysts.

Pentsak et al. studied the deactivation process of $\mathrm{Pd} / \mathrm{C}$ catalytic systems during catalysis under MW and conventional heat treatment (CHT). ${ }^{93}$ The catalyst preparation method was not detailed, but most likely wet impregnation and thermal decomposition were employed. Substantial transformation of the carbon support via the formation of pits, trenches, nanofibers and nanowalls during catalysis under both MW and CHT was observed. The narrow size distribution of PdNPs $(6 \mathrm{~nm})$ increased to $62 \mathrm{~nm}$ after $30 \mathrm{~min}$ of MW catalysis. The movement of hot metal particles on the carbon surface turned the carbon surface into a porous spongy framework. The initial $\mathrm{Pd}^{0}$ also turned into PdO (88\%) after $30 \mathrm{~min}$ of $\mathrm{MW}$ treatment in air. These transformations of the metal support were more dominant upon MW treatment due to the easy formation of metal hot spots. The same research group further showed that the modification of the carbon support could be minimized if MW irradiation is carried out under vacuum and that the selection of an appropriate metal salt is also crucial. ${ }^{94}$

Antonetti et al. used a low-boiling point alcohol or a mixture of alcohol (isopropanol/ethanol)/water as the solvent and a reducing agent to prepare RuNPs/CNT under MW irradiation. ${ }^{95}$ The MWassisted synthesis of unsupported RuNPs in isopropanol was first optimized using poly( $N$-vinyl-2-pyrrolidone), PVP, as a stabilizing agent, and finally the idea of MW synthesis was extended to the in situ preparation of RuNPs/CNT. Two types of CNTs were used, one was purified CNT (via treatment with $\mathrm{HCl}$ ) and the other was $\mathrm{HNO}_{3}$-treated purified CNT (FCNT). Independent of the CNT type, the average diameter of the RuNPs was between 2.7 to $3.6 \mathrm{~nm}$. However, the carboxylic and oxygenated groups on FCNT produced a more homogeneous distribution of RuNPs and sufficient to stabilize the NPs without the need for PVP. The same in situ approach using FCNT was also evaluated in aqueous ethanol (EtOH/ $\left.\mathrm{H}_{2} \mathrm{O} 20 / 80\right)$ at $150{ }^{\circ} \mathrm{C}$ under excess pressure. Again, small-sized particles with a homogeneous distribution were confirmed. In contrast, the solvent-free one-pot MW thermolytic route was found to be unsuitable for the production of welldispersed Ru on FCNT. $^{96,97}$ Hemraj-Benny et al. used nonfunctional single-walled CNT (SWCNT) to prepare an SWCNT-Ru catalyst via the reduction of $\mathrm{RuCl}_{3}$ in and ethanolic solution of $\mathrm{NaBH}_{4} \cdot{ }^{98}$ The average size of the RuNPs was dependent on the MW temperature, where $100{ }^{\circ} \mathrm{C}$ yielded smaller $(2.0 \pm 0.5 \mathrm{~nm})$ 
$\mathrm{Ru}^{0} \mathrm{NPs}$. In contrast, a higher temperature caused partial agglomeration. In another investigation, the ethanol reduction of $\mathrm{RuCl}_{3}$ at $150{ }^{\circ} \mathrm{C}$ was examined to determine the effect of the weight percentage $(0.05-1.00 \mathrm{wt} \%)$ of $\mathrm{RuCl}_{3}$ on the size distribution of the RuNPs in an SWCNT-Ru catalyst. ${ }^{99}$ An increase in $\mathrm{RuCl}_{3}$ content from 0.05 to $1.00 \mathrm{wt} \%$ resulted in an increase in particle size from $2.0 \pm 0.5 \mathrm{~nm}$ to around $45 \mathrm{~nm} \mathrm{Ru}$ clusters.

Graphene (G), an allotrope of carbon with a hexagonal atomic layer structure, is another important support material with unique properties such as high surface area and good thermal, chemical and mechanical stability. ${ }^{100-104}$ Fei et al. prepared a series of embedded monodispersed atomic transition metals in nitrogen-doped G (NG) via MW heating. ${ }^{105}$ The prepared nanocomposites were named $\mathbf{M}-\mathrm{NG}-\mathbf{M W}$, where $\mathbf{M}$ represents $\mathrm{Co} / \mathrm{Ni} / \mathrm{Cu}$. Initially, an aqueous solution of GO was reacted with ammonia solution at $70{ }^{\circ} \mathrm{C}$ to produce aminefunctionalized GO (AGO). Typically, a certain amount of $\mathrm{CoCl}_{2}$ solution was well mixed with the AGO solution and the freezedried product was MW irradiated in an argon atmosphere. The amino $\mathrm{N}$ in Co-AGO was the dominant species, but in Co-NGMW the amino $\mathrm{N}$ signal vanished due to its interaction with the uniformly distributed metal atoms.

In 2011, Siamaki et al. prepared Pd/G via batch-wise MW irradiation for $60 \mathrm{s.}{ }^{106}$ For this preparation, a mixture of dried graphite oxide (GrpO), requisite amount of $\mathrm{Pd}\left(\mathrm{NO}_{3}\right)_{2}$ and $\mathrm{HNO}_{3}$ was microwaved with $\mathrm{N}_{2} \mathrm{H}_{4}$ reducing agent following sonication. The complete reduction of GrpO to $\mathrm{G}$ by the reducing agent visibly improved the thermal stability of $\mathrm{Pd} / \mathrm{G}$ compared to $\mathrm{Pd} /$ GrpO. Subsequently, the success of the continuous scalable flow approach was tested with respect to the reproducibility and yield of the $\mathrm{Pd} / \mathrm{G}$ catalyst. ${ }^{107}$ A homogeneous suspension of GrpO in water containing $\mathrm{Pd}\left(\mathrm{NO}_{3}\right)_{2}$ and $\mathrm{N}_{2} \mathrm{H}_{4}$ solution was fed from two separate vessels at an equal rate into the MW reactor operating at $80{ }^{\circ} \mathrm{C}$ with an overall flow rate of $4 \mathrm{~mL} \mathrm{~min}^{-1}$. The produced $\mathrm{Pd} /$ $\mathrm{G}$ had an average particle diameter of $9.37 \mathrm{~nm}$ and contained $80 \% \mathrm{Pd}^{0}$ with the rest being $\mathrm{Pd}(\mathrm{II})$. Alternatively, Yang et al. employed a batch MW-assisted reduction approach under 1.2 $\mathrm{MPa}_{2}$ pressure to prepare $\mathrm{Pd} / \mathrm{G}, \mathrm{Pd} / \mathrm{AC}, \mathrm{Pd} / \mathrm{Grp}$ and $\mathrm{Pd} /$ $\mathrm{SiO}_{2}$ catalysts using a mixture of support and $\left[\mathrm{Pd}(\mathrm{OAc})_{2}\right]_{n}$ in $0.1 \mathrm{M}$ SDS. ${ }^{108}$ They found that the nature of the support influenced the Pd content in the catalyst.

Recently, Elazab et al. used a one-step MW irradiation approach to prepare magnetic $\mathrm{Pd}-\mathrm{Fe}_{3} \mathrm{O}_{4} / \mathrm{G}$ from reduced GO sheets (rGO). ${ }^{109}$ In a typical procedure, $\mathrm{Pd}\left(\mathrm{NO}_{3}\right)_{2}$ was added to an aqueous solution of $\mathrm{FeCl}_{3}$ and reduced under MW condition using $\mathrm{N}_{2} \mathrm{H}_{4}$. Well-dispersed $\mathrm{Fe}_{3} \mathrm{O}_{4}$ particles were observed. A similar method was also tested to prepare $\mathrm{Pd} / \mathrm{G}, \mathrm{Fe}_{3} \mathrm{O}_{4} / \mathrm{G}$ nanocomposites using $\mathrm{Pd}\left(\mathrm{NO}_{3}\right)_{2}$ and $\mathrm{FeCl}_{3}$ precursors.

Sulfonated $\mathrm{G}$ and GrpO (100 g) were evaluated to prepare $\mathrm{Pt} / \mathrm{G}$ and $\mathrm{Pt} / \mathrm{GrpO}$ by heating a mixture of crushed $\mathrm{K}_{2} \mathrm{PtCl}_{6}$ (variable: 14.5, 355, and $15 \mathrm{mg}$ ) and ionic liquid, 2-hydroxyethanaminium formate, $(5.0 \mathrm{~g})$ in a MW oven. ${ }^{110}$ PtNPs with a size of 5 to $30 \mathrm{~nm}$ were formed on sulfonated $\mathrm{G}$ or GrpO. The shape of the PtNPs on G was spherical, whereas that on GrpO was cubic. A higher amount of functional oxygen groups on GrpO increased the anchoring efficiency of Pt and also influenced the shape and size of the produced NPs. The onepot MW-assisted polyol synthesis of $\mathrm{Pt} / \mathrm{G}$ nanocomposite and subsequent heating at $500{ }^{\circ} \mathrm{C}$ produced flaky crystalline $\mathrm{G}$ sheets. ${ }^{111}$ The Pt/G3 (0.50\%) nanocomposite was comprised a comparatively uniform distribution of 7-11 nm-sized PtNPs.

3.1.2. Oxide-supported catalysts. In MW synthesis, different types of oxide minerals such as clay minerals (e.g., $\mathrm{SiO}_{2}$, vermiculite, and bentonite) and metal oxides (e.g. $\mathrm{Al}_{2} \mathrm{O}_{3}, \mathrm{MgO}, \mathrm{TiO}_{2}$, and $\mathrm{CeO}_{2}$ ) have been used as solid supports for various metal NPs. As support materials, many of them possess interesting and desirable properties including high thermal and chemical stability, high volume to surface area, easy functionalization capacity, low cost and easy availability.

3.1.2.1. Silica. Zuliani et al. used AlSBA-15, a mesoporous Al-coordinated $\mathrm{SiO}_{2}$ material, as a support for the preparation of MW-2\%Ag@AlSBA-15 and MW-2\%Au@AlSBA-15 via the simple MW in situ reduction of an ethanolic mixture of $\mathrm{AgNO}_{3}$ (0.04 mmol $) / \mathrm{AuBr}_{3}(0.02 \mathrm{mmol})$ at $150{ }^{\circ} \mathrm{C}$ for $3 \mathrm{~min} .{ }^{112}$ The abundant hydroxyl groups on the support surface stabilized the metal NPs. ${ }^{113,114}$ Alternatively, the mechanochemical ball milling (BM) technique was used to prepare the BM-2\%Ag@AlSBA-15 and BM-2\%Au@AlSBA-15 nanocatalysts developed by other researchers. ${ }^{115}$ However, a detailed characterization in terms of size distribution, valence state and crystallinity was not presented. Manno et al. had two different MW synthetic approaches, i.e., batch synthesis (three different times: 70, 35 and $17 \mathrm{~s}$ ) and continuous flow microfluidic synthesis (Fig. 2), to anchor $\mathrm{Ag}$ nanoclusters (AgNCs) on mesoporous amine-functionalized SBA-15 using an acrylic acid Na salt as a reducing and stabilizing agent. ${ }^{116,117}$ In the batch synthesis, an increase in irradiation time resulted in an increased in the mean particle size and the most uniform AgNCs $(1.6 \pm 0.7 \mathrm{~nm})$ were obtained at $17 \mathrm{~s}$. Slow cooling after MW heating in the batch system caused aggregation and size evolution of the clusters. In contrast, in a continuous flow reactor, rapid quenching to $4{ }^{\circ} \mathrm{C}$ within $21 \mathrm{~s}$ favored a reduction in the average diameter to $1.2 \pm$ $0.3 \mathrm{~nm}$. The continuous microfluidic approach produced better reproducibility and comparable inter-batch size distribution.

Jiang et al. used $40 \% \mathrm{H}_{2} \mathrm{SO}_{4}$-treated bentonite (AB) to prepare an Ni/AB catalyst via a MW-assisted drying process $(250 \mathrm{~W}$, $10 \mathrm{~min})$ and subsequent calcination $\left(550{ }^{\circ} \mathrm{C}, 3 \mathrm{~h}\right) .{ }^{118}$ The impregnation slurry was made from an ethanol-water solution of $\mathrm{Ni}\left(\mathrm{NO}_{3}\right)_{2} \cdot 6 \mathrm{H}_{2} \mathrm{O}$, cetyltrimethylammonium bromide (CTAB) and $\mathrm{AB}$ suspension and the obtained catalyst was named $\mathrm{Ni} / \mathrm{AB}-\mathrm{MW}$. Another batch of catalysts, named Ni/AB-CH, was prepared via conventional drying and calcination. MW-assisted drying improved the loading amount of $\mathrm{Ni}(16.1 \%)$ in Ni/ABMW and also favored the formation of smaller $\mathrm{Ni}$ and $\mathrm{NiO}$ crystallites due to the better interaction of $\mathrm{Ni}$ with the $\mathrm{AB}$ support.

Akay et al. used the combination of MW radiation, heat treatment and plasma reduction under a stream of $\mathrm{H}_{2}$ for $24 \mathrm{~h}$ at $400{ }^{\circ} \mathrm{C}$ and $550{ }^{\circ} \mathrm{C}$ to prepare porous $\mathrm{Co} / \mathrm{SiO}_{2}$ catalysts. ${ }^{119}$ The reduction under an $\mathrm{H}_{2}$ stream at $550{ }^{\circ} \mathrm{C}$ produced scattering signals due to the Co crystal lattice and $\mathrm{CoO}$ but reduction at 


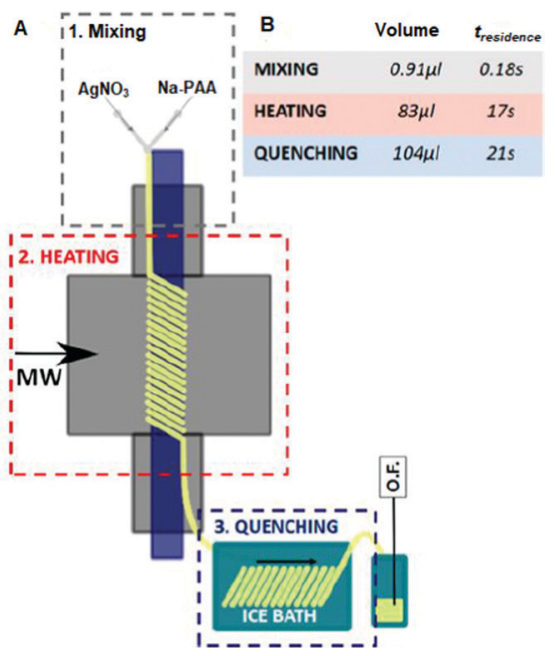

Fig. 2 (A) Schematic representation of the flow diagram for the continuous synthesis of AgNCs. Three different zones: mixing stage (grey color), MW heating zone (red color) and quenching stage (blue color). (B) Volume and calculated residence time for each stage (total flow rate $0.292 \mathrm{~mL} \mathrm{~min}^{-1}$ ). ${ }^{116}$ (Copyright 2020, the American Chemical Society.)

$400{ }^{\circ} \mathrm{C}$ did not result in any detectable metallic Co. The crystallite size of metallic Co at $550{ }^{\circ} \mathrm{C}$ was $15.6 \mathrm{~nm}$, larger than that of $\mathrm{CoO}(5.01 \mathrm{~nm})$. Simultaneously, another group attempted to prepare $\mathrm{Co} / \mathrm{SiO}_{2}$ via a similar four-step process, including the impregnation of porous $\mathrm{SiO}_{2}$ in $\mathrm{Co}\left(\mathrm{NO}_{3}\right)_{2} \cdot 6 \mathrm{H}_{2} \mathrm{O}$, MW drying, furnace drying at $550{ }^{\circ} \mathrm{C}$, and finally reduction under an $\mathrm{H}_{2}$ flow at $550{ }^{\circ} \mathrm{C}$ for 24 h. ${ }^{120}$ The scanning electron microscopy (SEM) and TEM images revealed that the MW catalyst had a better distribution and uniformity (crystallite size, 3-8 nm) and loading of CoNPs compared to that prepared via the conventional drying method. Similar to the previous literature, ${ }^{119}$ this investigation also suggested that the final reduction under an $\mathrm{H}_{2}$ flow is necessary to produce the Co metallic phase.

The MW in situ reduction of a dried $\mathrm{SiO}_{2}$-impregnated $\mathrm{H}_{2} \mathrm{PtCl}_{6} \cdot 6 \mathrm{H}_{2} \mathrm{O}$ precursor in EG containing $\mathrm{N}_{2} \mathrm{H}_{4}$ produced fine well-dispersed $\leq 2 \mathrm{~nm}$-sized PtNPs on an $\mathrm{SiO}_{2}$ support at the loading of $0.3 \mathrm{wt} \%{ }^{121}$ An increase in the Pt loading to $0.9 \mathrm{wt} \%$ slightly increased the particle size to $<10 \mathrm{~nm}$. Comparatively, the rotary chemical evaporation (RCE) method produced larger ( $\geq 20 \mathrm{~nm}$ )-sized PtNPs. The comparative study revealed that the MW-assisted reduction method is superior with respect to the organized distribution of smaller PtNPs on the surface of $\mathrm{SiO}_{2}$.

Wang et al. prepared a series of Ti-MCM-41 with different $\mathrm{Si}$ / Ti ratios (100 to 5) under MW irradiation using CTAB template, TEOS and tributyl titanate (TBOT). ${ }^{122}$ The obtained materials were calcined at $550{ }^{\circ} \mathrm{C}$ for $6 \mathrm{~h}$ in air to decompose the template. The $\mathrm{Ti}$ contents in the catalyst samples closely resembled the theoretical values. The arrangement of channels was slightly disturbed with an increase in the Ti content. Earlier, another research group prepared ZrMCM-41 mesoporous molecular sieves using $\mathrm{Zr}\left(\mathrm{SO}_{4}\right)_{2}$ and CTAB under MW irradiation. ${ }^{123}$ The BET specific surface area and pore volume decreased with an increase in the incorporated $\mathrm{Zr}$. The mesoporous ordering deteriorated with an increase in the thermal treatment temperature.

3.1.2.2. $\mathrm{Fe}_{3} \mathrm{O}_{4}$ and analogous oxides. $\mathrm{Fe}_{3} \mathrm{O}_{4}$ NPs possess interesting application properties as a catalyst support because the presence of $\mathrm{Fe}^{2+}$ ions provides some reducible oxide characters. ${ }^{124}$ Additionally $\mathrm{Co}_{3} \mathrm{O}_{4}$ and $\mathrm{Ni}(\mathrm{OH})_{2}$ also show good activity in the oxidation of CO. ${ }^{125,126}$ Elazab et al. proposed a method for the preparation of PdNPs supported on $\mathrm{Fe}_{3} \mathrm{O}_{4}$, $\mathrm{Co}_{3} \mathrm{O}_{4}$ and $\mathrm{Ni}(\mathrm{OH})_{2}$ NPs and nanoplates via MW irradiation. ${ }^{127}$ In a typical process for the preparation of $\mathrm{Pd} / \mathrm{Fe}_{3} \mathrm{O}_{4}$ containing $5,20,40$ and 50 wt $\% \mathrm{Pd}$, mixtures of $\mathrm{Fe}\left(\mathrm{NO}_{3}\right)_{3} \cdot 9 \mathrm{H}_{2} \mathrm{O}$ and $\mathrm{Pd}\left(\mathrm{NO}_{3}\right)_{2}$ solutions $\left(10 \mathrm{wt} \%\right.$ in $\left.10 \mathrm{wt} \% \mathrm{HNO}_{3}\right)$ were sonicated for $1 \mathrm{~h}$, and then irradiated in the presence of $\mathrm{N}_{2} \mathrm{H}_{4}$ in $60 \mathrm{~s}$ cycles for a total $7 \mathrm{~min}$. Similarly, with slight modification, $\mathrm{Pd} / \mathrm{Co}_{3} \mathrm{O}_{4}$ and $\mathrm{Pd} / \mathrm{Ni}(\mathrm{OH})_{2}$ catalysts containing variable wt $\%$ of Pd were prepared. The majority of the PdNPs were deposited on the surface of nanoplates. In another study, Elazab et al. reported the synthesis of a $\mathrm{Pd} / \mathrm{Fe}_{3} \mathrm{O}_{4}$ catalyst via continuous flow synthesis under MW irradiation. ${ }^{128}$ In this approach, two separate solutions, one containing the required amount of $\mathrm{Fe}\left(\mathrm{NO}_{3}\right)_{3} \cdot 6 \mathrm{H}_{2} \mathrm{O}$ and another containing $\mathrm{N}_{2} \mathrm{H}_{4}$, were injected and mixed before being introduced in the reactor. Different operating temperatures $\left(80{ }^{\circ} \mathrm{C}, 120{ }^{\circ} \mathrm{C}\right.$ and $\left.150{ }^{\circ} \mathrm{C}\right)$ and flow rates were studied. The XPS binding energy showed that a fraction of Pd was in PdO. An increase in MW temperature resulted in an increase in size and the saturation magnetization was reduced when the particle size was smaller. Continuous flow reaction was found to be advantageous for producing smaller (7-9 nm) PdNPs than that (12-14 nm) prepared under batch conditions.

Morad et al. prepared AuNPs on an $\mathrm{Mn}_{3} \mathrm{O}_{4}$ support by reducing an $\mathrm{HAuCl}_{4}$ hydrate solution using $\mathrm{N}_{2} \mathrm{H}_{4}$ under $\mathrm{MW}$ irradiation. ${ }^{129} \mathrm{Mn}(\mathrm{OH})_{2}$ gel was prepared via direct precipitation from $\mathrm{Mn}\left(\mathrm{NO}_{3}\right)_{2} \cdot 4 \mathrm{H}_{2} \mathrm{O}$ at $\mathrm{pH} 12$. The obtained gel was divided into two parts. One part was subjected to hydrothermal treatment (HT) at $150{ }^{\circ} \mathrm{C}$, filtered, washed, and then dried to obtain $\mathrm{Mn}_{3} \mathrm{O}_{4} \mathrm{HT}$. The other part of the gel, represented as $\mathrm{Mn}_{3} \mathrm{O}_{4}$, was directly filtered and dried at $100{ }^{\circ} \mathrm{C}$. The TEM images indicated the formation of cubic-, spheroid- and plate-shaped nanocatalysts $(\sim 33 \mathrm{~nm})$ without any $\mathrm{Au}$ aggregates. Almost simultaneously, another research group reported identical cubic-, spheroid- and plate-shaped PdNPs $/ \mathrm{Mn}_{3} \mathrm{O}_{4}$ nanostructures (38 nm) using an identical preparation method. ${ }^{130}$ The presence of PdNPs could not be confirmed from the TEM images, but the XPS results indicated the presence of $\mathrm{Pd}^{0}$ and $\mathrm{Pd}^{2+}$ species on the $\mathrm{Mn}_{3} \mathrm{O}_{4}$ support.

3.1.2.3. Other metal oxides. In an early attempt, Glaspell et al. observed that the use of a capping agent, poly(ethylene glycol), PEG, or PVP in the preparation of Au and Pd NPs on $\mathrm{CeO}_{2} / \mathrm{CuO} / \mathrm{ZnO}$ support materials accelerated the nucleation process of metal NPs and produced a narrow size distribution. ${ }^{131}$ The respective support was derived from precursor salts $\left(\mathrm{Ce}\left(\mathrm{NO}_{3}\right)_{4}, \mathrm{Cu}\left(\mathrm{NO}_{3}\right)_{2}\right.$ and $\mathrm{Zn}\left(\mathrm{NO}_{3}\right)_{2}$, respectively) and dopant $\mathrm{Au}$ or PdNPs were prepared via the addition of an 
appropriate amount of metal salt $\left(\mathrm{HAuCl}_{4}\right.$ or $\left.\mathrm{Pd}\left(\mathrm{NO}_{3}\right)_{2}\right)$ to obtain the desired dopant concentration (2\%, 5\% and $10 \%)$. Comparatively, the $10 \% \mathrm{Pd} / \mathrm{CeO}_{2}$ catalyst had the narrowest size distribution with average size 3-4 $\mathrm{nm}$. Chuang et al. used $\mathrm{CeO}_{2}$-TD, which was obtained via the thermal decomposition of Ce salt, to prepare $\mathrm{Cu} / \mathrm{CeO}_{2}-\mathrm{TD}(\mathrm{Cu} 5 \mathrm{wt} \%)$ by $\mathrm{MW}$ heating of an EG solution of $\mathrm{Cu}\left(\mathrm{NO}_{3}\right) \cdot 3 \mathrm{H}_{2} \mathrm{O}$ and PVP. ${ }^{132}$ Finally, the dried product was calcined at $475{ }^{\circ} \mathrm{C}$ for $4 \mathrm{~h}$. For comparison, commercial ceria $\left(\mathrm{CeO}_{2}-\mathrm{C}\right)$ and $\mathrm{AC}$ were also used as support materials. The size of the $\mathrm{Cu}$ particles was dependent on the nature and size of the support materials, where the minimum size $\left(33 \mathrm{~nm}\right.$ ) was found for the $\mathrm{Cu} / \mathrm{CeO}_{2}-\mathrm{TD}$ catalyst. Elazab et al. used different amounts $(347,329,292$, and $256 \mathrm{mg}$ ) of $\mathrm{Cu}_{2} \mathrm{H}_{10} \mathrm{~N}_{4} \mathrm{O}_{17}$ precursor salt to prepare a $\mathrm{Pd} / \mathrm{CuO}$ catalyst with variable Pd loadings $(5,10,20$, and $30 \mathrm{wt} \%) .{ }^{133,134}$ A simple one-step MW process was applied in the presence of $\mathrm{N}_{2} \mathrm{H}_{4}$. The TEM images revealed the formation of a 20-40 nm-sized catalyst and X-ray photoelectron spectroscopy (XPS) confirmed the valence states as $\mathrm{Cu}^{2+}$ and $\mathrm{Pd}^{0}$. The estimated Pd content in the catalyst was much lower than the theoretical content calculated from its formula.

The different forms of $\mathrm{Al}_{2} \mathrm{O}_{3}(\alpha, \beta$, and $\gamma)$ are perhaps the most important as catalyst supports due to their favorable combination of textural properties such as specific surface area, pore volume, pore size distribution, local microstructure, phase composition and acid/base characteristics. ${ }^{135}$ Song et al. prepared an $\mathrm{Ni} / \mathrm{Al}_{2} \mathrm{O}_{3}$ catalyst using PVP as a stabilizer and MW absorbent. ${ }^{136}$ The catalysts were denoted as $\mathrm{Ni20}-\mathrm{Al}_{2} \mathrm{O}_{3}-\mathrm{M}$ and $\mathrm{Ni20}-\mathrm{Al}_{2} \mathrm{O}_{3}-\mathrm{I}$, where 20 represents the loading amount of $\mathrm{Ni}$, and $\mathbf{M}$ and $\mathrm{I}$ stand for the MW and impregnation techniques, respectively. The MW method produced smaller $(\sim 10 \mathrm{~nm})$ NiNPs in Ni20- $\mathrm{Al}_{2} \mathrm{O}_{3}-\mathrm{M}$ compared to that $(15 \mathrm{~nm})$ in Ni20$\mathrm{Al}_{2} \mathrm{O}_{3}-\mathrm{I}$. The BET surface area and pore volume of $\mathrm{Ni20}-\mathrm{Al}_{2} \mathrm{O}_{3}-$ $\mathrm{M}$ were also higher. This indirectly confirmed that the impregnation method (IM) produced slight agglomeration and blocking of the pore structure. In another investigation, $\mathrm{Pd} / \mathrm{Al}_{2} \mathrm{O}_{3}$ catalysts were prepared via fixed-bed MW-induced plasma irradiation under three different conditions. ${ }^{137}$ Fig. 3 illustrates the fixed-bed reactor with MW-induced plasma jet. The particles prepared under different conditions were named PF (fixed bed reactor). The distance between the waveguide and particle bed influenced the distribution and size of Pd (Fig. 3). Sphericalshaped tiny Pd particles and the highest dispersion (25.3\%) were observed in sample PF-1 when a shorter distance was applied (3 cm). It is obvious that a short distance produced a higher temperature. The plasma treatment reduced $\mathrm{PdO}$ to $\mathrm{Pd}$ in a short time, which had an fcc structure. The crystalline phase of $\gamma-\mathrm{Al}_{2} \mathrm{O}_{3}$ was detected in all the catalysts. The same authors reported the use of an $\mathrm{MW}$-induced plasma-spouted bed reactor for the preparation of $\mathrm{Pd} / \mathrm{Al}_{2} \mathrm{O}_{3}$ under various operating conditions. ${ }^{138}$ The same catalyst was also prepared via CHT in an electric arc furnace. The MW-combined plasma treatment produced smaller PdNPs than that prepared by conventional heating at $500{ }^{\circ} \mathrm{C}$. The rapid heat change induced by an increase in MW power reportedly produced surface cracks in $\mathrm{Pd} / \mathrm{Al}_{2} \mathrm{O}_{3}$, whereas $\mathrm{CHT}$ at $500{ }^{\circ} \mathrm{C}$ did not produce surface cracks in the $\mathrm{Pd} / \mathrm{Al}_{2} \mathrm{O}_{3}$ samples.

Wang et al. observed that MW hydrothermal (MWH) treatment is superior to conventional IM in terms of the better dispersion of $\mathrm{WO}_{3}$ on an $\mathrm{Al}_{2} \mathrm{O}_{3}$ support and oxalic acid stabilizer had little effect on the dispersion. ${ }^{139}$ The catalyst prepared by IM also had a higher agglomeration of $\mathrm{WO}_{3}$. After $\mathrm{MWH}$ treatment, the dried $\mathrm{WO}_{3} / \mathrm{Al}_{2} \mathrm{O}_{3}$ was calcined at $550{ }^{\circ} \mathrm{C}$ for $4 \mathrm{~h}$ to produce $\mathrm{W} / \mathrm{Al}_{2} \mathrm{O}_{3}$.

$\mathrm{TiO}_{2}$ as a catalyst support is known to possess high thermal and chemical stability and offer outstanding resistance to corrosion in electrolytic media. ${ }^{140}$ Howe et al. prepared a $1 \mathrm{wt} \% \mathrm{Ru} / \mathrm{TiO}_{2}$ catalyst in an $\mathrm{MW}$ reactor from stock solutions of $\mathrm{Ru}(\mathrm{acac})_{3}$ or $\mathrm{RuCl}_{3} \cdot x \mathrm{H}_{2} \mathrm{O}$ in $\mathrm{EG}$ and $\mathrm{TiO}_{2}$ at $150{ }^{\circ} \mathrm{C}, 170{ }^{\circ} \mathrm{C}$ and $200{ }^{\circ} \mathrm{C}$ for 5, 10 and 15 min. ${ }^{141}$ The obtained catalysts were air dried at $110{ }^{\circ} \mathrm{C}$ for $16 \mathrm{~h}$. The catalysts were represented by the reductant-preparation temperature $\left({ }^{\circ} \mathrm{C}\right)$-preparation time, e.g. Acac-200-10. Independent of the precursor salt, MW treatment for a longer time at $200{ }^{\circ} \mathrm{C}$ caused sintering of the RuNPs, given that their mean diameter increased slightly. However, despite the sintering effect, the average size of the RuNPs was still less than $3 \mathrm{~nm}$. In either case, the catalysts exhibited a high surface carbon concentration.

To understand the detailed formation mechanism of various hybrids, Pt and AuNPs supported on $\mathrm{CeO}_{2}, \mathrm{TiO}_{2}, \mathrm{ZnO}, \mathrm{MgO}$, $\mathrm{Al}_{2} \mathrm{O}_{3}$, and $\mathrm{SiO}_{2}$ were prepared via the one-pot $\mathrm{MW}$-assisted
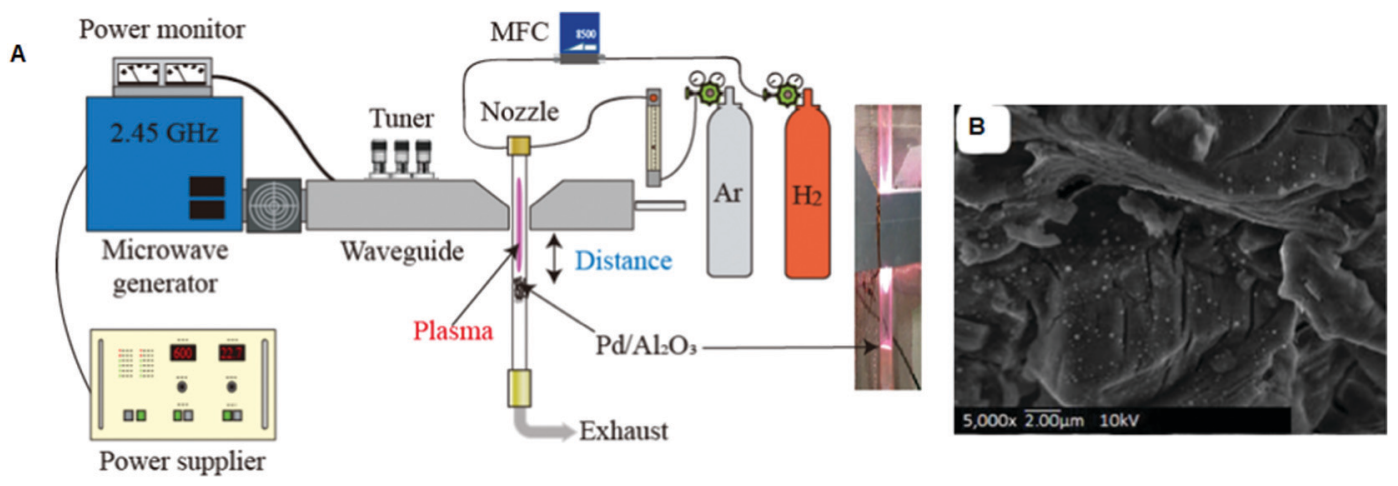

Fig. 3 (A) Schematic representation of the fixed bed reactor with plasma irradiation. (B) A typical SEM image of the $\mathrm{Pd} / \mathrm{Al}_{2} \mathrm{O}_{3} \mathrm{Catalyst}(\mathrm{PF}-1){ }^{137}$ (Copyright 2019, MDPI.) 
reduction of metal salts in EG. ${ }^{142}$ The size of the metal NPs was influenced by the efficiency of MW absorption by the support materials. Smaller and fine 2-3 nm-sized PtNPs were formed on $\mathrm{CeO}_{2}, \mathrm{TiO}_{2}$ and $\mathrm{ZnO}$ but not on the $\mathrm{SiO}_{2}$ particles. Comparatively, the low dielectric loss substrate $\mathrm{SiO}_{2}$ did not heat up rapidly. Likewise, on $\mathrm{MgO}$ and $\mathrm{TiO}_{2}$, the uniform decoration of AuNPs was observed, whereas on $\mathrm{Al}_{2} \mathrm{O}_{3}$ and $\mathrm{Si}$ substrates, very few particles were present. This is because the $\mathrm{Al}_{2} \mathrm{O}_{3}$ and $\mathrm{Si}$ substrates did not absorb MW radiation.

3.1.3. Metal carbide-supported catalysts. Transition metal carbides possess excellent catalytic properties, and thus have great potential as high surface area support materials for metal catalysts. ${ }^{143,144}$ However, only a few works are available in this area. For example, Shi et al. reportedly used two types of mesoporous WC/C for loading $10 \mathrm{wt} \% \mathrm{Pt}^{145}$ One was WC/C-F using the triblock copolymer Pluronic F127 as a soft template and the other was WC/C-S using mesoporous SBA-15 as a hard template. In both cases, the support material was dispersed in $\mathrm{H}_{2} \mathrm{PtCl}_{6}$ aqueous solution, mixed with EG, and then microwaved at $180{ }^{\circ} \mathrm{C}$ for $10 \mathrm{~min}$. In both the Pt-WC/C-F and Pt-WC/ $\mathrm{C}-\mathrm{S}$ catalysts, Pt had an fcc crystalline structure, but the latter was more crystalline. The average pore size of $\mathrm{WC} / \mathrm{C}-\mathrm{S}$ was $4.7 \mathrm{~nm}$, while that of $\mathrm{WC} / \mathrm{C}-\mathrm{F}$ was comparatively larger $(8.0 \mathrm{~nm})$. In both systems, the PtNPs were evenly distributed with little aggregation on the $\mathrm{WC} / \mathrm{C}-\mathrm{S}$ support. In a similar type of investigation, the stability of WC during the preparation of Pt@WC/organic mesoporous carbon abbreviated as Pt@WC/ OMC-MP electrocatalyst via a pulse MW-assisted polyol method was investigated. ${ }^{146}$ The loading of Pt in the Pt@WC/OMC-MP electrocatalyst was $20 \mathrm{wt} \%$. MW irradiation in absence of the Pt precursor had little effect on the stability of WC/OMC; however, in the presence of the Pt precursor, the stability of WC was significantly affected. XPS confirmed the partial oxidation of WC to $\mathrm{WO}_{3}$ during the preparation of the Pt@WC/OMC-MP catalyst. Asahara et al. studied the utility of Pd/SiC. ${ }^{147}$ Here, $\left[\mathrm{Pd}(\mathrm{OAc})_{2}\right]_{n}$ dissolved in acetonitrile and small pieces of SiC taken in a screw-caped test tube were MW-heated at $100{ }^{\circ} \mathrm{C}$ for $3 \mathrm{~h}$. The catalyst was represented as MW3. Catalyst MW1 was also prepared via the same method. For comparison, two catalysts, OB3 and OB10, were prepared via CHT for 3 and $10 \mathrm{~h}$, respectively. However, information on the size distribution, surface porosity, and valence state of Pd was not available, only the catalyst activity was detailed.

\subsection{Metal carbide catalysts}

In terms of application performance, metal carbides such as $\mathrm{W}$ and Mo carbides are considered alternatives to noble metal catalysts, particularly Pt. ${ }^{148}$ In 1973, Levy et al. showed that WC and $\mathrm{Pt}$ had similarities in electronic structure and catalysis behavior in water formation from $\mathrm{H}_{2}$ and $\mathrm{O}_{2}$ at room temperature. ${ }^{149}$ Following that groundbreaking work, these carbides were proven to be useful in a wide variety of catalytic reactions such as hydrogenation, hydrodeoxygenation, hydrodesulphurization, hydrodenitrogenation and isomerization. ${ }^{150-153}$ In this perspective, a few works carried out on the preparation and applications of supported metal carbides are discussed below.
3.2.1. Carbon-supported catalysts. Despite the fact that the catalytic properties of $\mathrm{Mo}_{2} \mathrm{C}$ resemble that of noble metals, the quick deactivation of bulk $\mathrm{Mo}_{2} \mathrm{C}$ is a problem. ${ }^{154}$ Accordingly, an $\mathrm{MW}$-assisted single-source route was investigated for the preparation of highly dispersed $\mathrm{Mo}_{2} \mathrm{C} / \mathrm{AC}$ using $\beta-\mathrm{Mo}_{2} \mathrm{C}$ as the precursor. ${ }^{155}$ XPS showed the existence of $\mathrm{Mo}(\mathrm{VI})$ species in $\mathrm{Mo}_{2} \mathrm{C} / \mathrm{AC}$, possibly resulting from surface oxidation in air. The TEM images confirmed the formation of highly dispersed $3 \mathrm{~nm}$-sized $\mathrm{Mo}_{2} \mathrm{C}$ NPs. Mnatsakanyan et al. used two different $\mathrm{MW}$-assisted routes to prepare $\mathrm{Mo}_{2} \mathrm{C} / \mathrm{C}$ and WC/C catalysts. ${ }^{156}$ The complete formation of $\mathrm{Mo}_{2} \mathrm{C}$ occurred after 3 min irradiation, whereas for the WC system, an irradiation time of 8 min was required. The initial size of the carbon from the SEM image was $\sim 50 \mathrm{~nm}$, and after irradiation the sizes of the $\mathrm{Mo}_{2} \mathrm{C} / \mathrm{C}$ and $\mathrm{WC} / \mathrm{C}$ catalysts increased to $50-70 \mathrm{~nm}$ and $300-500 \mathrm{~nm}$, respectively.

In 2009, Liang et al. described the preparation of WC/CNT via $\mathrm{MW}$-assisted metal-organic chemical vapor decomposition (MOCVD) under atmospheric pressure in a fluidized reactor. ${ }^{157}$ A precursor mixture made from $\mathrm{W}(\mathrm{CO})_{6}$ and $\mathrm{CNT}$ was placed in a quartz-tube reactor and fluidized with an argon flow for $2 \mathrm{~h}$ before irradiation in an MW oven. CNTs without pre-oxidized and pre-oxidized were evaluated as a support. A uniform distribution of 2-5 nm-sized WC was found on the surface of the CNTs. Overall, the results indicated that preoxidation of CNTs is not essential in the MW-assisted MOCVD method. In the following year, Pang et al. described the preparation of $\mathrm{Mo}_{2} \mathrm{C} / \mathrm{CNTS}$ utilizing the above-mentioned method. ${ }^{158}$ However, the CNTs were not pre-oxidized before use. In $16.7 \mathrm{wt} \%$ $\mathrm{Mo}_{2} \mathrm{C} / \mathrm{CNT}$, well-dispersed $5 \mathrm{~nm}$-sized $\mathrm{Mo}_{2} \mathrm{C}$ was detected. The average crystallite size of $\mathrm{Mo}_{2} \mathrm{C}$ increased with an increase in the Mo loading. Pt- $\mathrm{Mo}_{2} \mathrm{C} / \mathrm{CNT}$ was also prepared and 3-6 nm monodispersed PtNPs were formed.

\subsection{Metal oxide catalysts}

3.3.1. Carbon-supported catalysts. The use of carbon materials as support materials for metal oxide catalysts has scarcely been studied to date. Metal oxide catalysts gained prominence in the mid-1950s, given that they were found effective in catalyzing oxidation and acid-base reactions. Metal oxides have now found applications in the petrochemical industry, in synthesizing chemicals and improving environmental issues. ${ }^{159}$

Zhong et al. demonstrated the suitability of MW-assisted 3D heating in air for the rapid in situ synthesis of metal oxides $\left(\mathrm{CoO}_{x}, \mathrm{NiO}\right.$ and $\left.\mathrm{Fe}_{3} \mathrm{O}_{4}\right)$ using carbonized wood (C-wood) as a $3 \mathrm{D}$ heating substrate. ${ }^{75}$ In a typical experiment, the $\mathrm{Co}\left(\mathrm{NO}_{3}\right)_{2}$ precursor was dissolved in a 1:1 ethanol-water mixture, and then a piece of C-wood was immersed in this mixture for $10 \mathrm{~min}$ and dried for $20 \mathrm{~min}$ to obtain the $\mathrm{C}$-wood $/ \mathrm{Co}\left(\mathrm{NO}_{3}\right)_{2}$ precursor. The C-wood/Co( $\left(\mathrm{NO}_{3}\right)_{2}$ precursor was then microwaved at $1000 \mathrm{~W}$ for $4 \mathrm{~s}$ to produce C-wood/CoO . Around 11 nm-sized uniformly distributed $\mathrm{CoO}_{\mathrm{x}}$ NPs were formed on the C-wood substrate. The potential scalability of the 3D heating method was also verified with a larger-sized C-wood substrate.

Motshekga prepared MWCNT/SnO $\mathrm{MPs}_{2}$ via the conventional and $\mathrm{MW}$-assisted wet impregnation for application in optoelectronic devices. ${ }^{160}$ the SEM and TEM images confirmed 
the high loading of $\mathrm{SnO}_{2}$ NPs (2-4 nm) on MWCNT via MW method within $10 \mathrm{~min}$. There is also a report on the preparation of $\mathrm{TiO}_{2} / \mathrm{G}$ from GrpO, titanium isopropoxide, TTIP (variable) in isopropyl alcohol and $\mathrm{N}_{2} \mathrm{H}_{4}$ via $\mathrm{MW}$ irradiation in a closed Pyrex glass bottle. ${ }^{161}$ The obtained dried precipitate was finally calcined at $400{ }^{\circ} \mathrm{C}$ for $4 \mathrm{~h}$.

3.3.2. Silica-supported catalysts. Mohamed et al. studied the effect of MW irradiation time ( $\mathrm{min}$ ) during preparation of $\mathrm{CeO}_{2}-\mathrm{SiO}_{2} \mathrm{NPs}$ from an acidic solution of CTAB, TEOS and $\mathrm{Ce}\left(\mathrm{NO}_{3}\right)_{3} \cdot 6 \mathrm{H}_{2} \mathrm{O}$ in ethanol. ${ }^{162}$ Finally, the washed and dried product was heat treated at $500{ }^{\circ} \mathrm{C}$ for $4 \mathrm{~h}$. Irrespective of the irradiation time, all the MW-irradiated samples contained a pure $\mathrm{CeO}_{2}$ phase. An increase in the irradiation time resulted in an increase in the crystallinity and average crystallite size, but a decrease in the BET surface area. The TEM image analysis for sample M-30 (irradiation time $30 \mathrm{~min}$ ) indicated the formation of cubic-shaped particles with an average size of $8 \mathrm{~nm}$, whereas conventional HT for $24 \mathrm{~h}(\mathrm{H}-24 \mathrm{~h})$ produced comparatively larger spherical $(15 \mathrm{~nm})$ particles.

$\mathrm{Li}$ et al. prepared an $\mathrm{NiO} /$ vermiculite or $\mathrm{NiO} / \mathrm{Vmt}$ catalyst with $10 \mathrm{wt} \%$ loading from a dried precursor comprising Vmt in $\mathrm{Ni}\left(\mathrm{NO}_{3}\right)_{2} \cdot 6 \mathrm{H}_{2} \mathrm{O}$ aqueous solution. ${ }^{163}$ The precursor was divided into two parts, where one part was subjected to CHT and the other part was subjected to MW treatment to obtain CHT-NiO/ Vmt and MW-NiO/Vmt, respectively. The NiO NPs were well dispersed, but MW irradiation produced smaller particles (3 nm) compared to that from CHT (6 nm). The estimated crystallite size in the MW-NiO/Vmt catalyst was $2.4 \mathrm{~nm}$, lower than that in the CHT-NiO/Vmt catalyst $(2.7 \mathrm{~nm})$. In a similar investigation, 2-D layered Vmt was used to prepare $\mathrm{MW}$ assisted $\mathrm{MW}-\mathrm{NiO} / 2 \mathrm{D}-\mathrm{Vm}$ t and compared with muffle furnace (MF) calcination. ${ }^{164}$ The overall size distribution and crystallinity again confirmed that the MW method is superior for producing smaller-grained highly crystalline NiO.

3.3.2. Metal-supported catalysts. $\mathrm{A} \mathrm{Co}_{3} \mathrm{O}_{4} @$ stainless steelmesh (SUS) micro-rod array electrocatalyst was prepared with the aid of diethylenetriamine (DETA) as an anchoring agent for $\mathrm{Co}^{2+}$ (Fig. 4). ${ }^{165}$ For comparison, $\mathrm{Co}_{3} \mathrm{O}_{4}$ layered nanosheets
$\left(\mathrm{Co}_{3} \mathrm{O}_{4}\right.$-LNS $)$ were prepared via the same method without the SUS substrate. MW heating allowed recrystallization of the rod-shaped $\mathrm{Co}(\mathrm{OH})_{2}$ in the $\mathrm{Co}_{3} \mathrm{O}_{4}$ @SUS electrocatalyst, while in the absence of the SUS substrate, a flower-like $\mathrm{Co}(\mathrm{OH})_{2}$ nanomaterial was formed. In either case, the annealing at $400{ }^{\circ} \mathrm{C}$ resulted in the complete conversion of $\mathrm{Co}(\mathrm{OH})_{2}$ to $\mathrm{Co}_{3} \mathrm{O}_{4}$. The average crystallite size of $\mathrm{Co}_{3} \mathrm{O}_{4}$ in $\mathrm{Co}_{3} \mathrm{O}_{4}$ @SUS and $\mathrm{Co}_{3} \mathrm{O}_{4}$-LNS was 33.41 and $29.33 \mathrm{~nm}$, respectively. Fig. 4 confirms the different appearances of $\mathrm{Co}_{3} \mathrm{O}_{4}$ in the presence and absence of the SUS substrate.

May-Masnou discussed the preparation of anatase $\mathrm{TiO}_{2} \mathrm{NPS}$ attached to larger anisotropic $\mathrm{Au}$ via an $\mathrm{MW}$-assisted method. ${ }^{166}$ Firstly, $\mathrm{TiO}_{2}$ NPs were synthesized from a homogeneous solution of titanium butoxide (TBOT) and PVP in benzyl alcohol (BA) in an MW reactor at $50{ }^{\circ} \mathrm{C}$, and then again heated at $190{ }^{\circ} \mathrm{C}$ for $10 \mathrm{~min}$. In the second step, two different sized AuNPs (Fig. 5) were prepared in the presence of $\mathrm{TiO}_{2} \mathrm{NPS}$ dispersed in EG using (a) 100 and (b) $600 \mathrm{mg}$ of PVP. Part of the sample was dried overnight and the other part was calcined in air at $400{ }^{\circ} \mathrm{C}, 450{ }^{\circ} \mathrm{C}, 550{ }^{\circ} \mathrm{C}$, and $600{ }^{\circ} \mathrm{C}$ for $2 \mathrm{~h}$ to remove PVP and increase the contact between $\mathrm{Au}$ and $\mathrm{TiO}_{2}$. The PVP-capped $\mathrm{TiO}_{2}$ NPs possessed a pure crystalline anatase phase with an average size of $9 \pm 2 \mathrm{~nm}$. The TEM photographs (Fig. 5) indicated that $100 \mathrm{mg}$ of PVP produced >50 nm-sized $\mathrm{Au}$ NPs, whereas $600 \mathrm{mg}$ of PVP produced smaller $(8 \pm 2 \mathrm{~nm})$ AuNPs. The larger AuNPs were randomly decorated with smaller $\mathrm{TiO}_{2}$ NPs but the smaller AuNPs were only surrounded by $\mathrm{TiO}_{2}$. Calcination had a larger effect on the shape of $\mathrm{Au}$ than that of the $\mathrm{TiO}_{2}$ NPs.

\subsection{Binary metal catalysts}

Binary and ternary metal catalysts, which are considered more active compared to simple metal catalysts, are particularly useful as electrocatalysts in proton exchange membrane fuel cells (PEMFCs) and direct alcohol fuel cells. ${ }^{167,168}$ In early investigations, electrocatalysts based on precious metals such as $\mathrm{Pt}$ or $\mathrm{Au}$ were mostly investigated. However, the low durability and high cost Pt and Au metal catalysts hinder their

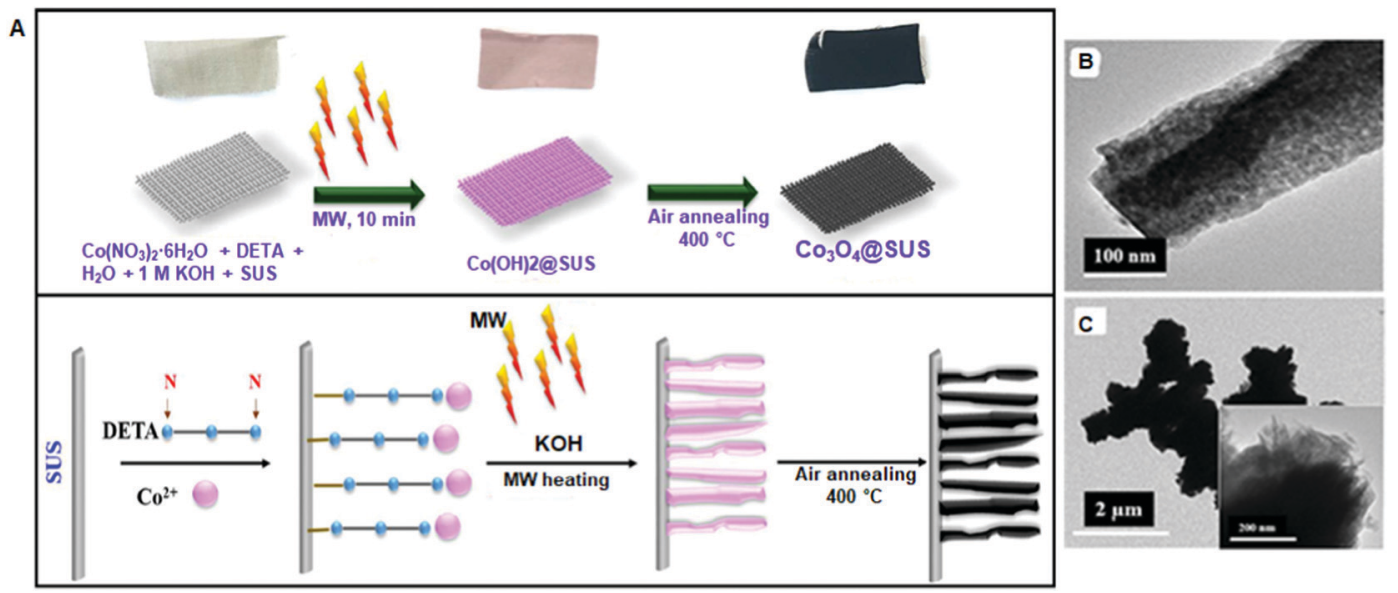

Fig. 4 (A) Proposed mechanism for the controlled synthesis of $\mathrm{CO}_{3} \mathrm{O}_{4} @ \mathrm{aSUS}$. TEM images of (B) $\mathrm{Co}_{3} \mathrm{O}_{4}$ @SUS and (C) $\mathrm{CO}_{3} \mathrm{O}_{4}$ - $\mathrm{LNS}^{165}$ (Copyright 2017 , the American Chemical Society.) 

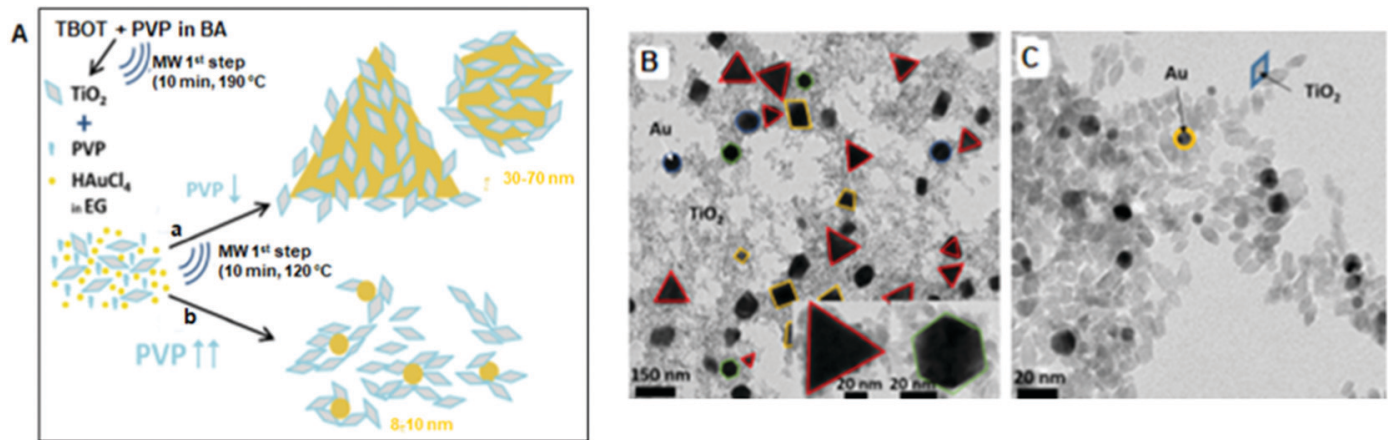

Fig. 5 (A) Schematic diagram of the two-step MW-assisted synthesis of $\mathrm{Au} / \mathrm{TiO}_{2}$ nanostructures. (a) $\mathrm{TiO}_{2}: \mathrm{PVP}: \mathrm{HAuCl}_{4}=1: 0.097: 0.155$ and (b) $\mathrm{TiO}_{2}:$ PVP: $\mathrm{HAuCl}_{4}=1: 0.583: 0.155$ (molar ratios). TEM images of the as-synthesized (B) sample 'a' and (C) sample 'b'. ${ }^{166}$

commercial application. Additionally, supported Pt-based catalysts exhibit sluggish oxygen reduction reaction (ORR) activity at the cathode. Accordingly, doping with transition metals containing Pt or Au reportedly improved their durability. ${ }^{169,170}$ The search for alternative low-cost materials with high electrocatalytic activity and good durability has led to the development of ternary metal catalysts either by replacing or reducing the Pt or Au content.

3.4.1. Carbon-supported catalysts. Stevanović et al. used a carbon support for the synthesis of Pt, PtRh and PtSn catalysts with 20 wt\% metal loading. ${ }^{171}$ Initially, the bimetallic NPs first prepared via polyol MW-treatment of $\mathrm{H}_{2} \mathrm{PtCl}_{6}$ and $\mathrm{SnCl}_{2} / \mathrm{RhCl}_{3}$ in EG. The supported catalysts were prepared by blending bimetallic NPs with a carbon support, acid treatment, and finally drying in an $\mathrm{N}_{2}$ atmosphere. The alloy structure of the $\mathrm{PtSn} / \mathrm{C}$ and $\mathrm{PtRh} / \mathrm{C}$ catalysts was confirmed, and the TEM images showed the uniform distribution of $\sim 3 \mathrm{~nm}$-sized NPs on the carbon support for all the catalysts. The valence state of the metals was not identified. In 2017, Tsuji et al. tried to prepare PtY/ $\mathrm{C}$ alloy NPs via MW co-reduction of a precursor mixture of cis- $\left[\mathrm{Pt}\left(\mathrm{NH}_{3}\right)_{2}\left(\mathrm{NO}_{2}\right)_{2}\right]$ or $\mathrm{Pt}\left(\mathrm{C}_{5} \mathrm{H}_{7} \mathrm{O}_{2}\right)_{2}$ and $\mathrm{Y}\left(\mathrm{CH}_{3} \mathrm{COO}\right)_{3} \cdot 4 \mathrm{H}_{2} \mathrm{O}$ in the presence of a carbon support in EG. ${ }^{172}$ Irrespective of the Pt precursor, the composition revealed the formation of monodispersed $\mathrm{Pt}-\mathrm{YO}_{x} / \mathrm{C}$ catalysts. The obtained catalysts were denoted as Pt-YO $\mathrm{YO}_{x} / \mathrm{C}(\mathrm{A}): 5: 5$ and $\mathrm{Pt}-\mathrm{YO}_{x} / \mathrm{C}(\mathrm{B}): 5: 5$, where $\mathrm{A}$ and $\mathrm{B}$ represent the cis-[Pt $\left.\left(\mathrm{NH}_{3}\right)_{2}\left(\mathrm{NO}_{2}\right)_{2}\right]$ and $\mathrm{Pt}\left(\mathrm{C}_{5} \mathrm{H}_{7} \mathrm{O}_{2}\right)_{2}$ precursor, respectively. To overcome the solubilization of the $\mathrm{YO}_{x}$ component in acid fuel solution, the samples were treated with $\mathrm{HNO}_{3}$ to produce PtY/C alloy catalysts. After acid treatment, both samples contained a small amount of $\mathrm{Y}$ component and the catalyst size with a narrow distribution was retained. The addition of $\mathrm{Y}\left(\mathrm{CH}_{3} \mathrm{COO}\right)_{3} \cdot 4 \mathrm{H}_{2} \mathrm{O}$ was found to be beneficial for producing monodispersed $\mathrm{Pt} / \mathrm{C}(\mathrm{A}, \mathrm{B})$ particles. To enhance the binding between the PtNPs and carbon supports, a $\mathrm{Pt}_{3} \mathrm{Cu} / \mathrm{C}$ catalyst was prepared with a theoretical $\mathrm{Pt}$ loading of $20 \mathrm{wt} \% .{ }^{173} \mathrm{~A}$ mixture of metallic precursors $\left(\mathrm{H}_{2} \mathrm{PtCl}_{6}\right.$. $6 \mathrm{H}_{2} \mathrm{O}$ and $\mathrm{CuCl}_{2} \cdot 2 \mathrm{H}_{2} \mathrm{O}$ ) and carbon support in an EG-water mixture was microwaved at $\mathrm{pH} 10$ for approximately $6 \mathrm{~min}$ at $125{ }^{\circ} \mathrm{C}$. The $\mathrm{Pt}_{3} \mathrm{Cu}$ NPs $(2.31 \mathrm{~nm})$ were uniformly distributed on the support. Pt and $\mathrm{Cu}$ had an fcc crystalline alloy structure. The metallic state of $\mathrm{Pt}$ and $\mathrm{Cu}$ was also confirmed. By just changing the amount of $\mathrm{Cu}$ precursor in the recipe, $\mathrm{Pt}_{4} \mathrm{Cu} / \mathrm{C}(2.14 \pm$ $0.88 \mathrm{~nm})$ and $\mathrm{Pt}_{2} \mathrm{Cu} / \mathrm{C}(3.49 \pm 1.097 \mathrm{~nm})$ were also prepared and characterized. In the synthesis of an $\mathrm{Pd}-\mathrm{Au} / \mathrm{C}$ catalyst, relative to CHT, catalyst activation by MW irradiation produced a much higher degree of Pd-Au alloying and better homogeneity of the bimetallic phase. ${ }^{174}$ The use of acetone as a solvent also improved the homogeneity of the Pd-Au phase compared to the aqueous solution. The catalyst samples produced by MW irradiation also contained an increase Pd content at the surface of the NPs. The poor ORR activity of $20 \% \mathrm{CoSe} / \mathrm{C}$ encouraged the preparation of the corresponding $\mathrm{CoSe}_{2} / \mathrm{C}^{175-177}$ Accordingly, a homogeneous precursor solution of $\mathrm{Co}\left(\mathrm{CH}_{3} \mathrm{COO}\right)_{2}$ and $\mathrm{SeO}_{2}$ was placed in an MW oven at a power of $800 \mathrm{~W}$ for $180 \mathrm{~s}$, and the product was washed and dried before mixing with carbon black. Diffraction signals of the $\mathrm{CoSe}_{2}$ phase were not observed up to an Se/Co ratio of 4.0 due to their uniform distribution. In another investigation, $\mathrm{FeSe}_{2} / \mathrm{C}$ NPs were prepared via an MW method under identical conditions with the $\mathrm{FeSe}_{2}$ loading adjusted to $36 \% .{ }^{178}$ The average particle diameter was in the range of 3-12 $\mathrm{nm}$.

Sulfonated MWCNT (SF-MWCNT) was used to prepare SF-MWCNT-PdSn and SF-MWCNT-PdNi via MW-assisted solvothermal co-reduction $\left(1000 \mathrm{~W}, 170{ }^{\circ} \mathrm{C}, 60 \mathrm{~s}\right)$ of the precursor salts in EG. ${ }^{179}$ Pd had a well-defined fcc crystalline structure, but $\mathrm{Ni}$ and Sn possessed a partially amorphous structure. The alloy structure was confirmed and the XPS spectra suggested the presence of Pd in the metallic and oxide forms with $\mathrm{Ni}$ in the oxo-nickel species (i.e., $\mathrm{Ni}_{x} \mathrm{O}_{y}$ and $\mathrm{NiOOH}$ ). However, the uniform distribution of the bimetallic catalysts was not analyzed. Nassr et al. used oxygen-functionalized CNT (FCNT) to prepare a PtNi/ FCNT catalyst via the polyol MW reduction of metal salts, $\mathrm{H}_{2} \mathrm{PtCl}_{6}$ and $\mathrm{Ni}\left(\mathrm{NO}_{3}\right) \cdot 6 \mathrm{H}_{2} \mathrm{O}$, either continuously for a defined time or in pulse mode with a duration of $20 \mathrm{~s}^{180}$ The transition of the NiO peaks to PtNi alloy occurred at $90 \mathrm{~s}$. However, in pulse mode, the formation of the PtNi alloy was observed even at a lower pulse number of 6. An increase in the irradiation time enhanced the particle size of PtNi/CNT from 2.7 to $3.3 \mathrm{~nm}$. Comparatively, the size of PtNi/CNT prepared in the pulse mode was almost independent of the pulse number given that the average size was around $2.5 \mathrm{~nm}$. Rahsepar et al. prepared a PtRu/MWCNT catalyst using $\mathrm{MW}$-assisted reduction at $\mathrm{pH} \sim 12.5$ from a water solution of metal precursors, pretreated MWCNT and HCHO reducing agent. ${ }^{181}$ After re-acidification and drying, additional heating at $300{ }^{\circ} \mathrm{C}$ under a flow of $\mathrm{H}_{2}$ helped to form well-dispersed 
PtRu alloy NPs (1.5-3.5 nm) on the surface of MWCNT. The XPS signals indicated the presence of a large amount of $\mathrm{Pt}^{0}(72.15 \%)$ and $\mathrm{Ru}^{0}(68.07 \%)$ with a small amount of $\mathrm{Pt}(\mathrm{II}), \mathrm{Pt}(\mathrm{IV}), \mathrm{RuO}_{2}$ and $\mathrm{RuO}_{2} \cdot \mathrm{xH}_{2} \mathrm{O}$ species. Al-Tememy had MWCNT-doped G nanoplatelets (MWCNT-GNP) to support a PtPd bimetallic catalyst by microwaving a mixture of metal precursors and the support dispersed in an EG-isopropanol mixture at $\mathrm{pH} 12 .{ }^{182}$ For comparison, PtPd/GNP and PtPd/MWCNT catalysts were also investigated. The doping of $\mathrm{G}$ nanoplatelets by MWCNT improved the metal loading (35.1\%), dispersity and crystallinity index of the PtPd NPs. Independent of the support material, all the catalysts contained graphitic carbon and fcc-structured metals. The average sizes were in the range of $2.47-2.70 \mathrm{~nm}$.

\subsubsection{Oxide-supported catalysts}

3.4.2.1. Silica. Verma et al. discussed the preparation of Pd$\mathrm{Ag} / \mathrm{SiO}_{2}$ and $\mathrm{Pd}-\mathrm{Au} / \mathrm{SiO}_{2}$ bimetallic catalysts in two steps. ${ }^{183}$ Firstly, $1 \mathrm{wt} \%$ of either Au or Ag was incorporated on SBA-15 via the MW-assisted polyol method, and then decorated with PdNPs via a localized surface plasmon resonance-assisted deposition method under visible light irradiation. Spherical NPs of Pd-Ag and Pd-Au with diameters of 4.2 and $4.9 \mathrm{~nm}$ were formed. The formation of the alloy via the electron transfer mechanism was proved by XPS. Tripathi et al. demonstrated the preparation of $\mathrm{Cu}-\mathrm{Ag} / \mathrm{MgO}-\mathrm{SiO}_{2}$ via four different techniques including conventional impregnation, MW-assisted method, PVA/ $\mathrm{NaBH}_{4}$-assisted method and benzoxazine-assisted method. ${ }^{184}$ In the MW method, drying was carried out at $80{ }^{\circ} \mathrm{C}$ in an MW oven before calcination at $400{ }^{\circ} \mathrm{C}$ for $4 \mathrm{~h}$. MW drying and benzoxazine-assisted reduction efficiently produced a higher surface area and pore volume. Partial oxidation of $\mathrm{Cu}$ to $\mathrm{CuO}$ was observed in $\mathrm{Cu}-\mathrm{Ag} / \mathrm{MgO}-\mathrm{SiO}_{2}$. However, other characterizations were not presented. In another investigation, Ti-inserted ordered mesoporous $\mathrm{SiO}_{2}$ (Ti-SBA-15) was used to support a CoMo catalyst. ${ }^{185}$ 20Ti-SBA15 (Si/Ti molar ratio 20) was prepared via hydrolysis and aging in an MW reactor from TEOS and TTIP in the presence of
Pluronic P123 as a structure-directing agent. The crystallized product was further calcined at $450{ }^{\circ} \mathrm{C}$ for $6 \mathrm{~h}$. As expected, the insertion of Ti reduced the surface area and pore size of SBA-15. The Ti loading in 20Ti-SBA-15 and CoMo/20Ti-SBA15 was 2.9 and $2.4 \mathrm{wt} \%$, respectively, which was close to the theoretical value.

3.4.2.2. Metal oxides. In an early investigation, $\mathrm{Ru}-\mathrm{Sn} / \mathrm{ZnO}$ catalysts were synthesized by subjecting a mixture of $\mathrm{RuCl}_{3}$. $3 \mathrm{H}_{2} \mathrm{O}$ dissolved in EG containing $\mathrm{SnCl}_{2} \cdot 2 \mathrm{H}_{2} \mathrm{O}$ and $\mathrm{ZnO}$ (targeted metal loading $2 \%$ ) to variable $\mathrm{MW}$ power. ${ }^{186}$ XPS analysis showed the formation of $\mathrm{Sn}^{0}$ in all the $\mathrm{Ru}-\mathrm{Sn} / \mathrm{ZnO}$ catalysts prepared at $450 \mathrm{~W}$ for 4 and $8 \mathrm{~min}$ and $\mathrm{Ru}^{0}$ was detected only when the MW power was set at $150 \mathrm{~W}$ for $20 \mathrm{~min}$. The rest of the samples mainly contained $\mathrm{Ru}^{n+}$. The morphological data for the $\mathrm{Ru}-\mathrm{Sn} / \mathrm{ZnO}$ catalysts was not available.

3.4.3. Metal-organic framework-supported catalysts. Tan et al. used zeolite-imidazole frameworks (ZIFs) to construct dispersed $\mathrm{Co}-\mathrm{N}-\mathrm{C}$ catalysts, and then prepared an $\mathrm{Ni}_{3} \mathrm{Fe} / \mathrm{Co}-$ N-C catalyst via a rapid MW method (Fig. 6). ${ }^{187}$ The fcc structure of $\mathrm{Ni}_{3} \mathrm{Fe}$ together with a broad diffraction plane of carbon was detected. The Ni, Fe and Co contents (ICP analyses) in $\mathrm{Ni}_{3} \mathrm{Fe} / \mathrm{Co}-\mathrm{C}-\mathrm{N}$ were $20.04 \%, 6.53 \%$ and $1.26 \%$, respectively. After decoration with $\mathrm{Ni}_{3} \mathrm{Fe}$, the size of the respective catalysts did not change (Fig. 6). The bimetal particle size was around $11.2 \mathrm{~nm}$.

\subsection{Mixed metal oxide catalysts}

3.5.1. Carbon-supported catalysts. Elazab et al. prepared three different catalysts $\left(\mathrm{Pd}-\mathrm{Fe}_{3} \mathrm{O}_{4} / \mathrm{G}, \mathrm{Pd}-\mathrm{Co}_{3} \mathrm{O}_{4} / \mathrm{G}\right.$ and $\mathrm{Pd}-$ $\left.\mathrm{Ni}(\mathrm{OH})_{2} / \mathrm{G}\right)$ by irradiating a mixture of $\mathrm{GO}$ nanosheets, precursor salts and $\mathrm{N}_{2} \mathrm{H}_{4}$ for 60 s. ${ }^{188}$ In the $\mathrm{Pd}-\mathrm{Fe}_{3} \mathrm{O}_{4} / \mathrm{G}$ and $\mathrm{Pd}-\mathrm{Co}_{3} \mathrm{O}_{4} /$ G catalysts, well dispersed $35 \pm 2 \mathrm{~nm}$ and $25 \pm 2 \mathrm{~nm}$ PdNPs were formed, while the sizes of $\mathrm{Fe}_{3} \mathrm{O}_{4}$ and $\mathrm{Co}_{3} \mathrm{O}_{4}$ were $(52 \pm$ $2 \mathrm{~nm})$ and $(45 \pm 2 \mathrm{~nm})$, respectively. The binding energies confirmed the valence states as $\mathrm{Pd}^{0}$ and $\mathrm{Pd}^{2+}$. The magnetic property of $\mathrm{Pd}-\mathrm{Fe}_{3} \mathrm{O}_{4} / \mathrm{G}$ was also confirmed. The same group

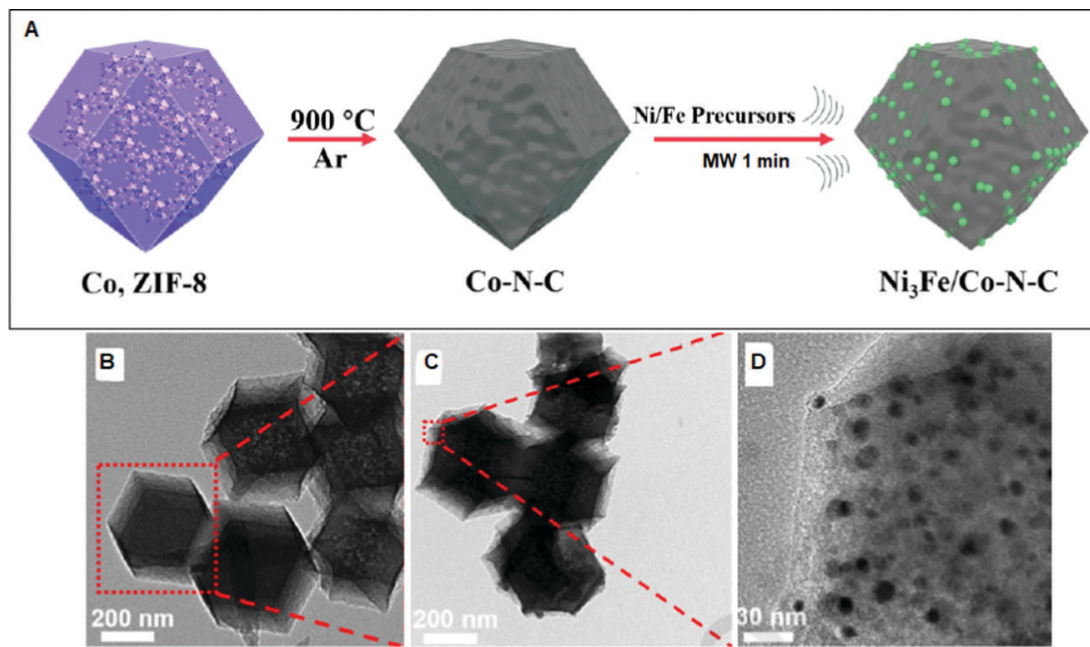

Fig. 6 (A) Preparation scheme of the Nis Fe/Co-N-C bifunctional electrocatalyst. TEM (B and C) and HRTEM (D) images of (B) Co-N-C and (C and D) $\mathrm{Ni}_{3} \mathrm{Fe} / \mathrm{Co}-\mathrm{N}-\mathrm{C}^{187}$ (Copyright 2020, Elsevier B.V.) 
also prepared four magnetically recyclable $\mathrm{Pd}-\mathrm{Fe}_{3} \mathrm{O}_{4} / \mathrm{G}$ catalysts labeled as 1-4 with the Pd loading varying from $50 \mathrm{wt} \%$ in Catalyst 1 to $6 \mathrm{wt} \%$ in Catalyst $4 .{ }^{189}$ Catalyst 3 contained the highest $\mathrm{Pd}(0) / \mathrm{Pd}(\mathrm{II})$ ratio. Khalid et al. prepared $\mathrm{Ag}-\mathrm{TiO}_{2} / \mathrm{G}$ composites via an $\mathrm{MW}$-assisted hydrothermal method from a GO dispersion in an ethanol-water (1:1) mixture containing anatase $\mathrm{TiO}_{2}$ and varying amounts of $0.01 \mathrm{~mol} \mathrm{~L}^{-1} \mathrm{AgNO}_{3}{ }^{190}$ The weight ratio of $\mathrm{Ag}$ to the $\mathrm{TiO}_{2}-\mathrm{G}$ composite was controlled at $0,0.03,0.06,0.09,0.12$, and 0.15 and composites were named TG, ATG3, ATG6, ATG9, ATG12, and ATG15, respectively. A crystalline anatase $\mathrm{TiO}_{2}$ phase was found, but $\mathrm{G}$ and $\mathrm{Ag}$ could not be detected in $\mathrm{Ag}-\mathrm{TiO}_{2} / \mathrm{G}$ owing to their low content. The valence states were confirmed to be $\mathrm{Ti}^{4+}$ and $\mathrm{Ag}^{0}$ in the composites. Pan et al. used N-doped coal-derived carbon to support $\mathrm{Co} / \mathrm{CoO}_{x}{ }^{191}$ Depending on the heat treatment temperature, the coal-derived carbons were labeled as MC800, MC950, MC1050 and MC1100. The high-temperature treatment of the carbon (MC1050) was found to be favorable for producing structural disorder and subsequent introduction of $\mathrm{Co} /$ $\mathrm{CoO}_{x}$. The Co nucleation was followed by strong electrostatic interaction between the oxygen functional groups on the surface and $\mathrm{Co}$ cations. The $\mathrm{Co} / \mathrm{CoO}_{x}$ particles were homogeneously distributed at a lower Co content. Galal et al. discussed the preparation of Ru-based perovskites supported on RGO. ${ }^{192}$ The preparation was carried out via the redox reaction of metal salts $\left(\mathrm{Sr}\left(\mathrm{NO}_{3}\right)_{2} / \mathrm{Ba}\left(\mathrm{NO}_{3}\right)_{2} / \mathrm{Ca}\left(\mathrm{NO}_{3}\right)_{2}\right), \mathrm{RuCl}_{3}$ and $\mathrm{GO}$ via either conventional or MW heating. Both conventional and MW heating allowed the formation of $\mathrm{SrRuO}_{3}$ in combination with $\mathrm{RuO}_{2}$ or RuNPs. Highly crystalline nanosized $\mathrm{CaRuO}_{3}$ was detected as the main phase using MW heating. In comparison, around $1 \mathrm{~nm}$-sized $\mathrm{BaRuO}_{3}$ particles with $\mathrm{RuO}_{2}$ were formed via conventional heating, while MW heating produced amorphous $\mathrm{BaRuO}_{3}$.
Li et al. used carboxymethyl cellulose (CMC), an inexpensive biobased polymer, to support $\mathrm{Ag}-\mathrm{Fe}_{3} \mathrm{O}_{4} \cdot{ }^{193}$ Firstly, Ag@CMC was prepared via the MW heating of $\mathrm{Ag}\left(\mathrm{NH}_{3}\right)^{2+}$ salt in the presence of aqueous CMC sodium salt. ${ }^{194,195}$ Secondly, $\mathrm{Fe}_{3} \mathrm{O}_{4}$ was co-precipitated under MW irradiation and alkaline conditions to afford $\mathrm{Ag}-\mathrm{Fe}_{3} \mathrm{O}_{4} @ \mathrm{CMC}$ (Fig. 7). Monodispersed AgNPs (2.3 \pm $0.3 \mathrm{~nm}$ ) were formed in $\mathrm{Ag} @ \mathrm{CMC}$, but the magnetic $\mathrm{Fe}_{3} \mathrm{O}_{4} \mathrm{NPs}$ $(15.3 \pm 3.5 \mathrm{~nm})$ were slightly polydispersed (Fig. 7).

\subsubsection{Oxide-supported catalysts}

3.5.2.1. Metal oxide. Jing et al. prepared a $\mathrm{CuNiZnO} / \gamma-\mathrm{Al}_{2} \mathrm{O}_{3}$ catalyst via the MW-assisted thermal hydrolysis of urea. ${ }^{196}$ The required amounts of $\mathrm{Ni}\left(\mathrm{NO}_{3}\right)_{2} \cdot 6 \mathrm{H}_{2} \mathrm{O}$ and $\gamma-\mathrm{Al}_{2} \mathrm{O}_{3}$ powder were taken in $\mathrm{Cu}\left(\mathrm{NO}_{3}\right)_{2} \cdot 3 \mathrm{H}_{2} \mathrm{O}$ and $\mathrm{Zn}\left(\mathrm{NO}_{3}\right)_{2} \cdot 6 \mathrm{H}_{2} \mathrm{O}$ aqueous solution, sonicated, and finally heated in an MW oven at $80{ }^{\circ} \mathrm{C}, 85^{\circ} \mathrm{C}, 90{ }^{\circ} \mathrm{C}$ or $95{ }^{\circ} \mathrm{C}$ for $2 \mathrm{~h}$. The recovered dried product was calcined at $350{ }^{\circ} \mathrm{C}$ for $5 \mathrm{~h}$. The composition analysis of the four catalysts indicated that the $\mathrm{Cu}$ content gradually decreased with an increase in the MW temperature, whereas both the Ni and $\mathrm{Zn}$ contents increased. The surface area and pore volume of the $\gamma-\mathrm{Al}_{2} \mathrm{O}_{3}$ support decreased as usual following modification. A higher MW temperature produced uniform smaller particles with better dispersion.

A $\mathrm{Ce}_{0.8} \mathrm{Zr}_{0.2} \mathrm{O}_{2}$ solid solution was synthesized via a rather long process of citrate complexation $(17 \mathrm{~h})$ and supported on different loadings of $\mathrm{Al}_{2} \mathrm{O}_{3}$ via the impregnation (CI) or $\mathrm{MW}$ combustion technique (CC), and finally calcined at $800{ }^{\circ} \mathrm{C}$ for 5 h. ${ }^{197}$ The CZ loading was found to be optimum at $40 \mathrm{wt} \%$, and a greater CZ loading produced agglomeration. Accordingly, samples CZ40A-CC and CZ40A-CI contained relatively finer particles.

\subsection{Ternary metal catalysts}

3.6.1. Carbon-supported catalysts. Zheng et al. prepared a series of ternary $\left(\mathrm{Co}_{x} \mathrm{Ni}_{1-x}\right) \mathrm{Se}_{2} / \mathrm{C}(0<x<1.0)$ catalysts via a simple MW polyol method to replace the poor-performing
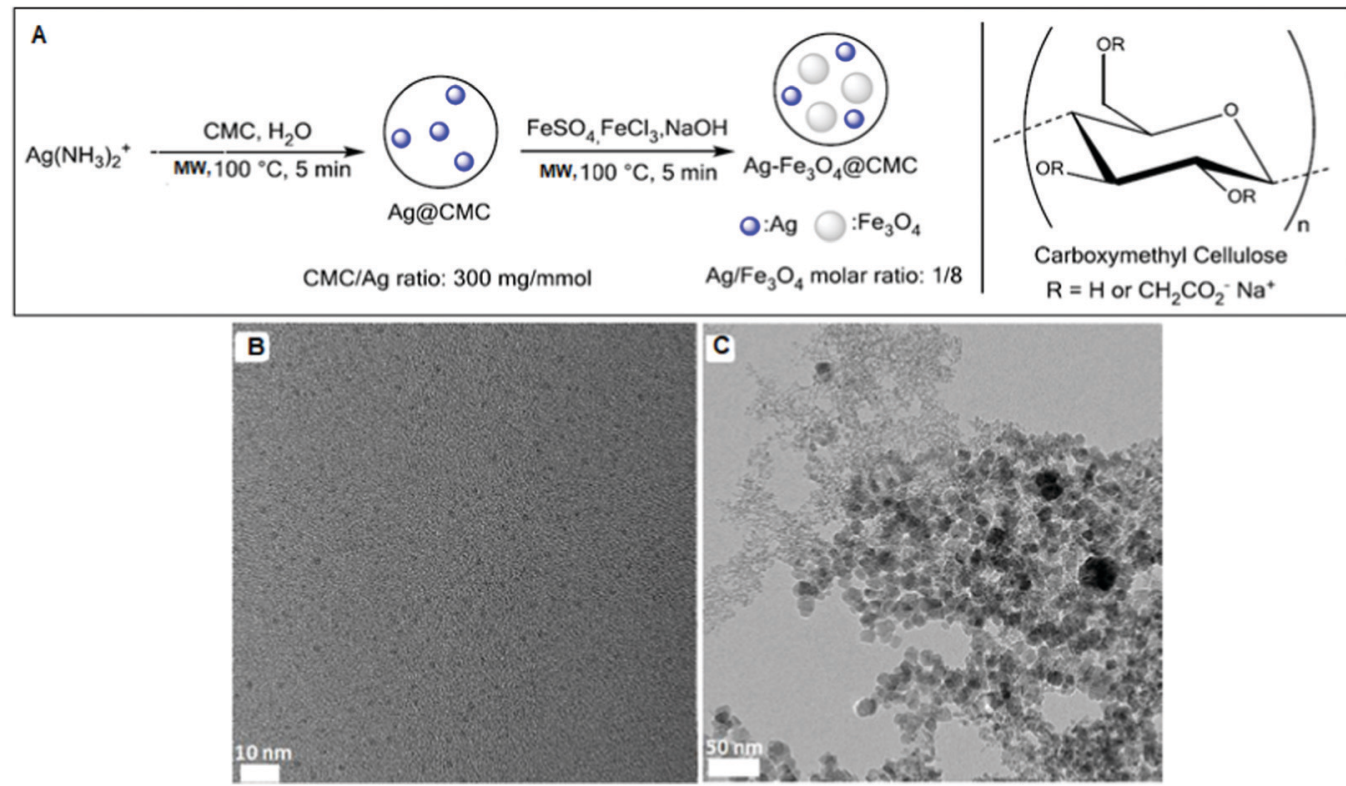

Fig. 7 (A) Preparation scheme of $\mathrm{Ag}\left(\mathrm{aCMC}\right.$ and $\mathrm{Ag}-\mathrm{Fe}_{3} \mathrm{O}_{4}$ (aCMC catalysts. TEM images of (B) Ag@CMC and (C) $\mathrm{Ag}-\mathrm{Fe}_{3} \mathrm{O}_{4} @ \mathrm{aCMC}$ catalysts. ${ }^{193}$ (Copyright 2016, the American Chemical Society.) 
binary $\mathrm{NiSe}_{2} / \mathrm{C}$ electrocatalyst. ${ }^{198}$ In the synthesis, $\mathrm{Co}\left(\mathrm{CH}_{3} \mathrm{COO}\right)_{2}$, $\mathrm{Ni}\left(\mathrm{CH}_{3} \mathrm{COO}\right)_{2}$ and $\mathrm{SeO}_{2}$ were used as the starting materials. The ternary catalyst solid solution was comprised mainly of cubic $\mathrm{NiSe}_{2}$ and $\mathrm{CoSe}_{2}$. An increase in the Co content reduced the average crystallite size of $\left(\mathrm{Co}_{x} \mathrm{Ni}_{1-x}\right) \mathrm{Se}_{2} / \mathrm{C}$ from $32.1 \mathrm{~nm}$ to $20.6 \mathrm{~nm}$. The TEM image confirmed the uniform distribution of NPs $(<2 \mathrm{~nm})$ on the carbon support. In another study, ternary ultra-small composites named $\mathrm{Pt}_{4.5} \mathrm{Sn}_{1.5} \mathrm{Rh}_{1} \mathrm{USNP} / \mathrm{C}, \mathrm{Pt}_{3} \mathrm{Sn}_{1} \mathrm{Rh}_{1}$ USNP/C and $\mathrm{Pt}_{4.5} \mathrm{Sn}_{1} \mathrm{Rh}_{1.5}$ USNP/C containing 20\% Pt loading were prepared via a rapid and simple one-step MW polyol method (Fig. 8A). ${ }^{199}$ The TEM images of $\mathrm{Pt}_{4.5} \mathrm{Sn}_{1.5} \mathrm{Rh}_{1} \mathrm{USNP} / \mathrm{C}$, $\mathrm{Pt}_{3} \mathrm{Sn}_{1} \mathrm{Rh}_{1} \quad \mathrm{USNP} / \mathrm{C}$ and $\mathrm{Pt}_{4.5} \mathrm{Sn}_{1} \mathrm{Rh}_{1.5} \quad \mathrm{USNP} / \mathrm{C}$ showed the uniform distribution of NPs on the carbon support with average diameters of $1.57 \pm 0.97,1.48 \pm 1.18$ and $1.75 \pm 1.14 \mathrm{~nm}$ (Fig. 8B-D), respectively. XPS analysis of $\mathrm{Pt}_{4.5} \mathrm{Sn}_{1.5} \mathrm{Rh}_{1} \mathrm{USNP} / \mathrm{C}$ revealed that $\mathrm{Pt}$ and $\mathrm{Rh}$ were in the metallic state, while Sn was in the oxidized state.

\section{Catalysis by supported simple metal catalysts}

The previous sections revealed that a variety of supported nanocatalysts has been prepared via MW-assisted methods. The supported nanocatalysts include simple metal catalysts such as $\mathrm{Cu},{ }^{81-83,105,132} \mathrm{Ni},{ }^{105,118,136} \mathrm{Co},{ }^{105,119,120} \mathrm{Fe},{ }^{84} \mathrm{Ru},{ }^{85,86,95-99,141}$ $\mathrm{Ag},{ }^{112,116} \mathrm{Au},{ }^{112,129,131,142} \mathrm{Pt},{ }^{87-92,106,111,121,142,145,146} \mathrm{Ti}^{122}{ }^{122}{ }^{123}$ Pd, ${ }^{93,106-108,127,128,130,133,134,137,138,147}$ and W. ${ }^{139}$ Several attempts have also been made to prepare supported simple metal oxide $\left(\mathrm{CoO}_{x}, \mathrm{Co}_{3} \mathrm{O}_{4}, \mathrm{NiO}, \mathrm{Fe}_{3} \mathrm{O}_{4}, \mathrm{SnO}_{2}, \mathrm{CeO}_{2}\right.$, and $\left.\mathrm{TiO}_{2}\right)$ nanocatalysts for application in the petrochemical industry. ${ }^{75,160-166}$ To improve the catalytic activity and versatility of the application potential of simple metal or metal oxide nanocatalysts, investigations on supported bimetal, ${ }^{171-175,177-187}$ mixed metal oxide $^{188-193,196,197}$ and ternary metal ${ }^{198,199}$ nanocatalysts have also been performed. MW-assisted synthesis has been claimed to be an economically viable, short, green method to produce supported nanocatalysts. However, to achieve high catalytic efficiency, strong bonding of the nanocatalyst to the support materials without damaging the support materials due to MW irradiation is essential. Moreover, the loading amount, nanocatalyst size and distribution, and reduction efficiency of the precursor salt during the preparation of catalysts are also known to contribute to their catalytic activity. Consequently, the following section covers the usefulness of various MW-synthesized supported nanomaterials in catalysis with emphasis on their catalytic performance, stability and recycling efficiency. The performance is compared with that prepared via conventional methods, if available. For better comparison, this section is divided into subsections under different reaction types such as oxidation, reduction/reductive degradation, hydrodesulfurization/hydrodearomatization, photocatalytic degradation, hydrogenation, cross couplings, synthetic reaction (cycloisomerization, dehydrogenation, transesterification, and photocatalytic hydrogen generation) and electrocatalysis. Some of these reactions are illustrated in Scheme S1 (ESI $\dagger)$. It is worth mentioning that only the articles which published after 2012 are considered in the following section.

\subsection{Oxidation reactions}

Chuang et al. observed that smaller (16 nm) CuNPs and a cubic morphology in $\mathrm{Cu} / \mathrm{AC}-700 \mathrm{~W}-60 \mathrm{~s}-12$ prepared under the optimized MW conditions were favorable for obtaining the highest oxidation of $\mathrm{CO} .{ }^{81}$ The same observation was made with the $\mathrm{Cu} / \mathrm{CeO}_{2}-\mathrm{TD}$ catalyst during $\mathrm{CO}$ oxidation (95.8\% conversion) due to the better dispersion and smaller CuNPs $(33 \mathrm{~nm}) .{ }^{132}$ The catalytic efficiency of $\mathrm{Cu} / \mathrm{CeO}_{2}$-TD was comparable to that of $\mathrm{Cu} / \mathrm{CeO}_{2}$ nanorods prepared via the wet IM and hydrothermal method. ${ }^{200,201}$ A comparative study on $\mathrm{Pd} / \mathrm{Co}_{3} \mathrm{O}_{4}, \mathrm{Pd} / \mathrm{Fe}_{3} \mathrm{O}_{4}$ and $\mathrm{Pd} / \mathrm{Ni}(\mathrm{OH})_{2}$ catalysts for the $\mathrm{CO}$ oxidation in a programmable flow tube furnace reactor indicated that both 30 wt $\% \mathrm{Pd} / \mathrm{Co}_{3} \mathrm{O}_{4}$ and $50 \mathrm{wt} \% \mathrm{Pd} / \mathrm{Fe}_{3} \mathrm{O}_{4}$ catalysts can produce $100 \% \mathrm{CO}$ oxidation at $127^{\circ} \mathrm{C}$ given that the $\mathrm{Co}_{3} \mathrm{O}_{4}$ support
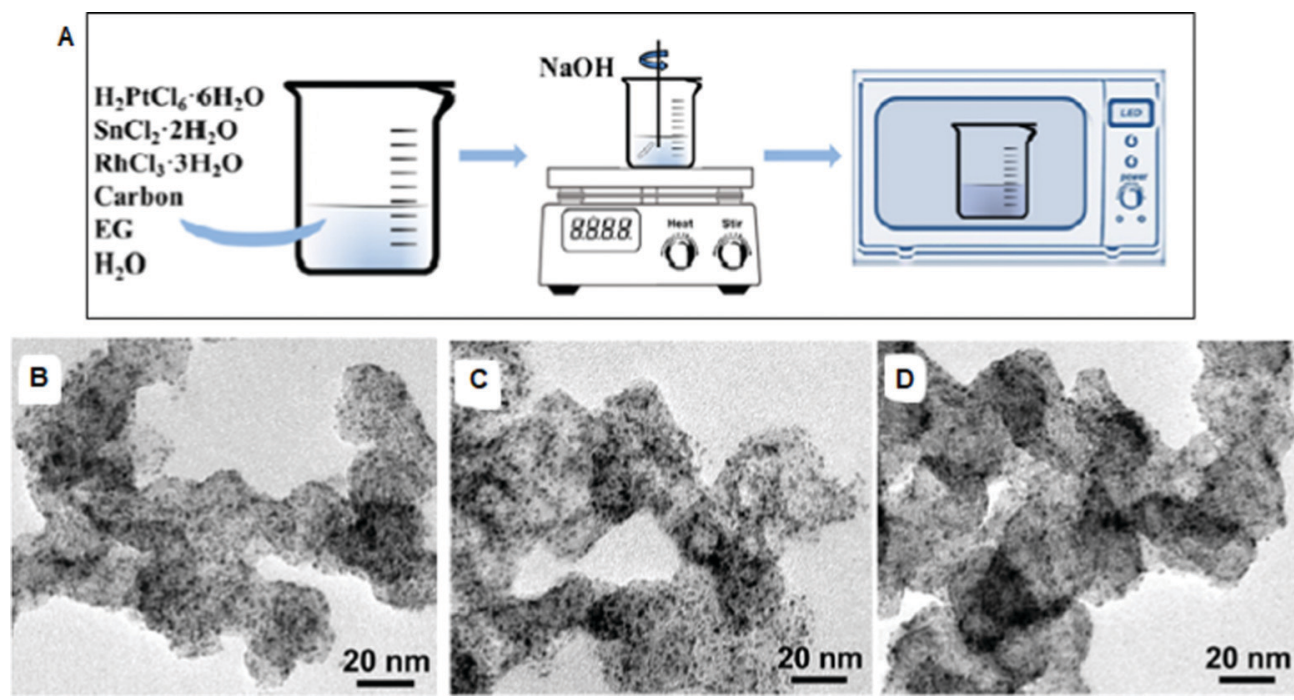

Fig. 8 (A) Scheme of the preparation of ternary Pt-Sn-Rh USNP/C composites. TEM images of (B) $\mathrm{Pt}_{4.5} \mathrm{Sn}_{1.5} \mathrm{Rh}_{1} \mathrm{USNP} / \mathrm{C},(\mathrm{C}) \mathrm{Pt}_{3} \mathrm{Sn}_{1} \mathrm{Rh} \mathrm{h}_{1} \mathrm{USNP} / \mathrm{C}$ and (D) $\mathrm{Pt}_{4.5} \mathrm{Sn}_{1} \mathrm{Rh}_{1.5}$ USNP/C composites. ${ }^{199}$ (Copyright 2020, Elsevier B.V.) 
itself has significant conversion efficiency. ${ }^{127}$ In a related report, the $\mathrm{Pd} / \mathrm{Fe}_{2} \mathrm{O}_{3}-573$ catalyst ( $\mathrm{Pd} 1.87 \mathrm{wt} \%$ ) prepared via coprecipitation followed by calcination at $573 \mathrm{~K}$ produced $100 \%$ CO oxidation efficiency at only $60{ }^{\circ} \mathrm{C}^{202}$ This was due to the smaller $(\sim 10 \mathrm{~nm})$ crystalline size of the $\mathrm{Fe}_{2} \mathrm{O}_{3}$ support compared to $\mathrm{Fe}_{3} \mathrm{O}_{4}(25-30 \mathrm{~nm})$. The deposition of AuNPs on the $\mathrm{Mn}_{3} \mathrm{O}_{4}$ support improved the catalytic oxidation of $\mathrm{CO}$ and the $4-\mathrm{Au} / \mathrm{Mn}_{3} \mathrm{O}_{4}$ catalyst $(4 \mathrm{wt} \% \mathrm{Au})$ resulted in $100 \%$ conversion at $98{ }^{\circ} \mathrm{C} .{ }^{129}$ The stability test of $4-\mathrm{Au} / \mathrm{Mn}_{3} \mathrm{O}_{4}$ at $50{ }^{\circ} \mathrm{C}$ and $125{ }^{\circ} \mathrm{C}$ exhibited its excellent stability up to $20 \mathrm{~h}$, and then it started to deactivate slowly, losing $4 \%$ of its initial activity after $30 \mathrm{~h}$. Likewise, the best catalytic activity was obtained over the 4- $\mathrm{Pd} / \mathrm{Mn}_{3} \mathrm{O}_{4}$ (containing $4 \mathrm{wt} \% \mathrm{Pd}$ ) catalyst given that $100 \% \mathrm{CO}$ oxidation occurred at only $20{ }^{\circ} \mathrm{C}$, a much lower temperature than that of the previous $4-\mathrm{Au} / \mathrm{Mn}_{3} \mathrm{O}_{4}$ catalyst. ${ }^{130}$ This activity was almost on par with the mesostructured $2.7 \mathrm{wt} \%$ Pd-loaded $\mathrm{Pd} / \mathrm{Mn}_{3} \mathrm{O}_{4}$ catalyst prepared via impregnation and reduction. ${ }^{203}$ The stability of $4-\mathrm{Pd} / \mathrm{Mn}_{3} \mathrm{O}_{4}$ was also better and found to be stable up to $30 \mathrm{~h}$ without any remarkable decrease in its activity.

Both the loading method (e.g., complexation-MW assisted combustion, CC, and complexation-impregnation, CI) and weight percentage of Ce- $\mathrm{Zr}$ solid solution in the $\mathrm{Ce}_{0.8} \mathrm{Zr}_{0.2} \mathrm{O}_{2} /$ $\mathrm{Al}_{2} \mathrm{O}_{3}$ catalyst influenced the oxidation of $\mathrm{CO} .{ }^{197}$ Obviously, the conversion degree increased with the loading of $\mathrm{Ce}_{0.8} \mathrm{Zr}_{0.2} \mathrm{O}_{2}$ and the MW-assisted (CC) method resulted in better oxidation activity. CZ40A-CC converted $98 \%$ and $100 \% \mathrm{CO}$ at $250{ }^{\circ} \mathrm{C}$ and $275{ }^{\circ} \mathrm{C}$, respectively, but CZ40A-CI converted $100 \%$ CO at only the higher temperature $\left(275{ }^{\circ} \mathrm{C}\right)$. The maximum conversion achieved by the CZ40A catalysts was due to the proper amount of $\mathrm{Al}_{2} \mathrm{O}_{3}$, reasonable surface area and higher dispersion of ceria and zirconia. However, the stability of the catalysts was not studied.

Ren et al. evaluated the performance of a hollow $\mathrm{Cu} / \mathrm{AC}$ nanocatalyst in the oxidative carbonylation of methanol to dimethyl carbonate (DMC) ${ }^{83}$ Compared to solid $\mathrm{Cu} / \mathrm{AC}-4$, the hollow structure of CuNPs with exposed $\mathrm{Cu}(111)$ crystals improved the selectivity. ${ }^{204,205}$ An irradiation temperature of $360{ }^{\circ} \mathrm{C}$ for a longer duration during the preparation of catalyst was found to be undesirable given that the catalytic efficiency was reduced due to the change in initial morphology. ${ }^{206}$

An MW-NiO/2D-Vmt catalyst exhibited better activity than an MF-NiO/2D-Vmt catalyst for acetylene carbonylation in a constant volume sealed container for the synthesis of acrylic acid (AA). ${ }^{164}$ Again, smaller $\mathrm{NiO}$ grains in the $\mathrm{MW}-\mathrm{NiO} / 2 \mathrm{D}$-Vmt catalyst produced a higher yield of AA (86\%), whereas the MF-NiO/2D-Vmt catalyst produced $68 \%$ yield. However, the MW-NiO/2D-Vmt catalyst was unstable, demonstrating a drastic change in morphology and disappearance of the NiO signal after the first cycle.

An Fe/AC catalyst removed $93 \%$ of added phenol (concentration unknown) after $180 \mathrm{~min}$ at $30{ }^{\circ} \mathrm{C}$ during oxidative degradation but its stability was not that good given that the removal efficiency dropped to $20 \%$ after the fourth recycle due to severe leaching of its Fe ions. ${ }^{84}$ However, the Fe/AC catalyst ( $4 \mathrm{wt} \% \mathrm{Fe}$ ), prepared by heat treatment in air, was worse in terms of performance and stability. ${ }^{207}$

\subsection{Reduction/reductive degradation reactions}

Independent of the Ru content, both Ru/CPM-1 (0.5 wt $\%$ ) and $\mathrm{Ru} / \mathrm{CPM}-2(1.0 \mathrm{wt} \%)$ catalysts completely reduced $p$-nitroaniline ( $p$-NA) and crystal violet (CV) using $\mathrm{NaBH}_{4}$ reductant within $15 \mathrm{~min}$ and $30 \mathrm{~s}$, respectively. ${ }^{85}$ However, a smaller size of embedded RuNPs in the PDC@RuNP catalyst and porous structure helped to attain $98 \%$ elimination of the yellow color of $\mathrm{K}_{3} \mathrm{Fe}(\mathrm{CN})_{6}$ within $30 \mathrm{s.}^{86}$ Comparatively, commercial $\mathrm{Ru} / \mathrm{C}$ took a longer time $(>30 \mathrm{~s})$ due to its insufficient porous structure. The PDC@RuNPs catalyst was fairly stable, retaining $\sim 85 \%$ catalytic activity after six consecutive cycles. The specific surface area decreased slightly after the 6th run but no leaching of Ru was detected. The complete degradation of new fuchsin (NF) dye was also possible over the PDC@RuNP catalyst.

The smaller $(2.0 \pm 0.5 \mathrm{~nm})$ size and dense distribution of RuNPs in the SWCNT-Ru catalyst produced through MW reduction at $100{ }^{\circ} \mathrm{C}$ for 15 min degraded Congo red (CR) dye at both low concentration $(0.01 \mathrm{mM}, 63.8 \%, 2.1 \mathrm{~min})$ and high concentration $(0.06 \mathrm{mM}, 91.0 \%, 3.2 \mathrm{~min}) .{ }^{99}$ The reusability of the SWCNT-Ru catalyst did not show any significant drop in degradation after the third cycle. The same research group observed that the SWCNT-Ru catalyst prepared using ethanol as a reducing agent degraded up to $98.2 \%$ of $0.04 \mathrm{mM}$ CR dye solution within 4 min. ${ }^{100}$ The formation of larger Ru clusters at a higher Ru loading reduced its activity.

Independent of the NP incorporation method (IM or DR), $\mathrm{Pd}-\mathrm{Au} / \mathrm{C}$ catalysts activated by MW irradiation exhibited better hydrodechlorination, $\mathrm{HdCl}$, activity than that activated by thermal treatment in hydrogen. ${ }^{174}$ The improved catalytic activity was attributed to the better homogeneity in the Pd-Al alloy. The deactivation of the PdAu-DR-MW catalyst was also lower owing to the better homogeneity of the Pd-Au alloy phase.

\subsection{Photocatalytic/thermal degradation}

A smaller size and homogeneous distribution of PtNPs and $\mathrm{Mo}_{2} \mathrm{C}$ in $\mathrm{Pt} / \mathrm{G}$ and $\mathrm{Mo}_{2} \mathrm{C} / \mathrm{C}$ catalysts, respectively, again showed good to excellent methylene blue (MB) photodegradation and hydrous hydrazine decomposition activities. ${ }^{11,156}$ The MWassisted catalytic decomposition with a power of $180 \mathrm{~W}$ produced complete decomposition over the $\mathrm{Mo}_{2} \mathrm{C} / \mathrm{C}$ catalyst within 4 min. The WC/AC-H catalyst prepared by the rather long procedure of impregnation and carbothermal hydrogen reduction, produced complete hydrazine conversion at $50{ }^{\circ} \mathrm{C}^{208} \mathrm{CeO}_{2}-\mathrm{SiO}_{2}$ NPs abbreviated as $\mathrm{M}-30$ (irradiation time $30 \mathrm{~min}$ ), exhibited better $\mathrm{MB}$ decomposition activity under UV light, also due to their lower particle size and higher surface area and pore volume. ${ }^{162}$ In this case, the degradation efficiency was $99.9 \%$ at $\mathrm{pH} 7$. On the contrary, the same $\mathrm{CeO}_{2}-\mathrm{SiO}_{2}$ catalyst $(\mathrm{H}-24 \mathrm{~h})$ prepared via the hydrothermal process showed only $85 \%$ degradation efficiency.

\subsection{Hydrogenation reaction}

The selective hydrogenation reaction of $p$-chloronitrobenzene ( $p$-CNB) to $p$-chloroaniline ( $p$-CAN) in the presence of either $\mathrm{Ru} /$ CNT or Ru/FCNT catalysts indicated that the Ru/FCNT catalysts prepared without/with a PVP stabilizer had better activity with 
$100 \%$ selectivity at $100 \%$ conversion after 30 min of reaction. ${ }^{95}$ These findings were consistent with the more homogeneous distribution of RuNPs and stronger anchoring of the RuNPs on the FCNT surface. Further, the selectivity (96\%) of commercial $\mathrm{Ru} / \mathrm{CNT}$ was comparatively lower. In a study on the effect of the precursor type $\left(\mathrm{Ru}(\mathrm{acac})_{3} / \mathrm{RuCl}_{3}\right)$ on the catalytic activity of an $\mathrm{Ru} / \mathrm{TiO}_{2}$ catalyst, it was found that an increase in the irradiation time resulted in an increase in the particle size. ${ }^{141}$ This reduced the yield of $\gamma$-valerolactone (GVL) from the hydrogenation of levulinic acid (LA).

An MW-synthesized Ni/AB-MW catalyst was found to be superior to an Ni/AB-CH catalyst in the hydrogenation of nitrobenzene to aniline with respect to conversion $(98.7 \%)$ and selectivity (93.3\%). ${ }^{118}$ MW synthesis produced a smaller and uniform size as well as a higher loading of metallic $\mathrm{Ni}$ and NiO particles. The stability of the Ni/AB-MW catalyst was also better given that the $\mathrm{Ni}$ crystallite size indicated an increase in size by $27.4 \%$ after $60 \mathrm{~h}$ of reaction, while in the Ni/AB-CH catalyst, the size increase was more dominant (26.5\% after $36 \mathrm{~h}$ ).

$\mathrm{Pd} / \mathrm{Al}_{2} \mathrm{O}_{3}$ catalysts prepared via plasma-induced MW irradiation, designated as PF (plasma fixed-bed reactor) and PS (plasma spouted bed reactor), were used for the hydrogenation of acetylene and compared with CM (conventional thermal treatments). ${ }^{137}$ In the plasma fixed-bed reactor, three catalysts named PF-1, PF-2 and PF-3 were prepared by controlling the distance between the waveguide and particle bed in the range of 3 to $7 \mathrm{~cm}$. Overall, PF-1 possessed the maximum activity due to formation of the Pd (100) plane and a better dispersion. The highest selectivity for consecutive acetylene hydrogenation towards ethane was also possible in the presence of PF-1. In another investigation, the authors proved that although plasma spouted bed treatment produced a higher gas temperature than conventional heat treatment at $500{ }^{\circ} \mathrm{C}$, the former method prevented Pd metal from sintering due to its shorter reaction time. ${ }^{138}$

\subsection{Hydrodesulfurization/hydrodearomatization}

Hydrodesulfurization (HDS) is an industrial process required for reducing the sulfide content in fuel. $\mathrm{A} \mathrm{W} / \mathrm{Al}_{2} \mathrm{O}_{3}$ catalyst (identified as MWH-B) prepared via the part-wise addition of oxalic acid showed enhanced HDS activity due to the good dispersion of $\mathrm{WO}_{3}{ }^{139}$ The overall analysis suggested that the catalyst prepared via the MWH method had superior HDS activity relative to that prepared by IM. Nguyen et al. found that the HDS conversion of 4,6-dimethyldibenzothiophene (4,6DMDBT) over the CoMo/Ti-SBA-15 catalyst was 1.35-times higher than that on the CoMo/SBA-15 catalyst. ${ }^{185}$ Alternatively, the insertion of $\mathrm{Ti}$ in the CoMo/SBA-15 catalyst reduced the hydrodearomatization (HDA) activity of 1-methylnaphthalene (1-MN) and phenanthrene by half. Hence, the inclusion of $\mathrm{Ti}$ promised control of the HDA activity over the CoMo/SBA-15 catalyst.

\subsection{Coupling reactions}

To understand the deactivation process, $\mathrm{Pd} / \mathrm{C}$ and $\mathrm{Pd} / \mathrm{Grp}$ catalysts were subjected to MW irradiation for variable times $(30 \mathrm{~s}, 5 \mathrm{~min}$ and $30 \mathrm{~min}$ ) before the Suzuki-Miyaura (phenylboronic acid and $p$-nitrobromobenzene) and Mizoroki-Heck (iodobenzene, butyl acrylate, and triethylamine) coupling transformations. ${ }^{93}$ A longer MW irradiation time between 5 to $30 \mathrm{~min}$ produced a considerable loss in catalytic activity for the $\mathrm{Pd} / \mathrm{C}$ catalyst, which was more severe for the $\mathrm{Pd} /$ Grp catalyst after irradiation for $30 \mathrm{~s}$. The deactivation of the catalyst resulted from an increase in particle size, dissolution of carbon inside the metal NPs and formation of metal oxide. In another investigation, $1 \mathrm{~mol} \%$ of $\mathrm{Pd} / \mathrm{G}$ catalyst prepared by continuous flow synthesis produced $100 \%$ conversion in the MW-assisted batch Suzuki-Miyaura coupling reaction between bromobenzene and phenylboronic acid. ${ }^{107}$ However, the recyclability test was not promising given that conversion decreased from $100 \%$ to $77 \%$ in the fourth cycle of the coupling reaction. Comparatively, the MW-assisted Suzuki-Miyaura coupling reaction between bromobenzene and phenylboronic acid over a magnetic $\mathrm{Pd}-\mathrm{Fe}_{3} \mathrm{O}_{4} / \mathrm{G}$ nanocomposite showed better stability with $100 \%$ conversion up to the 3 rd cycle. ${ }^{109}$ Further recycling reduced the conversion to around $81 \%$ in the 9 th cycle, which is still good. Controlling the MW temperature between $25-80{ }^{\circ} \mathrm{C}$ is important given that an increase in temperature to $100{ }^{\circ} \mathrm{C}$ reduced the conversion after $10 \mathrm{~min}$ of reaction, indicating destabilization of the catalyst.

Elazab et al. observed that a Pd content of $20 \mathrm{wt} \%$ in $\mathrm{Pd} / \mathrm{CuO}$ catalysts is optimum for obtaining $100 \%$ conversion in the MWassisted Suzuki-Miyaura coupling reaction between aryl halides and phenylboronic acid. ${ }^{133}$ The application of the $20 \mathrm{wt} \% \mathrm{Pd} /$ $\mathrm{CuO}$ catalyst for other substrates also produced good conversion (82-90\%). The conversion drastically dropped to $60 \%$ in the sixth run due to the agglomeration of the PdNPs. Elazab et al. also investigated the applicability of $\mathrm{Pd} / \mathrm{CuO}$ catalysts for the MizorokiHeck (aryl bromide and alkene) and Sonogashira-Hagihara (aryl bromide and alkyne) coupling reactions under MW irradiation. ${ }^{134}$ The Mizoroki-Heck coupling reaction between bromobenzene and alkene on $2 \mathrm{~mol} \%$ of the $20 \mathrm{wt} \% \mathrm{Pd} / \mathrm{CuO}$ catalyst produced the maximum conversion of $93 \%$ at the optimized temperature of $150{ }^{\circ} \mathrm{C}$. The catalyst was found to be fairly stable up to 5 cycles.

Interestingly, the $\mathrm{Pd} / \mathrm{SiC}$ catalyst, labeled as MW3, exhibited high catalytic activity up to 20 reaction cycles with more than $>90 \%$ yield in the Mizoroki-Heck (iodobenzene and methyl acrylate) coupling reaction. ${ }^{147}$ Comparatively, the OB3 catalyst, which was prepared via conventional heating, produced $100 \%$ yield in the first cycle, but this was drastically reduced to $75 \%$ yield. In contrast, the commercial Pd/C catalyst was usable for only one Mizoroki-Heck reaction cycle. The better catalytic activity, i.e., longer catalytic life of MW3 was due to larger amounts of PdNPs on the support. MW3 was also found applicable in the Suzuki-Miyaura coupling reaction.

In comparison to the $\mathrm{Pd} / \mathrm{Ag} / \mathrm{SBA}-15$ catalyst, the $\mathrm{Pd} / \mathrm{Au} / \mathrm{SBA}-$ 15 catalyst showed superior activity in the Suzuki-Miyaura coupling reaction between iodobenzene and aryl boronic acid and produced $\sim 70 \%$ conversion. ${ }^{183}$ The enhanced activity of aryl halides followed the order of $\mathrm{I}>\mathrm{Br}>\mathrm{Cl}$. A comparative study among the $\mathrm{Pd}-\mathrm{Fe}_{3} \mathrm{O}_{4} / \mathrm{G}, \mathrm{Pd}-\mathrm{Co}_{3} \mathrm{O}_{4} / \mathrm{G}$ and $\mathrm{Pd}-\mathrm{Ni}(\mathrm{OH})_{2} / \mathrm{G}$ catalysts for the Suzuki-Miyaura coupling reaction (bromobenzene with phenyl boronic acid) showed the lowest $(<60 \%)$ conversion 
over the $\mathrm{Pd}-\mathrm{Ni}(\mathrm{OH})_{2} / \mathrm{G}$ catalyst but both the $\mathrm{Pd}-\mathrm{Fe}_{3} \mathrm{O}_{4} / \mathrm{G}$ and $\mathrm{Pd}-\mathrm{Co}_{3} \mathrm{O}_{4} / \mathrm{G}$ catalysts produced $100 \%$ conversion within $10 \mathrm{~min}$ at $120{ }^{\circ} \mathrm{C} .{ }^{188}$ The good nano-size distribution of the catalyst on $\mathrm{G}$ nanosheets in both cases substantially improved the catalytic conversion. The $\mathrm{Pd}-\mathrm{Fe}_{3} \mathrm{O}_{4} / \mathrm{G}$ catalyst was fairly stable, producing $90 \%$ conversion in the fifth cycle. In an early article, Elazab et al. demonstrated that $0.3 \mathrm{~mol} \%$ of magnetically recyclable $\mathrm{Pd}-\mathrm{Fe}_{3} \mathrm{O}_{4} / \mathrm{G}$ catalyst, labeled as catalyst 3 (Pd $7.6 \mathrm{wt} \%$ ), produced 100\% conversion within 45 min in the Suzuki-Miyaura coupling reaction. ${ }^{189}$ Despite having a low Pd content, catalyst 3 had the highest activity because it contained the smallest Pd (3-4 nm) and $\mathrm{Fe}_{3} \mathrm{O}_{4}$ NPs (12-16 nm).

\subsection{Synthesis reactions}

The catalytic cycloisomerization of substituted propargylic urea to produce substituted imidazolone under optimized reaction conditions was carried out over MW-2\%Ag@AlSBA-15, MW2\%Au@AlSBA-15, BM-2\%Ag@AlSBA-15 and BM-2\%Au@AlSBA15 catalysts (Scheme 1). ${ }^{112}$ Irrespective of their preparation methods, the supported $\mathrm{Au}$ nanocomposites were almost inactive with a yield of less than 5\%. Alternatively, the ballmilled BM-2\%Ag@AlSBA-15 catalyst was more active (yield, 56\%) than the MW-synthesized MW-2\%Ag@AlSBA-15 catalyst (yield 35\%). However, despite the lower activity of the MWsynthesized catalyst, the authors claimed that the MW-assisted synthesis of the catalyst is favorable because it requires a few minutes for the one-step reduction compared to several hours required by ball milling-assisted synthesis. However, information on the size distribution, valence state and crystallinity of the nanocatalyst is not available, and thus it is difficult to predict the exact reason for the poor performance by the MW2\%Ag@AlSBA-15 catalyst. However, another author reported $99 \%$ yield of 2 a (Scheme 2 ) with $100 \%$ conversion at $50{ }^{\circ} \mathrm{C}$ using a similar type of $0.96 \mathrm{wt} \%$ AgNCs/SBA-15 catalyst during the cyclization of propargylguanidine. ${ }^{116}$ This result is remarkable compared to that of $\mathrm{Ag}$ salts and AgNCs, although the metal loading is much lower. ${ }^{209,210}$ The conversion was retained at $>90 \%$ conversion after 4 cycles, and no Ag leaching was detected and the morphology with the size distribution of the recovered catalyst remained unchanged. The cyclization of 2-(phenylethynyl)phenol in the presence of $0.96 \%$ AgNCs/SBA-15 catalyst also resulted in $100 \%$ conversion with $93 \%$ selectivity for 2-phenylbenzofuran (4a) at $70{ }^{\circ} \mathrm{C}$ (Scheme 2).

Song et al. observed superior $\mathrm{CO}_{2}$ methanation activity over an $\mathrm{Ni}-\mathrm{Al}_{2} \mathrm{O}_{3}-\mathrm{M}$ catalyst compared to that over an $\mathrm{Ni}-\mathrm{Al}_{2} \mathrm{O}_{3}-\mathrm{I}$

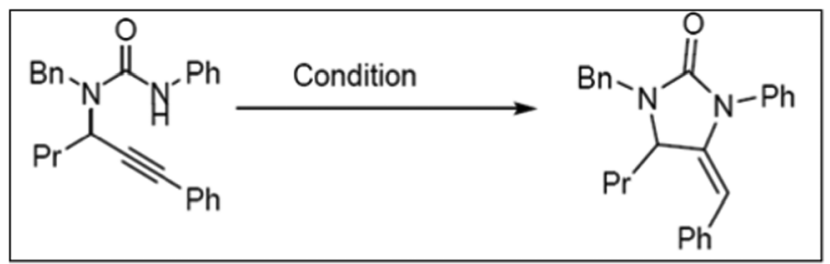

Scheme 1 The catalytic cycloisomerization of substituted propargylic urea. ${ }^{112}$ (Copyright 2019, the American Chemical Society.)

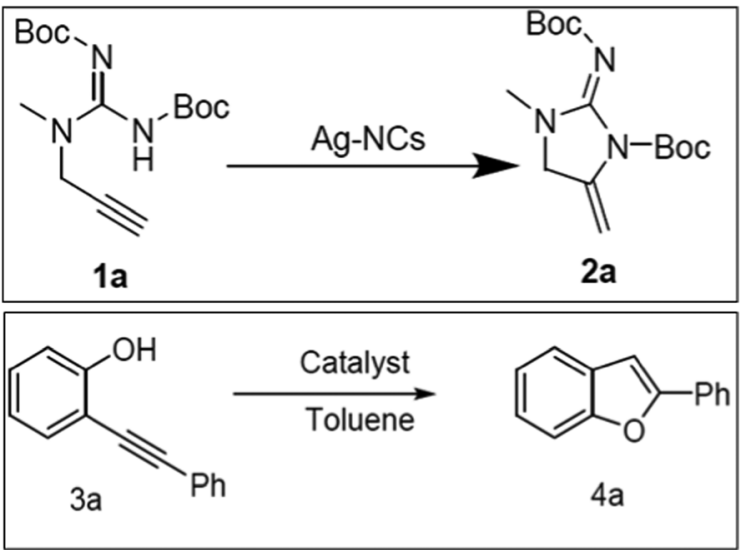

Scheme 2 The catalytic cyclization of propargylguanidine (1a) and 2-(phenylethynyl)phenol (3a). ${ }^{116}$ (Copyright 2020, the American Chemical Society.)

catalyst. ${ }^{136}$ The maximum conversion efficiency of $91.6 \%$ was possible at $325{ }^{\circ} \mathrm{C}$ over the $\mathrm{Ni20}-\mathrm{Al}_{2} \mathrm{O}_{3}-\mathrm{M}$ catalyst (20 wt $\% \mathrm{Ni}$ ) and the selectivity for $\mathrm{CH}_{4}$ in the temperature range of 200$400{ }^{\circ} \mathrm{C}$ was around $99.3 \%$. The catalyst was stable at $325{ }^{\circ} \mathrm{C}$ for up to $72 \mathrm{~h}$ given that the conversion remained high (91.6\%). The anti-sintering stability of the $\mathrm{Ni20}-\mathrm{Al}_{2} \mathrm{O}_{3}-\mathrm{M}$ catalyst was confirmed.

Akay et al. tested a $\mathrm{Co} / \mathrm{SiO}_{2}$ catalyst in non-thermal plasmapromoted Fisher-Tropsch synthesis (FTS) involving $\mathrm{CO}$ and $\mathrm{H}_{2}$ gases. ${ }^{119}$ Catalyst-ABC-550, where metal oxide was reduced in a plasma reactor under a stream of $\mathrm{H}_{2}$ for $24 \mathrm{~h}$ at $550{ }^{\circ} \mathrm{C}$, was found to be the best, producing $100 \%$ CO conversion. CatalystABC-550 also possessed better stability given that the $\mathrm{CO}$ conversion of $100 \%$ remained constant over the complete test period of $175 \mathrm{~h}$. It was possible to restore the complete catalytic activity of the deliberately deactivated Catalyst-ABC-550 by reduction with $\mathrm{H}_{2}\left(25 \mathrm{~mL} \mathrm{~min}^{-1}\right)$ at a plasma power of $90 \mathrm{~W}$ for $24 \mathrm{~h}$ at $250{ }^{\circ} \mathrm{C}$. In contrast, the $\mathrm{Co} / \mathrm{SiO}_{2}$ catalyst prepared by depositing Co monolayers on a $10 \mathrm{~nm}$-thick $\mathrm{SiO}_{2}$ film demonstrated poor stability in the FTS reaction. ${ }^{211}$ In another investigation, $\mathrm{Co} / \mathrm{SiO}_{2}$ catalysts prepared via conventional drying offered better CO conversion (68.3\%) compared to that prepared via the MW method (42.1\%) but the selectivity towards liquid hydrocarbons of $\mathrm{C}_{5+}$ was higher $(63.2 \%)$ for the catalyst prepared via the MW method. ${ }^{120}$ However, it is not clear whether the MW method caused any damage to the support or agglomeration.

A comparative study between MW-NiO/Vmt and CHT-NiO/ Vmt catalysts for $\mathrm{CO}$ methanation in a stainless steel tubular microreactor in the temperature range of $250-500{ }^{\circ} \mathrm{C}$ showed the better $\mathrm{CO}$ conversion (99.6\%) and $\mathrm{CH}_{4}$ selectivity $(93.8 \%)$ by the $\mathrm{MW}$-synthesized $\mathrm{MW}-\mathrm{NiO} / \mathrm{Vmt}$ catalyst at $400{ }^{\circ} \mathrm{C} .{ }^{163}$ MW-NiO/Vmt was also found to be comparatively more stable.

The ethanol conversion in the range of $250-450{ }^{\circ} \mathrm{C}$ with a constant $\mathrm{H}_{2}$ flow over $\mathrm{Pt} / \mathrm{SiO}_{2}$ catalysts, which were prepared with different Pt loadings via the MW-assisted solution and RCE methods, increased markedly with an increase in temperature, but decreased slightly with the Pt loading, which was 
affected by the dispersion behavior of the PtNPs. ${ }^{121}$ The selectivity toward ethylene (dehydration) at $450{ }^{\circ} \mathrm{C}$ for the 0.6 and $0.9 \mathrm{wt} \%$ Pt-loaded catalysts prepared via the MW method was higher $(50-53 \%)$ compared to that $(47 \%)$ for the samples prepared via the RCE method.

The photocatalytic activity of $\mathrm{TiO}_{2} / \mathrm{Au}$ NPs for $\mathrm{H}_{2}$ production from a mixture of ethanol and water in the gas phase through a tubular reactor suggested that the removal of the capping agent, PVP, via calcination is necessary to improve the efficiency. ${ }^{166}$ The optimal calcination temperature was $450{ }^{\circ} \mathrm{C}$ for the best $\mathrm{H}_{2}$ evolution of $\sim 5.3 \mathrm{H}_{2} \mathrm{~g}_{\text {cat }}{ }^{-1} \mathrm{~h}^{-1}$ (sample $\mathrm{A}$, $100 \mathrm{mg}$ of PVP) and $\sim 3.5 \mathrm{H}_{2} \mathrm{~g}_{\text {cat }}{ }^{-1} \mathrm{~h}^{-1}$ (sample B, $600 \mathrm{mg}$ of PVP). A higher calcination temperature $\left(>550{ }^{\circ} \mathrm{C}\right)$ reduced the catalytic performance via aggregation. The higher catalytic activity of sample A was due to the larger interface area between $\mathrm{Au}$ and $\mathrm{TiO}_{2}$, which favored the interaction between the Au and $\mathrm{TiO}_{2}$ NPs. ${ }^{212}$ A comparative study of the catalytic property between $\mathrm{Pd} / \mathrm{Ag} / \mathrm{SBA}-15$ and $\mathrm{Pd} / \mathrm{Au} / \mathrm{SBA}-15$ catalysts for hydrogen production from ammonia borane $(\mathrm{AB})$ under both dark and visible light irradiation conditions indicated the superior catalytic activity of the $\mathrm{Pd} / \mathrm{Ag}$ catalyst. ${ }^{183}$ Khalid et al. observed that the catalysis power of an $\mathrm{Ag}-\mathrm{TiO}_{2} / \mathrm{G}$ composite for hydrogen production from methanol aqueous solution was superior to that of the pure $\mathrm{TiO}_{2}, \mathrm{Ag}-\mathrm{TiO}_{2}$ and $\mathrm{TiO}_{2} / \mathrm{G}$ samples. ${ }^{190}$ Hence, the inclusion of a $\mathrm{G}$ support and $\mathrm{Ag}$ played a vital role in enhancing the photocatalytic activity. The hydrogen production efficiency from methanol over four different copper-based catalysts $\left(\mathrm{CuNiZnO} / \gamma-\mathrm{Al}_{2} \mathrm{O}_{3}\right)$, which were prepared at different MW temperatures $\left(80{ }^{\circ} \mathrm{C}, 85{ }^{\circ} \mathrm{C}, 90{ }^{\circ} \mathrm{C}\right.$ and $\left.95{ }^{\circ} \mathrm{C}\right)$ indicated that the content of $\mathrm{Cu}, \mathrm{Ni}$ and $\mathrm{Zn}$ had an effect on the catalyst power. ${ }^{196}$ The MW-Cu/Ni-80 catalyst contained a higher amount of $\mathrm{Cu}(47.92 \mathrm{wt} \%)$, resulting in higher activity at a lower reaction temperature $\left(200{ }^{\circ} \mathrm{C}\right)$. In contrast, the other catalysts processed at higher MW temperatures contained larger amounts of $\mathrm{Ni}$ and $\mathrm{Zn}$ than the $\mathrm{MW}-\mathrm{Cu} / \mathrm{Ni}-80$ catalyst, which played the main role for increasing methanol conversion at a higher temperature $\left(\geq 225{ }^{\circ} \mathrm{C}\right.$ ). The catalytic selectivity with respect to $\mathrm{H}_{2}$ production increased with an increase in the reaction temperature for $\mathrm{MW}-\mathrm{Cu} / \mathrm{Ni}-80$, but for $\mathrm{MW}-\mathrm{Cu} / \mathrm{Ni}-90$ and $\mathrm{MW}-\mathrm{Cu} / \mathrm{Ni}-95$ this trend could not be distinctly confirmed and the overall yield was relatively high for both $\mathrm{MW}-\mathrm{Cu} / \mathrm{Ni}-90$ and $\mathrm{MW}-\mathrm{Cu} / \mathrm{Ni}-95$. The formation of an increasing amount of $\mathrm{Ni}$ possibly inhibited the formation of methyl formate and increased the selectivity for $\mathrm{H}_{2}$ and CO in methanol decomposition..$^{213,214}$ The MW-Cu/Ni-90 catalyst was fairly stable and methanol conversion was maintained at $100 \%$ for up to $26 \mathrm{~h}$, only slightly decreasing to $98.8 \%$ after $30 \mathrm{~h}$.

\subsection{Electrocatalysis}

In the last few decades, a considerable amount of research has been devoted towards the application of Pt NPs in PEMFCs, ${ }^{215,216}$ water splitting, ${ }^{217}$ and direct alcohol fuel cells. ${ }^{218}$ However, due to the high cost of Pt, its application is limited, and thus researchers are focusing more on the development of multicomponent (binary or ternary) catalysts to promote the catalytic performance. The combination of Pt with non-precious metals can also reduce the dosage of $\mathrm{Pt}$ and is beneficial for improving its resistance to poisoning. ${ }^{219,220}$

Sharma et al. studied the electrocatalytic activity of $\mathrm{Pt} / \mathrm{C}$ electrocatalysts prepared using different precursors. ${ }^{92} \mathrm{~A}$ comparative study of the cyclic voltammograms (CV) suggested that relative to the commercial $\mathrm{Pt} / \mathrm{C}$ catalyst, the $\mathrm{H}_{2} \mathrm{PtCl}_{6}-$ and $\left(\mathrm{NH}_{4}\right)_{2} \mathrm{PtCl}_{6}$-sourced $\mathrm{MW}$-synthesized $\mathrm{Pt} / \mathrm{C}$ catalysts possessed a higher and almost identical electrochemical surface area (ECSA). The $\left(\mathrm{NH}_{4}\right)_{2} \mathrm{PtCl}_{6}$-sourced $\mathrm{Pt} / \mathrm{C}$ catalyst exhibited a comparable ORR performance with that of the commercial and $\mathrm{H}_{2} \mathrm{PtCl}_{6}$-sourced catalysts. The electrocatalytic activity of $\mathrm{CoSe}_{2}$ / $\mathrm{C}$ catalysts prepared with different Se/Co ratios showed that an Se/Co ratio of 3.0 is the best for ORR activity and stability. ${ }^{177}$ An excess amount of Se oxide reduced the ORR activity due to the occurrence of severe aggregation of the $\mathrm{CoSe}_{2}$ NPs. Likewise, $\mathrm{FeSe}_{2} / \mathrm{C}$ NPs prepared with different $\mathrm{Fe} / \mathrm{Se}$ ratios exhibited the best ORR activity at $\mathrm{Se} / \mathrm{Fe}$ ratios of 2.0 and 4.0 , respectively. ${ }^{178}$ These ratios were equivalent to $47.21 \%$ and $48.2 \%$ of the total amount of $\mathrm{FeSe}_{2}$ and $\mathrm{FeSe}$, respectively. An increase in $\mathrm{Co}$ content in a series of ternary $\left(\mathrm{Co}_{x} \mathrm{Ni}_{1-x}\right) \mathrm{Se}_{2} / \mathrm{C}$ catalysts improved their electrocatalytic activities towards the ORR. ${ }^{198}$ The beneficial effect of the incorporation of Co was further confirmed by the increase in the ORR potential $\left(E_{\text {ORR }}\right)$. The incorporation of $\mathrm{Co}$ in binary $\mathrm{NiSe}_{2} / \mathrm{C}$ was also advantageous for the enhanced stability of the $\left(\mathrm{Co}_{0.75} \mathrm{Ni}_{0.25}\right) \mathrm{Se}_{2} / \mathrm{C}$ electrocatalyst.

The addition of $\mathrm{Sn}$ to a $\mathrm{Pt} / \mathrm{C}$ catalyst greatly enhanced its electrocatalytic activity for ethanol oxidation (EO), whereas the addition of Rh only modestly improved the electrochemical performance. ${ }^{171}$ Chronoamperometric tests suggested that $\mathrm{PtSn} / \mathrm{C}$ is considerably less poisoned compared to the $\mathrm{Pt} / \mathrm{C}$ or $\mathrm{PtRh} / \mathrm{C}$ catalysts. Similarly, the inclusion of $\mathrm{Cu}$ in $\mathrm{Pt} / \mathrm{C}(\mathrm{Pt} 3 \mathrm{Cu} /$ $\mathrm{C}, \mathrm{Pt} 4 \mathrm{Cu} / \mathrm{C}$, and $\mathrm{Pt} 2 \mathrm{Cu} / \mathrm{C}$ ) catalysts improved their electrocatalytic performances compared to the commercial Pt/C catalyst for $\mathrm{EO}$ and $\mathrm{MO} .{ }^{173}$ The $\mathrm{Pt} 3 \mathrm{Cu} / \mathrm{C}$ catalyst had the highest mass activity, MA, (1.61 $\mathrm{A} \mathrm{mg}^{-1}$ ) and surface specific activity, SA, (3.23 $\mathrm{mA} \mathrm{cm} \mathrm{cm}^{-2}$ ) towards EO. The Pt3Cu/C catalyst also displayed the highest MA (1.92 $\mathrm{A} \mathrm{mg}^{-1}$ ) towards MO. The inclusion of $\mathrm{Cu}$ also improved the durability of $\mathrm{PtCu} / \mathrm{C}$ towards the EO and MO reactions. SF-MWCNT-Pd and its mixed bimetallic SF-MWCNT-PdSn ${ }_{\text {mix }}$ and SF-MWCNT-PdNi ${ }_{\text {mix }}$ nanocatalysts were found to be more active towards EO compared to alloyed SF-MWCNT-PdNi and SF-MWCNT-PdSn catalysts produced via MW assisted co-reduction. ${ }^{179}$ The addition of Sn to $\mathrm{Pd}$ produced the maximum influence on electrocatalytic property. However, chronopotentiometric experiments showed that SF-MWCNT-PdNi $\mathrm{i}_{\text {mix }}$ was more tolerant to CO poisoning

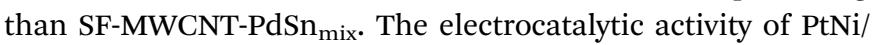
FCNT analyzed in MO was dependent on the metal loading and mode of irradiation. ${ }^{180}$ The catalysts prepared at different irradiation times had almost the same stability, but higher than that of the reference $\mathrm{Pt} / \mathrm{C}$ catalyst. Three different ternary catalysts labeled as $\mathrm{Pt}_{4.5} \mathrm{Sn}_{1.5} \mathrm{Rh}_{1} \mathrm{USNP} / \mathrm{C}, \mathrm{Pt}_{3} \mathrm{Sn}_{1} \mathrm{Rh}_{1} \mathrm{USNP} / \mathrm{C}$ and $\mathrm{Pt}_{4.5} \mathrm{Sn}_{1} \mathrm{Rh}_{1.5}$ USNP/C also showed an improvement in electrocatalytic performance towards both MO and EO than $20 \mathrm{wt} \% \mathrm{Pt} / \mathrm{C} .{ }^{199}$ Notably, the highest MA and SA were observed for the $\mathrm{Pt}_{4.5} \mathrm{Sn}_{1.5} \mathrm{Rh}_{1}$ USNP/C catalyst. The stability tests also 
confirmed the superiority of the $\mathrm{Pt}_{4.5} \mathrm{Sn}_{1.5} \mathrm{Rh}_{1}$ USNP/C catalyst. The structures and morphologies after 1000 sweeping cycles did not change for all the Pt-Sn-Rh/C catalysts, whereas for the $20 \mathrm{wt} \% \mathrm{Pt} / \mathrm{C}$ catalyst, severe aggregation was observed. A trimetallic AuPdPt@WC/C catalyst also showed an improvement in electrocatalytic MO reaction compared to the commercial $\mathrm{Pt} / \mathrm{C}$ catalyst. ${ }^{200}$ The anti-poisoning ability of trimetallic AuPdPt@WC/C was 5-times better than that of the commercial Pt/C catalyst. The formation of highly dispersed AuPdPt metals on a WC support and the coupling effect between NPs enhanced the electrocatalytic performance.

The MW synthesis of PtRu/MWCNT NPs resulted in an improvement in poisoning resistance to $\mathrm{CO}$ following the formation of a homogeneously dispersed alloy phase. ${ }^{181}$ In a similar investigation, the PtPd/MWCNT-GNP catalyst was found to possess the highest electrochemical stability and durability compared to PtPd/MWCNT and PtPd/GNP catalysts. ${ }^{182}$ This behavior was ascribed to its better dispersion, smallest NP size and highest specific surface area $\left(164 \mathrm{~m}^{2} \mathrm{~g}^{-1}\right)$.

The electrochemical activity of the $\mathrm{Co}_{3} \mathrm{O}_{4} @$ @SUS electrode towards the OER in water splitting was compared with reference materials including commercial $\mathrm{RuO}_{2}$ @SUS and $\mathrm{Co}_{3} \mathrm{O}_{4}$-LNS@SUS catalysts. ${ }^{165} \mathrm{Co}_{3} \mathrm{O}_{4} @ S U S$ exhibited the most favorable OER kinetics due to its rod-like morphology and highest surface to volume ratio. The stability of the $\mathrm{Co}_{3} \mathrm{O}_{4} @$ @US catalyst was good towards the OER with $78 \%$ current retention after $24 \mathrm{~h}$ and the initial morphology of the catalyst was maintained. Meanwhile, a metal organic framework, Co-N-C, supported $\mathrm{Ni}_{3} \mathrm{Fe}$ catalyst offered the best OER activity and best reaction kinetics compared to $\mathrm{Ni}_{3} \mathrm{Fe} / \mathrm{N}-\mathrm{C}, \mathrm{IrO}_{2}$, and Co-N-C. ${ }^{187} \mathrm{~A}$ negligible decay in current density was observed for the $\mathrm{Ni}_{3} \mathrm{Fe} /$ $\mathrm{Co}-\mathrm{N}-\mathrm{C}$ catalyst after 3000 potential sweeps. Subsequently, the $\mathrm{Ni}_{3} \mathrm{Fe} / \mathrm{Co}-\mathrm{N}-\mathrm{C}$ showed a comparable ORR performance. Hence, the $\mathrm{Ni}_{3} \mathrm{Fe} / \mathrm{Co}-\mathrm{N}-\mathrm{C}$ catalyst can be an efficient bifunctional electrocatalyst for the OER and ORR. Pan et al. also demonstrated an improvement in OER activity for a supported $\mathrm{Co} / \mathrm{CoO}_{x}$ catalyst following the inclusion of Co. ${ }^{191}$

\section{Scope and outlook}

This review article focused on evaluating the feasibility of MW-assisted methods over conventional methods for the preparation of durable and effective supported heterogeneous metal/metal oxide/their hybrid nanocatalysts. It was already mentioned that unsupported nanocatalysts are prone to aggregation, are unstable in air, and promote leaching, and thus deactivate easily during catalysis. In this regard, the anchoring or mobilization of nanocatalysts on an inert or catalytically active support could help to improve the catalyst lifetime by inhibiting leaching, enhancing its stability, reducing its poisoning and maintaining its nano-size distribution.

Numerous variations in MW-assisted routes have been developed and evaluated for the preparation of supported nanocomposite catalysts. The predominantly used methods studied include MW-assisted polyol/alcohol reduction of metal
Salts, ${ }^{81,87,88,90-92,95,99,111,112,132,141,142,145,146,158,162,166,171-173,175-180, ~}$ 182,183,186,190,198,199 MW-assisted reduction in the presence of reducing agents or under $\mathrm{H}_{2}$ pressure, ${ }^{98,106-109,116,121,127-130 \text {, }}$ 133,134,161,181,188,189 MW heating with the aid of an MW absorber (ionic liquid), ${ }^{110}$ carbothermic MW reduction of impregnated metal salts, ${ }^{82,83} \mathrm{MW}$ thermal reduction of impregnated dried precursors ${ }^{75,84,85,96,97,105,154,163,164}$ drying and calcination under MW conditions followed by impregnation, ${ }^{89} \mathrm{MW}$ drying followed by impregnation, ${ }^{118,120,184}$ MW thermal decomposition of metal salts with or without subsequent drying and/or calcination, ${ }^{86,122,123,131,136,139,147,155,157,158,165,187,191,193,196}$ MW activation followed by wet impregnation of metal NPs, ${ }^{17,197}$ and MW-induced plasma irradiation. ${ }^{119,137,138}$ Most of these methods are carried out in a batch-wise fashion, except a few in continuous flow mode. ${ }^{107,116,128}$ The comparative study of MW-assisted methods and conventional methods, whenever investigated, demonstrated that MW methods promoted faster nucleation, produced more homogeneous smaller-size NPs within a shorter time, improved the catalyst loading and better alloying in the binary/ternary metallic phase because of the high loss tangent values, strong MW absorption, and thus faster heating and lower activation energy. ${ }^{112,118,120,121,136,138,139,160,162,163,174,184}$

The usefulness of MW-assisted methods is dependent on the ability to produce a perfectly homogeneous distribution of uniform nanosized catalyst with a controlled morphology on a solid support. The intimate contact with strong fixation is also a desirable requirement from the view point of stability and good dispersity of the nanocatalyst on the support. In almost all the above-mentioned articles, it was found that MW-assisted batch methods under optimum conditions favorably produced a well-dispersed, uniform, nano-sized distribution of metal/ metal oxide/their hybrid catalyst, reportedly down to even $1.6 \pm$ $0.7 \mathrm{~nm}$, which was observed for AgNCs. ${ }^{116}$ The addition of stabilizer was considered not essential to improve the size distribution, and thus the surface property of the nanocatalyst was easily maintained. The MW power, irradiation time, temperature, loading amount, functionality/porosity of the support materials, $\mathrm{pH}$ of the reaction medium, nature of the precursor salt and reducing agent all influenced the size distribution of the supported nanocatalysts. The use of a too high MW irradiation power and too long irradiation time sometimes caused sintering of the nanocatalysts ${ }^{116,141,157,162,180}$ and even damaged the support materials. ${ }^{94}$ Thus, a balance is needed between MW power and irradiation time to achieve the optimum nanosize distribution. MW irradiation under vacuum and the selection of an appropriate precursor salt were also found to be crucial in minimizing damage to the support. ${ }^{94}$ In some instances, functionality or porosity in the support materials was found beneficial for improving the metal loading, dispersibility and crystallinity index of the anchored nanocatalyst. ${ }^{86,95,110,116,120,121,162,180,191,193}$ Interestingly, a variation in the shape and morphology (e.g. spheroid, cubic, rod, plate, hollow, and porous) of nanocatalysts was also achieved by controlling the MW reaction conditions such as $\mathrm{pH}$, irradiation temperature and time, precursor and support materials. ${ }^{81-83,110,129,130,162,165}$ However, despite the successful 
preparation of various supported, well-dispersed nanocatalysts, the wide variations in $\mathrm{MW}$-assisted methods needed to be optimized in terms of simplicity, scalability, economic feasibility, processability and reproducibility. In this regard, methods such as the one-pot MW polyol/alcohol reduction method, one-pot MW-assisted reduction in the presence of reducing agents and one-pot thermal decomposition of the precursor without additional calcination can be preferentially suitable for mass production. These particular methods have been proven beneficial for preparing a large variety of supported welldispersed nanocatalysts (including $\mathrm{Pd}, \mathrm{Ag}, \mathrm{Cu}, \mathrm{Pt}, \mathrm{Ru}, \mathrm{Au}, \mathrm{Pd}-$ $\mathrm{Fe}_{3} \mathrm{O}_{4}, \mathrm{Pd}-\mathrm{Co}_{3} \mathrm{O}_{4}, \mathrm{Pt}-\mathrm{Mo}_{2} \mathrm{C}$, PtRh, PtSn, $\mathrm{CoSe}_{2}$, and PdNi) without aggregation. In the above-mentioned in situ methods, the addition of a solvent is desirable because the solvent-free MW method was not found to be conducive for obtaining a homogeneous distribution due to the aggregation of the particles. ${ }^{96,97}$ Although scarcely studied, the continuous flow MW-assisted method, which is favorable for improving the reproducibility, batch consistency and yield, was found to be promising for preparing supported, well-dispersed finely tuned, uniform nanocatalysts on a mass scale. ${ }^{107,116,128}$ Importantly, the average size of the nanocatalysts produced in the continuous flow mode was smaller compared to that prepared via the batch method. ${ }^{116,128}$

The second point is the analysis of the catalytic power of various MW-synthesized supported nanocatalysts, tested for different organic transformation reactions including electrocatalysis. In general, the MW irradiation conditions, particle size, dispersibility, morphology, loading amount, valence state of the active catalyst and nature of the support materials affect the catalyst efficiency. For example, irradiation for longer time reduced the catalyst efficiency due to a change in morphology, dispersity, damage to the support and formation of metal oxide. $^{83,94,141}$ Morphology also plays a key role, given that cubic-shaped smaller nanocatalyst particles showed better catalytic activity, which is ascribed to their higher surface area. ${ }^{81}$ Table S1 (ESI $\dagger$ ) summarizes the activity of various supported nanocatalysts prepared under MW irradiation and conventional reaction conditions. Interestingly, in most cases, the MW-assistedsynthesized supported nanocatalysts possessed better catalytic activity compared to the commercial ${ }^{95,101,147,162,186}$ and/or corresponding nanocatalysts prepared via conventional methods. ${ }^{118,120,121,136,139,147,162,163,174,221-223}$ Although the comparative data on the corresponding catalysts prepared by conventional methods is still inadequate, it is reasonable to conclude based on the available results that the MW-assisted-synthesized supported nanocatalysts possess good prospects for industrial use. Some authors even carried out the catalysis reactions under MW reaction conditions over supported nanocatalysts and found fairly good conversion and/or yield. ${ }^{112,119,120,128,156}$ The better catalytic activity of MW-synthesized supported nanocatalysts can be assumed to be due to the improved homogeneous distribution of smaller nanocatalyst particles, larger volume to surface ratio, surface heterogeneity, synergistic interaction between metals and stronger interaction between the nanocatalyst and support materials. The data on the stability of MW-synthesized nanocatalysts during recycle is scarce, and thus more investigation is needed in the area.
However, according to the limited available data, the stability and recyclability were found to be comparable to both the commercial and corresponding nanocatalysts prepared by conventional methods. In some instances, even better recycle stability was observed for MW-assisted synthesized supported nanocatalysts. ${ }^{118,164,174}$ However, although the data on the stability and recyclability of MW-synthesized nanocatalysts is encouraging, much more effort is necessary to further improve their performance, given that in some cases the activity decreased significantly after a few reaction cycles. ${ }^{85,86,95,98,99,107,116,133,174}$ The decrease in activity during recycle in either case occurred mostly due to the change in morphology, aggregation, graphitization and loss of the active catalyst via leaching of metal ions. $^{84,86,118,133,134,155,164}$ In this regard, the one-pot synthesis of supported nanocatalysts under mild MW conditions without additional calcination and use of a functional support for strong fixation can be attempted to further improve the recycle stability, thus reducing both the aggregation and leaching of the metal ions. It is noteworthy to mention that in batch catalysis reactions in a constant volume reactor, the activity of the nanocatalyst decreases sharply compared to that under continuous flow reaction conditions in a flow tube reactor (Table S1, ESI $\dagger$ ). The shorter residence time, more efficient heat transfer from the heating/cooling source due to faster mixing, faster reaction kinetics than their batch counterpart and reduction in frequent abrasion/collision due to the absence of additional stirring may have improved the catalyst life in the continuous flow reaction condition.

A considerable volume of research is also available on the testing of the electrocatalytic activity of MW-synthesized supported binary and ternary metal nanocatalysts, with the aim to reduce the cost/dosage of precious Pt-based supported nanocatalysts for applications in PEMFCs, water splitting and alcohol fuel cells. In many cases, improved electrochemical performances with improved durability were observed for MW-synthesized electrocatalysts compared to the reference/ commercial Pt/C electrocatalyst. ${ }^{92,145,165,171,173,178,180-182,187,199}$ The synergistic coupling effect, smaller size, and electronic and ionic effect helped to improve the electrocatalytic performance of binary and ternary metal nanocatalysts. Continuous irradiation rather than pulsed mode of irradiation was found to result in better electrocatalytic activity and better $\mathrm{CO}$ antipoisoning ability. ${ }^{180}$ The electrocatalytic activity suggested that a porous support enhanced the property due to the improved mass-transport property. ${ }^{105}$ Overall analyses suggested that bimetallic: $\mathrm{FeSe}_{2} / \mathrm{C}, \mathrm{Pt}-\mathrm{WC} / \mathrm{C}-\mathrm{F}, \mathrm{PtSn} / \mathrm{C}, \mathrm{PtRh} / \mathrm{C}$, $\mathrm{Pt} 3 \mathrm{Cu} / \mathrm{C}, \mathrm{PtNi} / \mathrm{FCNT}, \mathrm{PtRu} / \mathrm{MWCNT}$, PtPd/MWCNT-GNP, $\mathrm{Ni}_{3} \mathrm{Fe} /$ $\mathrm{Co}-\mathrm{N}-\mathrm{C}$, and $\mathrm{Co} / \mathrm{CoO}_{x} 40-\mathrm{MC} 1050$ and trimetallic: $\mathrm{Pt}-\mathrm{Sn}-\mathrm{Rh} / \mathrm{C}$, AuPdPt@WC/C can be good replacement for the commercial $\mathrm{Pt} / \mathrm{C}$ catalyst.

\section{Conclusion}

The MW-assisted methods available for the preparation of supported metal/metal oxide/their blend nanocatalysts were 
reviewed with the aim to evaluate their suitability and present suggestions for improving their performance, if any. Numerous variations in $\mathrm{MW}$-assisted methods have been developed for the preparation of a broad spectrum of supported nanocatalysts. In almost all the methods, well-dispersed, smaller, uniform supported nanocatalysts were successfully prepared with good catalytic properties. The limited data on durability and recyclability also indicated the better performance of MWsynthesized nanocatalysts compared to commercial and the corresponding supported nanocatalysts prepared via conventional methods. Thus, it can be concluded that MW-assisted methods can be used on an industrial scale for the preparation of supported nanocatalysts, and from now, efforts should be made to optimize the various processes into a few that can be used for mass scale production. Accordingly, the wide variations in $\mathrm{MW}$-assisted methods need to be simplified and optimized into scalable, one-step in situ methods, where all the reactants (precursor salt, solvent, MW absorber, and polyol/ alcohol/reducing agent) in the presence of the support materials can be MW treated. There is also scope to further improve the stability/recyclability of the used nanocatalyst, at least for up to 10 recycles. Presently only 5-6 recycles are possible, which are insufficient from an economic point. This can be done by eliminating high temperature calcination, which is employed on many occasions after MW synthesis, using a functional support to improve anchoring and by developing MW reactors for efficient heat transfer so that the MW power can be reduced to the minimum. Continuous flow MW reactors have also been tried on a limited scale, and this idea is interesting for mass scale production but more investigation is needed to check the efficiency of the reactor for synthesizing a wide variety of supported nanocatalysts with durable properties.

\section{Author contributions}

Hasan Ahmad: conceptualization, data curation, formal analysis, resources, writing - original draft, writing - review \& editing, supervision. Mohammad Kawsar Hossain: visualization, software.

\section{Conflicts of interest}

The authors declare that there are no conflicts to declare.

\section{References}

1 M. Nasrollahzadeh, M. Sajjadi, S. Iravani and R. S. Varma, Green-Synthesized Nanocatalysts and Nanomaterials for Water Treatment: Current Challenges and Future Perspectives, J. Hazard. Mater., 2021, 401, 123401, DOI: 10.1016/ j.jhazmat.2020.123401.

2 G. A. Ozin, A. C. Arsenault and L. Cademartiri, Nanochemistry: A Chemical Approach to Nanomaterials, Royal Society of Chemistry, London, United Kingdom, 2009.
3 C.-Y. Wu, W. J. Wolf, Y. Levartovsky, H. A. Bechtel, M. C. Martin, F. D. Toste and E. Gross, High-SpecialResolution Mapping of Catalytic Reactions on Single Particles, Nature, 2017, 541, 511-515, DOI: 10.1038/ nature20795.

4 M. O. N. van de ĽIsle and M. C. Orgega-Liebana, A. UncitiBroceta, Transition Metal Catalysts for the Bioorthogonal Synthesis of Bioactive Agents, Curr. Opin. Chem. Biol., 2021, 61, 32-42, DOI: 10.1016/j.cbpa.2020.10.001.

5 A. Trowbridge, S. M. Walton and M. J. Gaunt, New Strategies for the Transition-Metal Catalyzed Synthesis of Aliphatic Amines, Chem. Rev., 2020, 120, 2613-2692, DOI: 10.1021/acs.chemrev.9b00462.

6 M. V. Cañamares, J. V. Garcia-Ramos, J. D. Domingo and S. Sanchez-Cortes, Comparative Study of the Morphology, Aggregation, Adherence to Glass, and Surface-Enhanced Raman Scattering Activity of Silver Nanoparticles Prepared by Chemical Reduction of $\mathrm{Ag}^{+}$Using Citrate and Hydroxlamine, Langmuir, 2005, 21(18), 8546-8553, DOI: 10.1021/ la050030l.

7 A. Chakraborty, T. Chakraborty, M. I. Menendez and T. Chattopadhyay, Surfactant-Mediated Solubilization of Magnetically Separable Nanocatalysts for the Oxidation of Alcohols, ACS Omega, 2019, 4(7), 11558-11565, DOI: 10.1021/acsomega.9b01143.

8 T. Song, F. Gao, S. Guo, Y. Zhang, S. Li, H. You and Y. Du, A Review of the Role and Mechanism of Surfactants in the Morphology Control of Metal Nanoparticles, Nanoscale, 2021, 13, 3895-3910, DOI: 10.1039/D0NR07339C.

9 G. I. Dzhardimalieva, A. K. Zharmagambetova, S. E. Kudaibergenov and I. E. Uflyand, Polymer-Immobilized Clusters and Metal Nanoparticles in Catalysis, Kinet. Catal., 2020, 61, 198-223, DOI: 10.1134/S0023158420020044.

10 M. Shukla and I. Sinha, Catalytic Activation of Nitrobenzene on PVP Passivated Silver Cluster: a DFT Investigation, Int. J. Quantum Chem., 2018, 118(3), e25490, DOI: 10.1002/ qua.25490.

11 N. Sharma, A. Choudhary, M. Kaur, C. Sharma, S. Paul and M. Gupta, Modified Graphene Supported Ag-Cu NPs with Enhanced Bimetallic Synergistic Effect in Oxidation and Chan-Lam Coupling Reactions, RSC Adv., 2020, 10, 30048-30061, DOI: 10.1039/D0RA01540G.

12 S. Prabu and K.-Y. Chiang, Improved Catalytic Effect and Metal Nanoparticle Stability using Graphene Oxide Surface Coating and Reduced Graphee Oxide for Hydrogen Generation from Ammonia-Borane Dehydrogenation, Mater. Adv., 2020, 1, 1952-1962, DOI: 10.1039/ D0MA00441C.

13 M. Nasrollahzadeh, T. Baran, N. Y. Baran, M. Sajjadi, M. R. Tahsili and M. Shokouhimehr, Pd Nanocatalyst Stabilized on Amine-Modified Zeolite: Antibacterial and Catalytic Activities for Environmental Pollution Remediation in Aqueous Medium, Sep. Purif. Technol., 2020, 239, 116542, DOI: 10.1016/j.seppur.2020.116542.

14 L. Muthulakshmi, N. Rajini, H. Nellaiah, T. Kathiresan, M. Jawaid and A. V. Rajulu, Preparation and Properties of 
Cellulose Nanocomposite Film with In Situ Generated Copper Nanoparticles unsing Terminalia catappa Leaf Extract, Int. J. Biol. Macromol., 2017, 95, 1064-1071, DOI: 10.1016/j.ijbiomac.2016.09.114.

15 S. Keshipour, S. Shojaei and A. Shaabani, Palladium NanoParticles Supported on Ethylenediamine-Functionalized Cellulose as a Novel and Efficient Catalyst for the Heck and Sonogashira Couplings in Water, Cellulose, 2013, 20, 973-980, DOI: 10.1007/s10570-012-9852-8.

16 M. Niakan, M. Masteri-Farahani, H. Shekaari and S. Karimi, Pd Supported on Clicked Cellulose-Modified Magnetite-Graphene Oxide Nanocomposite for C-C Coupling Reactions in Deep Eutectic Solvent, Carbohydr. Polym., 2021, 251, 117109, DOI: 10.1016/j.carbpol. 2020.117109.

17 Y. Fu, D. Huang, G. Zheng, C. Lai, L. Qin, B. Li, J. He, H. Yi, M. Cheng and C. Zhang, Au Nanoparticles Decorated on Activated Coke via a Facile Preparation for Efficient Catalytic Reduction of Nitrophenols and Azo Dyes, Appl. Surf. Sci., 2019, 473, 578-588, DOI: 10.1016/ j.apsusc.2018.12.207.

18 M. Tariq, M. Muhammad, J. Khan, A. Raziq, M. K. Uddin, A. Niaz, S. S. Ahmed and A. Rahim, Removal of Rhodamine B Dye from Aqueous Solutions using Photo-Fenton Processes and Novel Ni-Cu@MWCNTs Photocatalyst, J. Mol. Liq., 2020, 312, 113399, DOI: 10.1016/j.molliq.2020.113399.

19 P. Wang, C. Qi, L. Hao, P. Wen and X. Xu, Sepiolite $/ \mathrm{Cu}_{2} \mathrm{O} /$ $\mathrm{Cu}$ Photocatalyst: Preparation and High Performance for Degradation of Organic Dye, J. Mater. Sci. Technol., 2019, 35(3), 285-291, DOI: 10.1016/j.jmst.2018.03.023.

20 M. Sajjadi, N. Y. Baran, T. Baran, M. Nasrollahzadeh, M. R. Tashili and M. Shokouhimehr, Palladium Nanoparticles Stabilized on a Novel Schiff Base Modified Unye Bentonite: Highly Stable, Reusable and Efficient Nanocatalyst for Treating Wastewater Contaminants and Inactivating Pathogenic Micobes, Sep. Purif. Technol., 2020, 237, 116383, DOI: 10.1016/j.seppur.2019.116383.

21 Y. Chi, Q. Yuan, Y. Li, J. Tu, L. Zhao, N. Li and X. Li, Synthesis of $\mathrm{Fe}_{3} \mathrm{O}_{4} @ \mathrm{SiO}_{2}-\mathrm{Ag}$ Magnetic Nanocomposite Based on Small-Sized and Highly Dispersed Silver Nanoparticles for Catalytic Reduction of 4-Nitrophenol, J. Colloid Interface Sci., 2012, 383(1), 96-102, DOI: 10.1016/j.jcis.2012.06.027.

22 M. Z. Sarker, M. M. Rahman, H. Minami, T. Suzuki, M. K. Hossain and H. Ahmad, Mesoporous Amine Functinalized $\mathrm{SiO}_{2}$ Supported $\mathrm{Cu}$ Nanocatalyst and a KineticMechanistic Degradation Study of Azo Dyes, Colloids Surf., A, 2021, 617, 126403, DOI: 10.1016/j.colsurfa.2021.126403.

23 Z. X. Li, F. B. Shi, L. L. Li, T. Zhang and C. H. Yan, A Facile Route to Ordered Mesoporous-Alumina-Supported Catalysts, and Their Catalytic Activities for CO Oxidation, Phys. Chem. Chem. Phys., 2011, 13, 2488-2491, DOI: 10.1039/ C0CP01309A.

24 K. Sato, A. Ito, H. Tononaga, H. Kanematsu, Y. Wada, H. Asakura, S. Hosokawa, T. Tanaka, T. Toriyama, T. Yamamoto, S. Matsumura and K. Nagaoka, Pt-Co Alloy
Nanoparticles on a $\gamma-\mathrm{Al}_{2} \mathrm{O}_{3}$ Support: Synergistic Effect between Isolated Electron-Rich Pt and Co for Automotive Exhaust Purification, ChemPlusChem, 2019, 84(5), 447-456, DOI: 10.1002/cplu.201800542.

25 M. A. Rabbi, M. M. Rahman, H. Minami, N. Yamashita, M. R. Habib and H. Ahmad, Magnetically Responsive Antibacterial Nanocrystalline Jute Cellulose Nanocomposites with Moderate Catalytic Activity, Carbohydr. Polym., 2021, 251, 117024, DOI: 10.1016/j.carbpol.2020.117024.

26 S. Sarkar, E. Guibal, F. Quignard and A. K. SenGupta, Polymer-Supported Metals and Metal Oxide Nanoparticles: Synthesis, Characterization, and Applications, J. Nanopart. Res., 2012, 14, 715, DOI: 10.1007/s11051-011-0715-2.

27 T. C. Damato, C. C. S. de Oliveira, R. A. Ando and P. H. C. Camargo, A Facile Approach to $\mathrm{TiO}_{2}$ Colloidal Spheres Decorated with Au Nanoparticles Displaying WellDefined Sizes and Uniform Dispersion, Langmuir, 2013, 29(5), 1642-1649, DOI: 10.1021/la3045219.

28 H. Xu and K. S. Suslick, Sonochemical Synthesis of Highly Fluorescent Ag Nanoclusters, ACS Nano, 2010, 4(6), 3209-3214, DOI: 10.1021/nn100987k.

29 R. G. Bai, K. Muthoosamy, M. Zhou, M. A. Kumar, N. M. Huang and S. Manickam, Biosens. Sonochemical and Sustainable Synthesis of Graphene-Gold (G-Au) Nanocomposites for Enzymeless and Selective Electrochemical Detection of Nitric Oxide, Biosensors Bioelectronics, 2017, 87, 622-629, DOI: 10.1016/j.bios.2016.09.003.

30 V. Rico, C. López-Gascón, J. P. Espinós, R. Lahoz, M. Laguna, A. R. González-Elipe and G. F. de la Fuente, Metallization of Ceramic Substrates by Laser Induced Decomposition of Coordination Complexes, J. Eur. Ceramic Soc., 2016, 36(11), 2831-2836, DOI: 10.1016/j.jeurceramsoc.2016.04.016.

31 M. I. Zhilnikova, V. V. Voronov and G. A. Shafeev, Laser Abalation of Metals in Salts Melts, Chem. Phys. Lett., 2020, 755, 137778, DOI: 10.1016/j.cplett.2020.137778.

32 N. Nityashree, U. K. Gautam and M. Rajamathi, Synthesis and Thermal Decomposition of Metal Hydroxide Intercalated Saponite, Appl. Clay Sci., 2014, 87, 163-169, DOI: 10.1016/j.clay.2013.10.026.

33 J. A. Gerbec, D. Magana, A. Washington and G. F. Strouse, Microwave-Enhanced Reaction Rates for Nanoparticle Synthesis, J. Am. Chem. Soc., 2005, 127(45), 15791-15800, DOI: $10.1021 /$ ja052463g.

34 H. M. A. Hassan, V. Abdelsayed, A. E. R. Khder, K. M. AbouZeid, J. Terner, M. S. El- Shall, S. I. Al-Resayes and A. El-Azhary, Microwave Synthesis of Graphene Sheets Supporting Metal Nanocrystals in Aqueous and Organic Media, J. Mater. Chem., 2009, 19, 3832-3837, DOI: 10.1039/ b906253j.

35 M. B. Mohamed, K. M. AbouZeid, V. Abdelsayed, A. A. Alijarash and M. S. El-Shall, Growth Mechanism of Anisotropic Gold Nanocrystals via Microwave Synthesis: Formation of Diolemamide by Gold Nanocatalysis, ACS Nano, 2011, 4(5), 2766-2772, DOI: 10.1021/nn9016179.

36 V. Abdelsayed, A. Aljarash, M. S. El-Shall, Z. A. Al Othman and A. H. Alghamdi, Microwave Synthesis of Bimetallic 
Nanoalloys and CO Oxidation on Ceria-Supported Nanoalloys, Chem. Mater., 2009, 21(13), 2825-2834, DOI: 10.1021/ cm9004486.

37 J. A. Hachtel, S. Yu, A. R. Lupini, S. T. Pantelides, M. Gich, A. Laromaine and A. Roig, Gold Nanotriangles Decorated with Superparamagnetic Iron Oxide Nanoparticles: a Compositional and Microstructural Study, Faraday Discuss., 2016, 191, 215-227, DOI: 10.1039/C6FD00028B.

38 M. B. Gawande, S. N. Shelke, R. Zboril and R. S. Varma, Microwave-Assisted Chemistry: Synthetic Applications for Rapid Assembly of Nanomaterials and Organics, Acc. Chem. Res., 2014, 47(4), 1338-1348, DOI: 10.1021/ar400309b.

39 C. Ray and T. Pal, Retracted Article: Recent Advances of Metal-Metal Oxide Nanocomposites and Their Tailored Nanostructures in Numerous Catalytic Applications, J. Mater. Chem. A, 2017, 5, 9465-9487, DOI: 10.1039/ C7TA02116J.

40 T. S. Rodrigues, A. G. M. da Silva and P. H. C. Camargo, Nanocatalysis by Noble Metal Nanoparticles: Controlled Synthesis for the Optimization and Understanding of Activities, J. Mater. Chem. A, 2019, 7, 5857-5874, DOI: 10.1039/C9TA00074G.

41 K. Hong, M. Sajjadi, J. M. Suh, K. Zhang, M. Nasrollahzadeh, H. W. Jang, R. S. Varma and M. Shokouhimehr, Palladium Nanoparticles on Assorted Nanostructured Supports: Application for Suzuk, Heck, and Sonogashira Cross-Coupling Reactions, ACS Appl. Nano Mater., 2020, 3(3), 2070-2103, DOI: 10.1021/acsanm.9b02017.

42 M. Sankar, Q. He, R. V. Engel, M. A. Sainna, A. J. Logsdail, A. Roldan, D. J. Willock, N. Agarwal, C. J. Kiely and G. H. Hutchings, Role of the Support in Gold-Containing Nanoparticles as Heterogeneous Catalysts, Chem. Rev., 2020, 120, 3890-3938, DOI: 10.1021/acs.chemrev.9b00662.

43 R. Tao, X. Ma, X. Wei, Y. Jin, L. Qiu and W. Zhang, Porous Organic Polymer Material Supported Palladium Nanoparticles, J. Mater. Chem. A, 2020, 8, 17360-17391, DOI: 10.1039/D0TA05175F.

44 P. G. Jamkhande, N. W. Ghule, A. H. Bamer and M. G. Kalaskar, Metal Nanoparticles Synthesis: a Overview on Methods of Preparation Advantages and Disadvantages, and Applications, J. Drug Delivery Sci. Technol., 2019, 53, 101174, DOI: 10.1016/j.jddst.2019.101174.

45 A. Kumar, Y. Kuang, Z. Liang and X. Sun, Microwave Chemistry, Recent Advancements, and Eco-Friendly Microwave-Assisted Synthesis of Nanoarchitechtures and Their Applicadtions: a Review, Mater. Today Nano, 2020, 11, 100076, DOI: 10.1016/j.mtnano.2020.100076.

$46 \mathrm{~J}$. Hoffmann, M. Nüchter, B. Ondruschka and P. Wasserscheid, Ionic Liquids and Their Heating Behavior during Microwave Irradiation - a State of the Art Report and Challange to Assessment, Green Chem., 2003, 5, 296-299, DOI: 10.1039/B212533A.

47 R. Gedye, F. Smith, K. Westaway, H. Ali, L. Baldisera, L. Laberge and J. Rousell, The Use of Microwave Ovens for Rapid Synthesis, Tetrahedron Lett., 1986, 27(3), 279-282, DOI: 10.1016/S0040-4039(00)83996-9.
48 R. J. Giguere, T. L. Bray, S. M. Duncan and G. Majetich, Application of Commercial Microwave Ovens to Organic Synthesis, Tetrahedron Lett., 1986, 27(41), 4945-4948, DOI: 10.1016/S0040-4039(00)85103-5.

49 T. E. Muñoz, R. T. Giberson, R. Demaree and J. R. Day, Microwave-Assisted Immunostaining: a New Approach Yields Fast and Consistent Results, J. Neurosci. Methods, 2004, 137(2), 133-139, DOI: 10.1016/j.jneumeth.2004.02.020.

50 A. K. Bose, M. S. Manhas, S. N. Ganguly, A. H. Sharma and B. K. Banik, MORE Chemistry for Less Pollution: Applications for Process Development, Synthesis, 2002, (11), 1578-1591, DOI: 10.1055/s-2002-33344.

51 M. B. Gawande, V. D. B. Bonifacio, R. Luque, P. S. Branco and R. S. Varma, Benign by Design: Catalyst-Free In-Water, OnWater Green Chemical Methodologies in Organic Synthesis, Chem. Soc. Rev., 2012, 42, 5522-5551, DOI: 10.1039/c3cs60025d.

52 M. B. Gawande, V. D. B. Bonifácio, R. Luque, P. S. Branco and R. S. Varma, Solvent-Free and Catalysts-Free Chemistry: a Benign Pathway to Sustainability, ChemSusChem, 2014, 7, 24-44, DOI: 10.1002/cssc.201300485.

53 V. Polshettiwar and R. S. Varma, Aqueous Microwave Chemistry: a Clean and Green Synthetic Tool for Rapid Drug Discovery, Chem. Soc. Rev., 2008, 37, 1546-1557, DOI: 10.1039/b716534j.

54 M. B. Gawande and P. S. Branco, A Efficient and Expeditious Fmoc Protection of Amines and Amino Acids in Aqueous Media, Green Chem., 2011, 13, 3355-3359, DOI: 10.1039/c1gc15868f.

55 M. N. Nadagouda, T. F. Speth and R. S. Varma, MicrowaveAssisted Green Synthesis of Silver Nanostructures, Acc. Chem. Res., 2011, 44(7), 469-478, DOI: 10.1021/ar1001457.

56 B. Baruwati and R. S. Varma, High Value Products from Waste: Grape Pomace Extract-a Three-in-One Package for the Synthesis of Metal Nanoparticles, ChemSusChem, 2009, 2(11), 1041-1044, DOI: 10.1002/cssc.200900220.

57 J. Kou and R. S. Varma, Beet Juice-Induced Green Fabrication of Plasmonic AgCl/Ag Nanoparticles, ChemSusChem, 2012, 5(12), 2435-2441, DOI: 10.1002/cssc.201200477.

58 J. Virkutyte and R. S. Varma, Green Synthesis of Metal Nanoparticles: Biodegradable Polymers and Enzymes in Stabilization and Surface Functionalization, Chem. Sci., 2011, 2, 837-846, DOI: 10.1039/C0SC00338G.

59 L. Shang, T. Bian, B. Zhang, D. Zhang, L.-Z. Wu, C.-H. Tung, Y. Yin and T. Zhang, Graphene-Supported Ultrafine Metal Nanoparticles Encapsulated by Mesoporous Silica: Robust Catalysts for Oxidation and Reduction Reactions, Angew. Chem., Int. Ed., 2014, 53(1), 250-254, DOI: 10.1002/anie.201306863.

60 A. K. Tagantsev, V. O. Sherman, K. F. Astafiev, J. Venkatesh and N. Setter, Ferroelectric Materials for Microwave Tunable Applications, J. Electroceram., 2003, 11, 5-66, DOI: 10.1023/B:JECR.0000015661.81386.e6.

61 I. Bilecka, I. Djerdj and M. Niederberger, One-Minute Synthesis of Crystalline Binary and Ternary Metal Oxide Nanoparticles, Chem. Commun., 2008, 886-888, DOI: 10.1039/B717334B. 
62 R. Martínez-Palou, Microwave-Assisted Synthesis using Ionic Liquids, Mol. Diversity, 2010, 14, 3-25, DOI: 10.1007/s11030-009-9159-3.

63 S. Liu, F. Lu and J.-J. Zhu, Highly Fluorescent Ag Nanoclusters: Microwave-Assisted Green Synthesis and $\mathrm{Cr}^{3+}$ Sensing, Chem. Commun., 2011, 47, 2661-2663, DOI: 10.1039/ c0cc04276e.

64 M. A. Rabbi, M. M. Rahman, H. Minami, M. R. Habib and H. Ahmad, Ag Impregnated Sub-Micrometer Crystalline Jute Cellulose Particles: Catalytic and Antibacterial Properties, Carbohydr. Polym., 2020, 233, 115742, DOI: 10.1016/ j.carbpol.2020.115842.

65 I. Bilecka and M. Niederberger, Microwave Chemistry for Inorganic Nanomaterials Synthesis, Nanoscale, 2010, 2, 1358-1374, DOI: 10.1039/b9nr00377k.

66 G. Garnweitner and M. Niederberger, Organic Chemistry in Inorganic Nanomaterials Synthesis, J. Mater. Chem., 2008, 18, 1171-1182, DOI: 10.1039/B713775C.

67 G. Cravotto and P. Cintas, The Combined Use of Microwaves and Ultrasound: Improved Tools in Process Chemistry and Organic Synthesis, Chemistry, 2007, 13(7), 1902-1909, DOI: 10.1002/chem.200601845.

68 S. S. Rao, K. S. Jayachandran and V. P. D. Rekha, Microwave-Assisted Rapid Synthesis of Silver Nanoparticles using Fucoidan: Characterization with Assessment of Biocompatibility and Antimicrobial Activity, Int. J. Biol. Macromol., 2020, 163, 745-755, DOI: 10.1016/ j.ijbiomac.2020.06.230.

69 P. Kunal, H. Li, B. L. Dewing, L. Zhang, K. Jarvis, G. Henkelman and S. M. Humphrey, Microwave-Assisted Synthesis of $\mathrm{Pd}_{x} \mathrm{Au}_{100-x}$ Alloy Nanoparticles: a Combined Experimental and Theoretical Assessment of Synthetic and Compositional Effects upon Catalytic Reactivity, ACS Catal., 2016, 6(8), 4882-4893, DOI: 10.1021/acscatal.6b01014.

70 C. Gutiérrez-Wing, R. Esparza, C. Vargas-Hernández, M. E. F. García and M. José-Yacamán, MicrowaveAssisted Synthesis of Gold Nanoparticles Self-Assembled into Self-Supported Superstructures, Nanoscale, 2012, 4, 2281-2286, DOI: 10.1039/c2nr12053d.

71 A. J. Nozik, Multiple Exciton Generation in Semiconductor Quantum Dots, Chem. Phys. Lett., 2008, 457(1-3), 3-11, DOI: $10.1016 /$ j.cplett.2008.03.094.

72 A. Mirzaei and G. Neri, Microwave-Assisted Synthesis of Metal Oxide Nanostructures for Gas Sensing Application: a Review, Sens. Actuators, B, 2016, 237, 749-775, DOI: 10.1016/j.snb.2016.06.114.

73 A. Verma, R. Dwivedi, R. Prasad and K. S. Bartwal, Microwave-Assisted Synthesis of Mixed Metal-Oxide Nanoparticles, J. Nanopart., 2013, 737831, DOI: 10.1155/2013/ 737831.

74 K. Kannan, D. Radhika, M. P. Nikolova, V. Andal, K. K. Sadasivuni and S. Krishna, Facile MicrowaveAssisted Synthesis of Metal Oxide CdO-CuO Nanocomposite: Photocatalytic and Antimicrobial Enhancing Properties, Optik, 2020, 218, 165112, DOI: 10.1016/j.ijleo. 2020.165112 .
75 G. Zhong, S. Xu, C. Chen, D. J. Kline, M. Giroux, Y. Pei, M. Jiao, D. Liu, R. Mi, H. Xie, B. Yang, C. Wang, M. R. Zachariah and L. Hu, Synthesis of Metal Oxide Nanoparticles by Rapid, High-Temperature 3D Microwave Heating, Adv. Funct. Mater., 2019, 29(48), 1904282, DOI: 10.1002/adfm.201904282.

76 M. B. Schütz, L. Xiao, T. Lehnen, T. Fischer and S. Mathur, Microwave-Assisted Synthesis of Nanocrystalline Binary and Ternary Metal Oxides, Int. Mater. Rev., 2017, 63, 341-374, DOI: 10.1080/09506608.2017.1402158.

77 W. Tu and H. Liu, Continuous Synthesis of Colloidal Metal Nanoclusters by Microwave Irradiation, Chem. Mater., 2000, 12(2), 564-567, DOI: 10.1021/cm990637l.

78 T.-Y. Ma, L. Liu and Z.-Y. Yuan, Direct Synthesis of Ordered Mesoporous Carbons, Chem. Soc. Rev., 2013, 42, 3977-4003, DOI: 10.1039/C2CS35301F.

79 E. Lam and Y. H. T. Luong, Carbon Materials as Catalyst Supports and Catalysts in the Transformation of Biomass to Fuels and Chemicals, ACS Catal., 2014, 4(10), 3393-3410, DOI: 10.1021/cs5008393.

80 Y. Chen and Y. Liu, Preparation of Porous Carbon with High Dispersion of Ru Nanoparticles by Sol-Gel Method and Its Application in Hydrogen Storage, J. Mater. Chem. A, 2014, 2, 9193-9199, DOI: 10.1039/C4TA01126K.

81 K.-H. Chuang, K. Shih and M.-Y. Wey, The Influences of Microwave Irradiation and Polyol Precursor $\mathrm{pH}$ on $\mathrm{Cu} / \mathrm{AC}$ Catalyst and Its CO Oxidation Performance, J. Nanopart. Res., 2012, 14, 1178, DOI: 10.1007/s11051-012-1178-9.

82 J. Ren, M. Ren, D. Wang, J. Lin and Z. Li, Mechanism of Microwave-Induced Carbothermic Reduction and Catalytic Performance of $\mathrm{Cu}$ /Activated Carbon Catalysts in the Oxidative Carbonylation of Methanol, J. Therm. Anal. Calorim., 2015, 120, 1929-1939, DOI: 10.1007/s10973-015-4519-y.

83 M. Ren, J. Ren, P. Hao, J. Yang, D. Wang, Y. Pei, J.-Y. Lin and $\mathrm{Z}$. $\mathrm{Li}$, Influence of Microwave Irradiation on the Structural Properties of Carbon-Supported Hollow Copper Nanoparticles and Their Effect on the Synthesis of Dimethyl Carbonate, ChemCatChem, 2016, 8(4), 861-871, DOI: $10.1002 /$ cctc. 201501182.

84 X. Liu, H. Yin, A. Lin and Z. Guo, Effective Removal of Phenol by Using Activated Carbon Supported Iron Prepared Under Microwave Irradiation as a Reusable Heterogeneous Fenton-Like Catalyst, J. Environ. Chem. Eng., 2017, 5(1), 870-876, DOI: 10.1016/j.jece.2017.01.010.

85 P. Veerakumar, N. Dhenadhayalan, K.-C. Lin and S.-B. Liu, Highly Stable Ruthenium Nanoparticles on 3D Mesoporous Carbon: an Excellent Opportunity for Reduction Reactions, J. Mater. Chem. A, 2015, 3, 23448-23457, DOI: 10.1039/C5TA06875D.

86 P. Veerakumar, K. Salamalai, P. Thanasekaran and K.C. Lin, Simple Preparation of Porous Carbon-Supported Ruthenium: Propitious Catalytic Activity in the Reduction of Ferrocyanate(III) and a Cationic Dye, ACS Omega, 2018, 3(10), 12609-12621, DOI: 10.1021/acsomega.8b01680.

87 W. X. Chen, J. Y. Lee and Z. Liu, Microwave-Assisted Synthesis of Carbon Supported Pt Nanoparticles for Fuel 
Cell Applications, Chem. Commun., 2002, (21), 2588-2589, DOI: $10.1039 / \mathrm{b} 208600 \mathrm{j}$.

88 Z. Liu, L. M. Gan, L. Hong, W. Chen and J. Y. Lee, CarbonSupported Pt Nanoparticles as Catalysts for Proton Exchange Membrane Fuel Cells, J. Power Sources, 2005, 139(1-2), 73-78, DOI: 10.1016/j.jpowsour.2004.07.012.

89 L. Bo, X. Quan, X. Wang and S. Chen, Preparation and Characteristics of Carbon-Supported Platinum Catalyst and Its Application iIn The Removal of Phenolic Pollutants in Aqueous Solution by Microwave-Assisted Catalytic Oxidation, J. Hazard. Mater., 2008, 157(1), 179-186, DOI: 10.1016/j.jhazmat.2007.12.111.

90 Z. Gan, X. Zheng, D. Wei, Q. Hu, A. Zhao, X. Zhang and G. Li, One-Pot Synthesis of One-Dimensional Array Pt Nanoparticles on Carbon Nanotubes via a Facile Microwave Polyol Method, Superlattices Microstruct., 2010, 47(6), 705-709, DOI: 10.1016/j.spmi.2010.04.001.

91 Z. Guo, H. Zhu, X. Zhang, F. Wang, Y. Guo and Y. Wei, Microwave-Assisted Synthesis of High-Loading, Highly Dispersed Pt/Carbon Aerogel Catalyst for Direct Methanol Fuel Cell, Bull. Mater. Sci., 2011, 34, 577-581, DOI: 10.1007/s12034-011-0082-8.

92 R. Sharma, Y. Wang, F. Li, J. Chamier and S. M. Anderson, Synthesis of a Pt/C Electrocatalyst from a User-Friendly Pt Precursor (Ammonium Hexachloroplatinate) through Microwave-Assisted Polyol Synthesis, ACS Appl. Energy Mater., 2019, 2(9), 6875-6882, DOI: 10.1021/acsaem.9b01336.

93 E. O. Pentsak, V. A. Cherepanova and V. P. Ananikov, Dynamic Behavior of Metal Nanoparticles in Pd/C and Pt/ C Catalytic Systems under Microwave and Conventional Heating, ACS Appl. Mater. Interfaces, 2017, 9(42), 36723-36732, DOI: 10.1021/acsami.7b09173.

94 E. O. Penstak, E. G. Gordeev and V. P. Ananikov, Noninnocent Nature of Carbon Support in Metal/Carbon Catalysts: Etching/Pitting vs Nanotube Growth under Microwave Irradiation, ACS Catal., 2014, 4(11), 3806-3814, DOI: 10.1021/ cs500934g.

95 C. Antonetti, M. Oubenali, A. M. R. Galletti, P. Serp and G. Vannucci, Novel Microwave Synthesis of Ruthenium Nanoparticles Supported on Carbon Nanotubes Active in the Selective Hydrogenation of $p$-Chloronitrobenzene to $p$ Chloroaniline, Appl. Catal., A, 2012, 421-422, 99-107, DOI: 10.1016/j.apcata.2012.02.003.

96 X. Ni, B. Zhang, C. Li, M. Pang, D. Su, C. T. Williams and C. Liang, Microwave-Assisted Green Synthesis of Uniform Ru Nanoparticles Supported on Non-Functional Carbon Nanotubes for Cinnamaldehyde Hydrogenation, Catal. Commun., 2012, 24, 65-69, DOI: 10.1016/j.catcom.2012.03.035.

97 B. Zhang, X. Ni, W. Zhang, L. Shao, Q. Zhang, F. Girgsdies, C. Liang, R. Schlögi and D. S. Su, Structural Rearrangements of Ru Nanoparticles Supported on Carbon Nanotubes Under Microwave Irradiation, Chem. Commun., 2011, 47, 10716-10718, DOI: 10.1039/c1cc13858h.

98 T. Hemraj-Benny, N. Tobar, N. Carrero, R. Sumner, L. Pimentel and G. Emeran, Microwave-Assisted Synthesis of Single-Walled Carbon Nanotube-Supported Ruthenium
Nanoparticles for the Catalytic Degradation of Congo Red Dye, Mater. Chem. Phys., 2018, 216, 72-81, DOI: 10.1016/ j.matchemphys.2018.05.081.

99 T. Hemraj-Benny, L. Pimentel and G. Emeran, Formation of Single-Walled Carbon Nanotube-Ruthenium Nanoparticles in Ethanol upon Microwave Radiation, Inorg. Chem. Commun., 2020, 112, 107707, DOI: 10.1016/j.inoche.2019.107707.

100 R. Samiee-Zafarghandi, A. Hadi and J. Karimi-Sabet, Graphene-Supported Metal Nanoparticles as Novel Catalysts for Syngas Production Using Supercritical Water Gasification of Microalgae, Biomass Bioenergy, 2019, 121, 13-21, DOI: 10.1016/j.biombioe.2018.11.035.

101 S. Ren, Q. Yu, X. Yu, P. Rong, L. Jiang and J. Jiang, Graphene-Supported Metal Single-Atom Catalysts: a Concise Review, Sci. China Mater., 2020, 63, 903-920, DOI: 10.1007/s40843-019-1286-1.

102 K. M. Yam, N. Guo, Z. Jiang, S. Li and C. Zhang, GrapheneBased Heterogeneous Catalysis: Role of Graphene, Catalysts, 2020, 10(1), 53, DOI: 10.3390/catal10010053.

103 M. Nasrollahzadeh, Z. Issaabadi, M. M. Tohidi and S. M. Sajadi, Recent Progress in Application of Graphene Supported Metal Nanoparticles in $\mathrm{C}-\mathrm{C}$ and $\mathrm{C}-\mathrm{X}$ Coupling Reactions, Chem. Rec., 2018, 18(2), 165-229, DOI: 10.1002/ tcr.201700022.

104 L. Shang, T. Bian, B. Zhang, D. Zhang, L.-Z. Wu, C.-H. Tung, Y. Yin and T. Zhang, Graphene-Supported Ultrafine Metal Nanoparticles Encapsulated by Mesoporous Silica: Robust Catalysts for Oxidation and Reduction Reactions, Angew. Chem., 2014, 126(1), 254-258, DOI: 10.1002/ange.201306863.

105 H. Fei, J. Dong, C. Wan, Z. Zhao, X. Xu, Z. Lin, Y. Wang, H. Liu, K. Zang, J. Luo, S. Zhao, W. Hu, W. Yan, I. Shakir and Y. Huang, Microwave-Assisted Rapid Synthesis of Graphene-Supported Single Atomic Metals, Adv. Mater., 2018, 30(35), 1802146, DOI: 10.1002/adma.201802146.

106 A. R. Siamaki, A. E. R. S. Khder, V. Abdelsayed, M. S. ElShall and B. F. Gupton, Microwave-Assisted Synthesis of Palladium Nanoparticles Supported on Graphene: A Highly Active and Recyclable Catalyst for Carbon-Carbon Cross-Coupling Reactions, J. Catal., 2011, 279(1), 1-11, DOI: 10.1016/j.jcat.2010.12.003.

107 K. W. Brinkley, M. Burkholder, A. R. Siamaki, K. Belecki and B. F. Gupton, The Continuous Synthesis and Application of Graphene Supported Palladium Nanoparticles: a Highly Effective Catalyst for Suzuki-Miyaura CrossCoupling Reactions, Green Process. Synth., 2015, 4, 241-246, DOI: 10.1515/gps-2015-0021.

108 J.-H. Yang and D. Ma, Graphene-Supported Pd Nanoparticles: Microwave-Assisted Synthesis and as Microwave-Active Selective Hydrogenation Catalysts, RSC $A d v .$, 2013, 3, 10131-10134, DOI: 10.1039/c3ra41340c.

109 H. A. Elazab, M. A. Radwan and M. A. Sadek, MicrowaveAssisted Synthesis of Graphene Supported Hexagonal Magnetite for Applications in Catalysis, Int. J. Innov. Technol. Exploring Eng., 2019, 8(12), 5511-5513, DOI: 10.35940/ ijitee.L2535219. 
110 J.-Y. Lee, T.-Y. Yung and L.-K. Liu, The Microwave-Assisted Ionic Liquid Nanocomposite Synthesis: Platinum Nanoparticles on Graphene and the Application on Hydrogenation of Styrene, Nanoscale Res. Lett., 2013, 8, 414, DOI: 10.1186/1556-276X-8-414.

111 K. Ullah, S. Ye, L. Zhu, Z.-D. Meng, S. Sarkar and W.-C. Oh, Microwave Assisted Synthesis of a Noble Metal-Graphene Hybrid Photocatalyst for High Efficient Decomposition of Organic Dyes Under Visible Light, Mater. Sci. Eng., B, 2014, 180, 20-26, DOI: 10.1016/j.mseb.2013.10.014.

112 A. Zuliani, P. Ranjan, R. Luque and E. V. V. Eycken, Heterogeneously Catalyzed Synthesis of Imidazolones via Cycloisomerizations of Propargylic Ureas Using $\mathrm{Ag}$ and Au/Al SBA-15 Systems, ACS Sustainable Chem. Eng., 2019, 7(5), 5568-5575, DOI: 10.1021/acssuschemeng.9b00198.

113 M. B. Gawande, Y. Monga, R. Zboril and R. K. Sharma, Silica-Decorated Magnetic Nanocomposites For Catalytic Applications, Coord. Chem. Rev., 2015, 288, 118-143, DOI: 10.1016/j.ccr.2015.01.001.

114 X. Deng, K. Chen and H. Tüysüz, Protocol for the Nanocasting Method: Preparation of Ordered Mesoporous Metal Oxides, Chem. Mater., 2017, 29(1), 40-52, DOI: 10.1021/ acs.chemmater.6b02645.

115 J. M. Campelo, T. D. Conesa, M. J. Gracia, M. J. Jurado, R. Luque, J. M. Marinas and A. A. Romero, Microwave Facile Preparation of Highly Active and Dispersed SBA-12 Supported Metal Nanoparticles, Green Chem., 2008, 10, 853-858, DOI: 10.1039/b801754a.

116 R. Manno, P. Ranjan, V. Sebastian, R. Mallada, S. Irusta, U. K. Sharma, E. V. V. Eycken and J. Santamaria, Continuous Microwave-Assisted Synthesis of Silver Nanoclusters Confined in Mesoporous SBA-15: Application in Alkyne Cyclizations, Chem. Mater., 2020, 32(7), 2874-2883, DOI: 10.1021/acs.chemmater.9b04935.

117 L. Uson, J. L. Hueso, V. Sebastian, R. Arenal, I. Florea, S. Irusta, M. Arruebo and J. Santamaria, In Situ Preparation of Ultra-Small Pt Nanoparticles Within Rod-Shaped Mesoporous Silica Particles: 3-D Tomography and Catalytic Oxidation of n-Hexane, Catal. Commun., 2017, 100, 93-97, DOI: 10.1016/j.catcom.2017.06.022.

118 Y. Jiang, X. Li and H. Ji, Acid-Treated Bentonite-Supported $\mathrm{Ni}$ Catalysts via Rapid Microwave-Assisted Drying for Nitrobenzene Hydrogenation, Chem. Eng. Commun., 2018, 205, 624-636, DOI: 10.1080/00986445.2017.1409737.

119 G. Akay, K. Zhang, W. S. S. Al-Harrasi and R. R. Sankaran, Catalytic Plasma Fischer-Tropsch Synthesis Using Hierarchically Connected Porous $\mathrm{Co} / \mathrm{SiO}_{2}$ Catalysts Prepared by Microwave-Induced Co-assembly, Ind. Eng. Chem. Res., 2020, 59(26), 12013-12027, DOI: 10.1021/acs.iecr.0c01585.

120 T. Mukhriza, K. Zhang and A. N. Phan, Microwave Assisted $\mathrm{Co} / \mathrm{SiO}_{2}$ Preparation for Fischer-Tropsch Synthesis, J. Nat., 2020, 20(2), 42-48, DOI: 10.24815/jn.v20i2.16889.

121 S. A. Hassan, H. M. Gobara, M. M. Gomaa, R. S. Mohamed and F. H. Khalil, Can Microwave Assisted In Situ Reduction of Supported Pt Nanoparticles Challenge The Chemical Method in Controlling the Dispersion Profile-Catalytic
Performance Relationship?, RSC Adv., 2015, 5(67), 54460-54470, DOI: 10.1039/C5RA08116E.

122 S. Wang, Y. Shi and X. Ma, Microwave Synthesis, Characterization and Transesterification Activities of Ti-MCM41, Microporous Mesoporous Mater., 2012, 156, 22-28, DOI: 10.1016/j.micromeso.2012.02.011.

123 T. S. Jiang, Y. H. Li, X. P. Zhou, Q. Zhao and H. B. Yin, Thermal and Hydrothermal Stability of Zrmcm-41 Mesoporous Molecular Sieves Obtained by Microwave Irradiation, J. Chem. Sci., 2010, 122, 371-379, DOI: 10.1007/ s12039-010-0042-7.

124 S. Chen, R. Si, E. Taylor, J. Janzen and J. Chen, Synthesis of Pd/ $\mathrm{Fe}_{3} \mathrm{O}_{4}$ Hybrid Nanocatalysts with Controllable Interface and Enhanced Catalytic Activities for CO Oxidation, J. Phys. Chem. C, 2012, 116(23), 12969-12976, DOI: 10.1021/jp3036204.

125 C.-J. Jia, M. Schwickardi, C. Weidenthaler, W. Schmidt, S. Korhonen, B. M. Weckhuysen and F. Schüth, $\mathrm{Co}_{3} \mathrm{O}_{4^{-}}$ $\mathrm{SiO}_{2}$ Nanocomposite: A Very Active Catalyst for CO Oxidation with Unusual Catalytic Behavior, J. Am. Chem. Soc., 2011, 133(29), 11279-11288, DOI: 10.1021/ja2028926.

126 W. Zhou, M. Yao, L. Guo, Y. Li, J. Li and S. Yang, Hydrazine-Linked Convergent Self-Assembly of Sophisticated Concave Polyhedrons of $\beta-\mathrm{Ni}(\mathrm{OH})_{2}$ and $\mathrm{NiO}$ from Nanoplate Building Blocks, J. Am. Chem. Soc., 2009, 131(8), 2959-2964, DOI: 10.1021/ja808784s.

127 H. A. Elazab, S. Moussa, B. F. Gupton and M. S. El-Shall, Microwave-Assisted Synthesis of Pd Nanoparticles Supported on $\mathrm{Fe}_{3} \mathrm{O}_{4}, \mathrm{Co}_{3} \mathrm{O}_{4}$, and $\mathrm{Ni}(\mathrm{OH})_{2}$ Nanoplates and Catalysis Application for CO Oxidation, J. Nanopart. Res., 2014, 16, 2477, DOI: 10.1007/s11051-014-2477-0.

128 H. A. Elazab, S. Moussa, K. W. Brinkley, B. F. Gupton and M. S. El-Shall, The Continuous Synthesis of Pd Supported on $\mathrm{Fe}_{3} \mathrm{O}_{4}$ Nanoparticles: a Highly Effective and Magnetic Catalyst for CO Oxidation, Green Process. Synth., 2017, 6, 413-424, DOI: 10.1515/gps-2016-0168.

129 M. Morad, M. A. Karim, H. M. Altass and A. E. R. S. Khder, Microwave-Assisted Synthesis of Gold Nanoparticles Supported on $\mathrm{Mn}_{3} \mathrm{O}_{4}$ Catalyst for Low Temperature CO Oxidation, Environ. Technol., 2021, 42, 2680-2689, DOI: 10.1080/ 09593330.2019.1709988.

130 A. E. R. S. Khder, H. M. Altass, M. I. Orif, S. S. Ashour and L. S. Almazroai, Preparation And Characterization of Highly Active Pd Nanoparticles Supported $\mathrm{Mn}_{3} \mathrm{O}_{4}$ Catalyst for Low-Temperature CO Oxidation, Mater. Res. Bull., 2019, 113, 215-222, DOI: 10.1016/j.materresbull.2019.02.011.

131 G. Glaspell, L. Fuoco and M. S. El-Shall, Microwave Synthesis of Supported Au and Pd Nanoparticle Catalysts for CO Oxidation, J. Phys. Chem. B, 2005, 109(37), 17350-17355, DOI: $10.1021 /$ jp0526849.

132 K.-H. Chuang, K. Shih, C.-Y. Lu and M.-Y. Wey, Copper Catalysts Prepared via Microwave-Heated Polyol Process for Preferential Oxidation of $\mathrm{CO}$ in $\mathrm{H}_{2}$-Rich Streams, Int. J. Hydrogen Energy, 2013, 38(1), 100-108, DOI: 10.1016/ j.ijhydene.2012.10.039.

133 H. A. Elazab, M. A. Sadek and T. T. El-Idreesy, MicrowaveAssisted Synthesis of Palladium Nanoparticles Supported 
on Copper Oxide in Aqueous Medium as an Efficient Catalyst for Suzuki Cross-Coupling Reaction, Adsorpt. Sci. Technol., 2018, 36(5-6), 1352-1365, DOI: 10.1177/ 0263617418771777.

134 H. A. Elazab, M. A. Radwan and T. T. El-Idreesy, Facile Microwave-Assisted Synthetic Approach to Palladium Nanoparticles Supported on Copper Oxide as an Efficient Catalyst for Heck and Sonogashira Cross-Coupling Reactions, Int. J. Nanosci., 2019, 18(5), 1850032, DOI: 10.1142/ S0219581X18500321.

135 M. Trueba and S. P. Trasatti, $\gamma$-Alumina as a Support for Catalysts: a Review of Fundamental Aspects, Eur. J. Inorg. Chem., 2005, (17), 3393-3403, DOI: 10.1002/ejic.200500348.

136 F. Song, Q. Zhong, Y. Yu, M. Shi, Y. Wu, J. Hu and Y. Song, Obtaining Well-Dispersed $\mathrm{Ni} / \mathrm{Al}_{2} \mathrm{O}_{3}$ Catalyst for $\mathrm{CO}_{2}$ Methanation with a Microwave-Assisted Method, Int. J. Hydrogen Energy, 2017, 42(7), 4174-4183, DOI: 10.1016/ j.ijhydene.2016.10.141.

137 J. Y. Chung, S. Khdama and H. Sekiguchi, Preparation of a $\mathrm{Pd} / \mathrm{Al}_{2} \mathrm{O}_{3}$ Catalyst with Microwave-Induced Plasma Jet Irradiation under Atmospheric Pressure, Nanomaterials, 2019, 9(12), 1734, DOI: 10.3390/nano9121734.

138 J. Y. Chung, S. Kodama and H. Sekiguchi, Preparation of Catalyst with Microwave Induced Plasma Jet Combined with Spouted Bed, J. Nanosci. Nanotechnol., 2019, 19(10), 6849-6855, DOI: 10.1166/jnn.2019.17122.

139 H. Wang, Z. Liu, Y. Wu, Z. Yao, W. Zhao, W. Duan and K. Guo, Preparation of Highly Dispersed W/ $/ \mathrm{Al}_{2} \mathrm{O}_{3}$ Hydrodesulfurization Catalysts via a Microwave Hydrothermal Method: Effect of Oxalic Acid, Arabian J. Chem., 2016, 9(1), 18-24, DOI: 10.1016/j.arabjc.2014.11.023.

140 S. Bagheri, N. M. Julkapli and S. B. A. Hamid, Titanium Dioxide as a Catalyst Support in Heterogeneous Catalysis, Sci. World J., 2014, 2014, 727496, DOI: 10.1155/2014/ 727496.

141 A. G. R. Howe, R. Maunder, D. J. Morgan and J. K. Edwards, Rapid Microwave-Assisted Polyol Synthesis of $\mathrm{TiO}_{2}$ Supported Ruthenium Catalysts for Levulinic Acid Hydrogenation, Catalysts, 2019, 9(9), 748, DOI: 10.3390/ catal9090748.

142 E. A. Anumol, P. Kundu, P. A. Deshpande, G. Madras and N. Ravishankar, New Insights into Selective Heterogeneous Nucleation of Metal Nanoparticles on Oxides by Microwave-Assisted Reduction: Rapid Synthesis of HighActivity Supported Catalysts, ACS Nano, 2011, 5(10), 8049-8061, DOI: 10.1021/nn202639f.

143 Z. Li, L. Yu, C. Milligan, T. Ma, L. Zhou, Y. Cui, Z. Qi, N. Libretto, B. Xu, J. Luo, E. Shi, Z. Wu, H. Xin, W. N. Delgass, J. T. Miller and Y. Wu, Two-Dimensional Transition Metal Carbides as Supports for Tuning the Chemistry of Catalytic Nanoparticles, Nat. Commun., 2018, 9, 5258, DOI: 10.1038/s41467-018-07502-5.

$144 \mathrm{~J}$. A. Rodriguez and F. Illas, Activation of Noble Metals on Metal-Carbide Surfaces: Novel Catalysts for CO Oxidation, Desulfurization and Hydrogenation Reactions, Phys. Chem. Chem. Phys., 2012, 14, 427-438, DOI: 10.1039/C1CP22738F.
145 M. Shi, L. Kang, Y. Jiang and C. Ma, Microwave-Assisted Synthesis of Mesoporous Tungsten Carbide/Carbon for Fuel Cell Applications, Catal. Lett., 2014, 144, 278-284, DOI: 10.1007/s10562-013-1132-1.

146 K. Wang, Z. Pan, F. Tzorbatzoglou, Y. Zhang, Y. Wng, P. Tsiakaras and S. Song, An Investigation of WC Stability During The Preparation of Pt@WC/OMC via a Pulse Microwave Assisted Polyol Method, Appl. Catal., B, 2015, 166167, 224-230, DOI: 10.1016/j.apcatb.2014.11.025.

147 H. Asahara, Y. Kuribayashi, P. Wang, K. Kobiro and N. Nishiwaki, An Effect of Microwave Irradiation on $\mathrm{Pd} / \mathrm{SiC}$ Catalyst for Prolonging the Catalytic Life, Curr. Microwave Chem., 2014, 1(1), 142-147, DOI: 10.2174/2213335601666140703184655.

148 M. Führer, T. van Haasterecht and J. H. Bitter, Molybdenum and Tungsten Carbides Can Shine Too, Catal. Sci. Technol., 2020, 10, 6089-6097, DOI: 10.1039/D0CY01420F.

149 R. B. Levy and M. Boudart, Platinum-Like Behavior of Tungsten Carbide in Surface Catalysis, Science, 1973, 181, 547-549, DOI: 10.1126/science.181.4099.547.

150 E. Furimsky, Metal Carbides and Nitrides as Potential Catalysts for Hydroprocessing, Appl. Catal., A, 2003, 240(1-2), 1-28, DOI: 10.1016/S0926-860X(02)00428-3.

151 C. E. Chan-Thaw and A. Villa, Metal Carbides for Biomass Valorization, Appl. Sci., 2018, 8(2), 259, DOI: 10.3390/ app8020259.

152 M. M. Sullivan, C. J. Chen and A. Bhan, Catalytic Deoxygenation on Transition Metal Carbide Catalysts, Catal. Sci. Technol., 2016, 6, 602-616, DOI: 10.1039/C5cy01665g.

153 S. Posada-Pérez, F. Viñes, J. A. Rodriguez and F. Illas, Fundamentals of Methanol Synthesis on Metal Carbide Based Catalysts: Activation of $\mathrm{CO}_{2}$ and $\mathrm{H}_{2}$, Top. Catal., 2015, 58, 159-173, DOI: 10.1007/s11244-014-0355-8.

154 S. J. Ardakani, X. Liu and K. J. Smith, Hydrogenation and Ring Opening of Naphthalene on Bulk and Supported $\mathrm{Mo}_{2} \mathrm{C}$ Catalysts, Appl. Catal., A, 2007, 324, 9-19, DOI: 10.1016/j.apcata.2007.02.048.

155 M. Pang, C. Liu, W. Xia, M. Muhler and C. Liang, Activated Carbon Supported Molybdenum Carbides as Cheap and Highly Efficient Catalyst in The Selective Hydrogenation of Naphthalene to Tetralin, Green Chem., 2012, 14, 1272-1276, DOI: 10.1039/c2gc35177c.

156 R. Mnatsakanyan, A. R. Zhurnachyan, V. A. Matyshak, K. V. Manukyan and A. S. Mukasyan, Microwave-Assisted Synthesis of Carbon-Supported Carbides Catalysts for Hydrous Hydrazine Decomposition, J. Phys. Chem. Solids, 2016, 96-97, 115-120, DOI: 10.1016/j.jpcs.2016.05.008.

157 C. Liang, L. Ding, A. Wang, Z. Ma, J. Qiu and T. Zhang, Microwave-Assisted Preparation and Hydrazine Decomposition Properties of Nanostructured Tungsten Carbides on Carbon Nanotubes, Ind. Eng. Chem. Res., 2009, 48(6), 3244-3248, DOI: 10.1021/ie801591x.

158 M. Pang, C. Li, L. Ding, J. Zhang, D. Su, W. Li and C. Liang, Microwave-Assisted Preparation of $\mathrm{Mo}_{2} \mathrm{C} / \mathrm{CNTs}$ Nanocomposites as Efficient Electrocatalyst Supports for Oxygen Reduction Reaction, Ind. Eng. Chem. Res., 2010, 49(9), 4169-4174, DOI: 10.1021/ie901741c. 
159 J. C. Védrine, Importance, Features and Uses of Metal Oxide Catalysts in Heterogeneous Catalysis, Chin. J. Catal., 2019, 40(11), 1627-1636, DOI: 10.1016/S18722067(18)63162-6.

160 S. Motshekga, S. K. Pillai and S. S. Ray, Conventional Wet Impregnation versus Microwave-Assisted Synthesis of $\mathrm{SnO}_{2} / \mathrm{CNT}$ Composites, J. Nanopart. Res., 2011, 13, 1093-1099, DOI: 10.1007/s11051-010-0098-9.

161 S. Gayathri, M. Kottaisamy and V. Ramakrishnan, Facile Microwave-Assisted Synthesis of Titanium Dioxide Decorated Graphene Nanocomposite for Photodegradation of Organic Dyes, AIP Adv., 2015, 5, 127219, DOI: 10.1063/ 1.4938544.

162 R. M. Mohamed and E. S. Aazam, Synthesis and Characterization of $\mathrm{CeO}_{2}-\mathrm{SiO}_{2}$ Nanoparticles by MicrowaveAssisted Irradiation Method for Photocatalytic Oxidation of Methylene Blue Dye, Int. J. Photoenergy, 2012, 928760, DOI: $10.1155 / 2012 / 928760$.

163 P. Li, B. Wen, F. Yu, M. Zhu, X. Guo, Y. Han, L. Kang, X. Huang, J. Dan, F. Ouyang and B. Dai, High Efficient Nickel/Vermiculite Catalyst Prepared via Microwave Irradiation-Assisted Synthesis for Carbon Monoxide Methanation, Fuel, 2016, 171, 263-269, DOI: 10.1016/ j.fuel.2015.12.076.

164 G. Hu, D. Guo, H. Shang, Y. Sun, J. Zeng and J. Li, Microwave-Assisted Rapid Preparation of VermiculiteLoaded Nano-Nickel Oxide as a Highly Efficient Catalyst for Acetylene Carbonylation to Synthesize Acrylic Acid, ChemistrySelect, 2020, 5(10), 2940-2948, DOI: 10.1002/ slct.201904667.

165 A. R. Jadhav, J. M. C. Puguan and H. Kim, Microwave-Assisted Synthesis of a Stainless Steel Mesh-Supported $\mathrm{Co}_{3} \mathrm{O}_{4}$ Microrod Array As a Highly Efficient Catalyst for Electrochemical Water Oxidation, ACS Sustainable Chem. Eng., 2017, 5(11), 11069-11079, DOI: 10.1021/acssuschemeng.7b03027.

166 A. May-Masnou, L. Soler, M. Torras, P. Salles, J. Llorca and A. Roig, Fast and Simple Microwave Synthesis of $\mathrm{TiO}_{2} / \mathrm{Au}$ Nanoparticles for Gas-Phase Photocatalytic Hydrogen Generation, Front. Chem., 2018, 6, 110, DOI: 10.3389/ fchem.2018.00110.

167 S.-S. Chen, Z.-Z. Yang, A.-J. Wang, K.-M. Fang and J.J. Feng, Facile Synthesis of Bimetallic Gold-Palladium Nanocrystals As Effective and Durable Advanced Catalysts for Improved Electrocatalytic Performances of Ethylene Glycol and Glycerol Oxidation, J. Colloid Interface Sci., 2018, 509, 10-17, DOI: 10.1016/j.jcis.2017.08.063.

168 G. Sheng, J. Chen, H. Ye, Z. Hu, X.-Z. Fu, R. Sun, W. Huang and C.-P. Wong, Hollow PdCo Alloy Nanospheres with Mesoporous Shells as High-Performance Catalysts for Methanol Oxidation, J. Colloid Interface Sci., 2018, 522, 264-271, DOI: 10.1016/j.jcis.2018.03.039.

169 S. Dutta, C. Ray, A. K. Sasmal, Y. Negishi and T. Pal, Fabrication of Dog-Bone Shaped Au $\mathrm{NR}_{\text {core }}-\mathrm{Pt} / \mathrm{Pd}_{\text {shell }}$ Trimetallic Nanoparticle-Decorated Reduced Graphene Oxide Nanosheets for Excellent Electrocatalysis, J. Mater. Chem. A, 2016, 4, 3765-3776, DOI: 10.1039/C6TA00379F.
170 J. Mao, W. Chen, D. He, J. Wan, J. Pei, J. Dong, Y. Wang, P. An, Z. Jin, W. Xin, H. Tang, Z. Zhuang, X. Liang, Y. Huang, G. Zhou, L. Wang, D. Wang and Y. Li, Design of Ultrathin Pt-Mo-Ni Nanowire Catalysts for Ethanol Electrooxidation, Sci. Adv., 2017, 3(8), e1603068, DOI: 10.1126/sciadv.1603068.

171 S. Stevanović, D. Tripković, J. Rogan, K. Popović, J. Lović, A. Tripković and V. M. Jovanović, Microwave-Assisted Polyol Synthesis of Carbon-Supported Platinum-Based Bimetallic Catalysts for Ethanol Oxidation, J. Solid State Electrochem., 2012, 16, 3147-3157, DOI: 10.1007/s10008012-1755-y.

172 M. Tsuji, K. Uto, T. Nagami, A. Muto, H. Fukushima and J. Hayashi, Synthesis of Carbon-Supported Pt-YO $\mathrm{Y}_{x}$ and PtY Nanoparticles with High Catalytic Activity for the Oxygen Reduction Reaction Using a Microwave-based Polyol Method, ChemCatChem, 2017, 9(6), 962-970, DOI: 10.1002/cctc.201601479.

173 P. Song, Y. Lei, X. Hu, C. Wang, J. Wang and Y. Tang, Rapid One-Step Synthesis of Carbon-Supported Platinum-Copper Nanoparticles with Enhanced Electrocatalytic Activity via Microwave-Assisted Heating, J. Colloid Interface Sci., 2020, 574, 421-429, DOI: 10.1016/j.jcis.2020.04.041.

174 M. Bonarowska, Z. Kaszkur, K. Matus, A. Drelinkiewicz, T. Szumelda and A. Kubas, Towards High Efficacy of Pd$\mathrm{Au} / \mathrm{C}$ Catalyst for Tetrachloromethane Hydrodechlorination, Chemistry, 2021, 3(1), 338-359, DOI: 10.3390/ chemistry3010025.

175 P. Nekooi, M. Akbari and M. K. Amini, CoSe Nanoparticles Prepared by the Microwave-Assisted Polyol Method as an Alcohol and Formic Acid Tolerant Oxygen Reduction Catalyst, Int. J. Hydrogen Energy, 2010, 35(12), 6392-6398, DOI: 10.1016/j.ijhydene.2010.03.134.

176 L. Zhu, P. C. Wong, K. C. Wong, F. Ernst, K. A. R. Mitchell and S. A. Campbell, Synthesis, Characterization of a $\mathrm{CoSe}_{2}$ Catalyst for the Oxygen Reduction Reaction, Appl. Catal., A, 2010, 386(1-2), 157-165, DOI: 10.1016/j.apcata.2010.07.048.

177 H. Li, D. Gao and X. Cheng, Simple Microwave Preparation of High Activity Se-Rich $\mathrm{CoSe}_{2} / \mathrm{C}$ for Oxygen Reduction Reaction, Electrochim. Acta, 2014, 138, 232-239, DOI: 10.1016/j.electacta.2014.06.065.

178 Q. Zheng, X. Cheng and H. Li, Microwave Synthesis of High Activity $\mathrm{FeSe}_{2} / \mathrm{C}$ Catalyst toward Oxygen Reduction Reaction, Catalysts, 2015, 5(3), 1079-1091, DOI: 10.3390/ catal5031079.

179 T. Ramulifho, K. I. Ozoemena, R. M. Modibedi, C. J. Jafta and M. K. Mathe, Fast Microwave-Assisted Solvothermal Synthesis of Metal Nanoparticles (Pd, Ni, Sn) Supported on Sulfonated MWCNTs: Pd-Based Bimetallic Catalysts for Ethanol Oxidation in Alkaline Medium, Electrochim. Acta, 2012, 59, 310-320, DOI: 10.1016/j.electacta.2011.10.071.

180 A. B. A. A. Nassr, I. Sinev, M.-M. Pohl, W. Grünert and M. Bron, Rapid Microwave-Assisted Polyol Reduction for the Preparation of Highly Active PtNi/CNT Electrocatalysts for Methanol Oxidation, ACS Catal., 2014, 4(8), 2449-2462, DOI: $10.1021 / \operatorname{cs} 401140$. 
181 M. Rahsepar and H. Kim, Microwave-Assisted Synthesis and Characterization of Bimetallic PtRu Alloy Nanoparticles Supported on Carbon Nanotubes, J. Alloys Compds., 2015, 649, 1323-1328, DOI: 10.1016/j.jallcom.2015.07.224.

182 M. G. H. Al-Tememy and Y. Devrim, Development of Effective Bimetallic Catalyst for High-Temperature PEM Fuel Cell to Improve CO Tolerance, Int. J. Energy Res., 2021, 45(2), 3343-3357, DOI: 10.1002/er.6032.

183 P. Verma, Y. Kuwahara, K. Mori and H. Yamashita, Pd/Ag and Pd/Au Bimetallic Nanocatalysts on Mesoporous Silica for Plasmon-Mediated Enhanced Catalytic Activity Under Visible Light Irradiation, J. Mater. Chem. A, 2016, 4, 10142-10150, DOI: 10.1039/C6TA01664B.

184 A. Tripathi, K. Faungnawakij, A. Laobuthee, S. Assabumrungrat and N. Laosiripojna, Catalytic Activity of Bimetallic $\mathrm{Cu}-\mathrm{Ag} /$ ${\mathrm{MgO}-\mathrm{SiO}_{2}}_{2}$ Toward the Conversion of Ethanol to 1,3Butadiene, Int. J. Chem. React. Eng., 2016, 14, 945-954, DOI: 10.1515/ijcre-2015-0164.

185 T. T. Nguyen and E. W. Qian, Synthesis of Mesoporous TiInserted SBA-15 and CoMo/Ti-SBA-15 Catalyst for Hydrodesulfurization and Hydrodearomatization, Microporous Mesoporous Mater., 2018, 265, 1-7, DOI: 10.1016/ j.micromeso.2018.01.026.

186 A. S. Rini, S. Radiman and M. A. Yarmo, Microwaveassisted Synthesis of $\mathrm{Ru}-\mathrm{Sn} / \mathrm{ZnO}$ for Catalysis Application, AIP Conf. Proc., 2010, 1284, 129, DOI: 10.1063/1.3515535.

187 J. Tan, T. Thomas, J. Liu, L. Yang, L. Pan, R. Cao, H. Shen, J. Wang, J. Liu and M. Yang, Rapid Microwave-Assisted Preparation of High-Performance Bifunctional $\mathrm{Ni}_{3} \mathrm{Fe} / \mathrm{Co}-$ N-C for Rechargeable Zn-Air Battery, Chem. Eng. J., 2020, 395, 125151, DOI: 10.1016/j.cej.2020.125151.

188 H. A. Elazab, S. Moussa, A. R. Siamaki, B. F. Gupton and M. S. El-Shall, The Effect of Graphene on Catalytic Performance of Palladium Nanoparticles Decorated with $\mathrm{Fe}_{3} \mathrm{O}_{4}$, $\mathrm{Co}_{3} \mathrm{O}_{4}$, and $\mathrm{Ni}(\mathrm{OH})_{2}$ : Potential Efficient Catalysts Used for Suzuki Cross-Coupling, Catal. Lett., 2017, 147, 1510-1522, DOI: 10.1007/s10562-017-1990-z.

189 H. A. Elazab, A. R. Siamaki, S. Moussa, B. F. Gupton and M. S. El-Shall, Highly Efficient and Magnetically Recyclable Graphene-Supported $\mathrm{Pd} / \mathrm{Fe}_{3} \mathrm{O}_{4}$ Nanoparticle Catalysts for Suzuki and Heck Cross-Coupling Reactions, Appl. Catal., A, 2015, 491, 58-69, DOI: 10.1016/j.apcata.2014.11.033.

190 N. R. Khalid, E. Ahmed, M. Ahmed, N. A. Niaz, M. Ramzan, M. Shakil, T. Iqbal and A. Majid, Microwave-Assisted Synth-

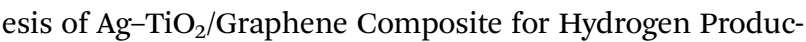
tion Under Visible Light Irradiation, Ceram. Int., 2016, 42(16), 18257-18263, DOI: 10.1016/j.ceramint.2016.08.149.

191 H. Pan, D. Wu, X. Huang, K. Xie, B. He, Z. Lu, P. Liu, J. Cheng, X. Zhao and J. Masa, Microwave-Assisted Synthesis of $\mathrm{Co} / \mathrm{CoO}_{x}$ Supported on Earth-Abundant CoalDerived Carbon for Electrocatalysis of Oxygen Evolution, J. Electrochem. Soc., 2019, 166(8), F479-F486, DOI: 10.1149/ 2.0281908jes.

192 A. Galal, H. K. Hassan, N. F. Atta, A. M. Abdel-Mageed and T. Jacob, Synthesis, Structural and Morphological Characterizations of Nano-Ru-Based Perovskites/RGO
Composites, Sci. Rep., 2019, 9, 7948, DOI: 10.1038/ s41598-019-43726-1.

193 A. Y. Li, M. Kaushik, C.-J. Li and A. Moores, MicrowaveAssisted Synthesis of Magnetic Carboxymethyl CelluloseEmbedded $\mathrm{Ag}-\mathrm{Fe}_{3} \mathrm{O}_{4}$ Nanocatalysts for Selective Carbonyl Hydrogenation, ACS Sustainable Chem. Eng., 2016, 4(3), 965-973, DOI: 10.1021/acssuschemeng.5b01048.

194 B. Liu, X. Li, C. Zheng, X. Wang and R. Sun, Facile and Green Synthesis of Silver Nanoparticles in Quaternized Carboxymethyl Chitosan Solution, Nanotechnology, 2013, 24(23), 235601, DOI: 10.1088/0957-4484/24/23/235601.

195 S. Horikoshi, H. Abe, K. Torigoe, M. Abe and N. Serpone, Access to Small Size Distributions of Nanoparticles by Microwave-Assisted Synthesis. Formation of Agnanoparticles in Aqueous Carboxymethylcellulose Solutions in Batch and Continuous-Flow Reactors, Nanoscale, 2010, 2, 1441-1447, DOI: 10.1039/c0nr00141d.

196 J. Jing, L. Li, W. Chu, Y. Wei and C. Jiang, MicrowaveAssisted Synthesis of High Performance Copper-Based Catalysts for Hydrogen Production from Methanol Decomposition, Int. J. Hydrogen Energy, 2018, 43(27), 12059-12068, DOI: 10.1016/j.ijhydene.2018.04.104.

197 L. Rezaee and M. Haghighi, Citrate Complexation Microwave-Assisted Synthesis of $\mathrm{Ce}_{0.8} \mathrm{Zr}_{0.2} \mathrm{O}_{2}$ Nanocatalyst over $\mathrm{Al}_{2} \mathrm{O}_{3}$ Used in CO Oxidation for Hydrogen Purification: Influence of Composite Loading and Synthesis Method, RSC Adv., 2016, 6, 34055-34065, DOI: 10.1039/ C6RA02973F.

198 J. Zheng, Q. Gong, X. Cheng, S. Gong, W. Yang and L. Huang, Microwave Synthesis of Carbon-Supported Cobalt Nickel Selenide Ternary Catalyst Toward the Oxygen Reduction Reaction, ChemElectroChem, 2018, 5(14), 2019-2028, DOI: 10.1002/celc.201800190.

199 X. Hu, P. Song, X. Yang, C. Wang, J. Wang, Y. Tang, J. Zhang and Z. Mao, One-Step Microwave-Assisted Synthesis of Carbon-Supported Ternary Pt-Sn-Rh Alloy Nanoparticles for Fuel Cells, J. Taiwan Inst. Chem. Eng., 2020, 115, 272-278, DOI: 10.1016/j.jtice.2020.10.008.

200 C. $\mathrm{Wu}, \mathrm{Z}$. Guo, X. Chen and H. Liu, $\mathrm{Cu} / \mathrm{CeO}_{2}$ as Efficient LowTemperature CO Oxidation Catalysts: Effects of Morphological Structure and $\mathrm{Cu}$ Content, React. Kinet., Mech. Catal., 2020, 131, 691-706, DOI: 10.1007/s11144-020-01870-0.

201 Y. Li, Y. Cai, X. Xing, N. Chen, D. Deng and Y. Wang, Catalytic Activity for $\mathrm{CO}$ Oxidation of $\mathrm{Cu}-\mathrm{CeO}_{2} \mathrm{Composite}$ Nanoparticles Synthesized by a Hydrothermal Method, Anal. Methods, 2015, 7, 3238-3245, DOI: 10.1039/ C5AY00261C.

202 F. Wang, Y. Xu, K. Zhao and D. He, Preparation of Palladium Supported on Ferric Oxide Nano-catalysts for Carbon Monoxide Oxidation in Low Temperature, NanoMicro Lett., 2014, 6, 233-241, DOI: 10.1007/BF03353787.

203 G. Li, L. Li, Y. Yuan, Y. Yuan, Y. Li, W. Zhao and J. Shi, Mesostructured $\mathrm{Pd} / \mathrm{Mn}_{3} \mathrm{O}_{4}$ Catalyst for Efficient LowTemperature CO Oxidation Especially Under Moisture Condition, RSC Adv., 2014, 4, 35762-35768, DOI: 10.1039/ C4RA01764A. 
204 G. Zhang, Z. Li, H. Zheng, T. Fu, Y. Ju and Y. Wang, Influence of the Surface Oxygenated Groups of Activated Carbon on Preparation of a Nano Cu/AC Catalyst and Heterogeneous Catalysis in the Oxidative Carbonylation of Methanol, Appl. Catal., B, 2015, 179, 95-105, DOI: 10.1016/j.apcatb.2015.05.001.

205 B. Yan, S. Huang, S. Wang and X. Ma, Catalytic Oxidative Carbonylation over $\mathrm{Cu}_{2} \mathrm{O}$ Nanoclusters Supported on Carbon Materials: The Role of the Carbon Support, ChemCatChem, 2014, 6(9), 2671-2679, DOI: 10.1002/cctc.201402201.

206 Q. Hua, T. Cao, X. K. Gu, J. Lu, Z. Jiang, X. Pan, L. Luo, W. X. Li and W. Huang, Crystal-Plane-Controlled Selectivity of $\mathrm{Cu}_{2} \mathrm{O}$ Catalysts in Propylene Oxidation with Molecular Oxygen, Angew. Chem., Int. Ed., 2014, 53(19), 4856-4861, DOI: 10.1002 /anie.201402374.

207 A. Rey, M. Faraldos, J. A. Casas, J. A. Zazo, A. Bahamonde and J. J. Rodríguez, Catalytic Wet Peroxide Oxidation of Phenol Over Fe/AC Catalysts: Influence of Iron Precursor and Activated Carbon Surface, Appl. Catal., B, 2009, 86(1-2), 69-70, DOI: 10.1016/j.apcatb.2008.07.023.

208 J. Sun, M. Zheng, X. Wang, A. Wang, R. Cheng, T. Li and T. Zhang, Catalytic Performance of Activated Carbon Supported Tungsten Carbide for Hydrazine Decomposition, Catal. Lett., 2008, 123, 150-155, DOI: 10.1007/s10562-0089409-5.

209 V. A. Peshkov, O. P. Pereshivko, A. A. Nechaev, A. A. Peshkov and E. V. Van Der Eycken, Reactions of Secondary Propargylamines with Heteroallenes for the Synthesis of Diverse Heterocycles, Chem. Soc. Rev., 2018, 47, 3861-3898, DOI: 10.1039/C7CS00065K.

210 Z. Chang, X. Jing, C. He, X. Liu and C. Duan, Silver Clusters as Robust Nodes and $\pi$-Activation Sites for the Construction of Heterogeneous Catalysts for the Cycloaddition of Propargylamines, ACS Catal., 2018, 8(2), 1384-1391, DOI: 10.1021/acscatal.7b02844.

211 Z. Yan, Z. Wang, D. B. Bukur and D. W. Goodman, FischerTropsch Synthesis on a Model $\mathrm{Co} / \mathrm{SiO}_{2}$ Catalyst, J. Catal., 2009, 268(2), 196-200, DOI: 10.1016/j.jcat.2009.09.015.

212 M. Haruta, Catalysis of Gold Nanoparticles Deposited on Metal Oxides, CATTECH, 2002, 6, 102-115, DOI: 10.1023/ A:1020181423055.

213 J. Y. Xi, W. P. Wang and G. X. Lu, Mechanism of Cu/ZnO Based Catalysts for Methanol Decomposition Promoted by Nickel, Acta Chim Sinica, 2002, 60(3), 419-426.

214 W. H. Cheng, Reaction and XRD Studies on $\mathrm{Cu}$ Based Methanol Decomposition Catalysts: Role of Constituents and Development of High-Activity Multicomponent Catalysts, Acta Chim. Sin., 1995, 130(1), 13-30, DOI: 10.1016/ 0926-860X(95)00102-6.

215 S. Chen, M. Li, M. Gao, J. Jin, M. A. V. Spronsen, M. B. Salmeron and P. Yang, High-Performance Pt-Co Nanoframes for Fuel-Cell Electrocatalysis, Nano Lett., 2020, 20(3), 1974-1979, DOI: 10.1021/acs.nanolett.9b05251.

216 J. Li, S. Sharma, X. Liu, Y.-T. Pan, J. S. Spendelow, M. Chi, Y. Jia, P. Zhang, D. A. Culllen, Z. Xi, H. Lin, Z. Yin, B. Shen, M. Muzzio, C. Yu, Y. S. Kim, A. A. Peterson, K. L. More, H. Zhu and S. Sun, Hard-Magnet-L1 $1_{0}$-CoPt Nanoparticles Advance Fuell Cell Catalysis, Joule, 2019, 3(1), 124-135, DOI: 10.1016/j.joule.2018.09.016.

217 J. Ding, Q. Shao, Y. Feng and X. Huang, Ruthenium-Nickel Sandwiched Nanoplates for Efficient Water Splitting Electrocatalysis, Nano Energy, 2018, 47, 1-7, DOI: 10.1016/ j.nanoen.2018.02.017.

218 Z. Yang, Y. Shi, X. Wang, G. Zhang and P. Cui, Boron As A Superior Activator for Pt Anode Catalyst in Direct Alcohol Fuel Cell, J. Power Sources, 2019, 431, 125-134, DOI: 10.1016/j.jpowsour.2019.05.052.

219 T. V. Reshetenko and J. St-Pierre, Effects of Propylene, Methyl Methacrylate and Isopropanol Poisoning on Spatial Performance of A Proton Exchange Membrane Fuel Cell, J. Power Sources, 2018, 378, 216-224, DOI: 10.1016/ j.jpowsour.2017.12.038.

220 W. Wang, W. Wang and S. Chen, The Effects of Hydrogen Dilution, Carbon Monoxide Poisoning for a Pt-Ru Anode in a Proton Exchange Membrane Fuel Cell, Int. J. Hydrogen Energy, 2016, 41(45), 20680-20692, DOI: 10.1016/ j.ijhydene.2016.09.151.

221 J. W. Sun, Y. S. Fu, G. Y. He, X. Q. Sun and X. Wang, Green Suzuki-Miyaura Coupling Reaction Catalyzed by Palladium Nanoparticles Supported on Graphitic Carbon Nitride, Appl. Catal., B, 2015, 165, 661-667, DOI: 10.1016/ j.apcatb.2014.10.072.

222 H. A. Elazab, M. A. Gadalla, M. A. Sadek and T. T. ElIdreesy, Hydrothermal Synthesis of Graphene Supported $\mathrm{Pd} / \mathrm{Fe}_{3} \mathrm{O}_{4}$ Nanoparticles as Efficient Magnetic Catalysts for Suzuki Cross - Coupling, Biointerface Res. Appl. Chem., 2019, 9, 3906-3911, DOI: 10.33263/BRIAC92.906911.

223 W. Fu, Y. Cao, Q. Feng, W. R. Smith, P. Dong, M. Ye and J. Shen, Pd-Co Nanoalloys Nested on Cuo Nanosheets for Efficient Electrocatalytic $\mathrm{N}_{2}$ Reduction and RoomTemperature Suzuki-Miyaura Coupling Reaction, Nanoscale, 2019, 11, 1379-1385, DOI: 10.1039/C8NR08724E. 